Universidade de São Paulo

Instituto de Física

\title{
Construção de Uma Armadilha Magneto-Ótica para Aplicações em Informação Quântica e Física Atômica
}

\author{
Hélio Zhang He \\ Orientador: Prof. Dr. Marcelo Martinelli \\ Dissertação de mestrado apresentada ao \\ Instituto de Física para a obtenção \\ do título de Mestre em Ciências
}

Banca Examinadora:

Prof. Dr. Marcelo Martinelli (IF-USP)

Prof. Dr. Paulo Teotonio Sobrinho (IF-USP)

Prof. Dr. Luís Eduardo Evangelista de Araujo (UNICAMP)

São Paulo 
FICHA CATALOGRÁFICA

Preparada pelo Serviço de Biblioteca e Informação do Instituto de Física da Universidade de São Paulo

Zhang He, Helio

Construçẫo de uma armadilha magneto-ótica para aplicações em informação quântica e física atômica- São Paulo, 2009.

Dissertaçẫo (Mestrado) - Universidade de Sã̃o Paulo. Instituto de Física. Departamento de Física Experimental.

Orientador: Prof. Dr. Marcelo Martinelli

Área de Concentração: Física Atômica e Ótica

Quântica

Unitermos: 1. Física Experimental; 2. Física Atômica; 3. Mecânica Quântica. 


\section{Resumo}

Construímos uma armadilha magneto-ótica (MOT) para átomos de rubídio visando o seu aprisionamento em um potencial periódico formado por feixes de luz (rede ótica) e a realização de experimentos em física atômica, com possíveis aplicações no campo da informação quântica. A necessidade de uma MOT vem dos problemas que o movimento térmico dos átomos impõem à realização de medidas precisas. Neste arranjo, combina-se a pressão de radiação de feixes laser com o efeito do campo magnético para resfriar e aprisionar átomos neutros.

Durante a execução deste projeto, construímos os lasers e o sistema eletrônico de controle de frequência, intensidade e temperatura; montamos o sistema de bombeamento de vácuo e a câmara de vácuo onde é feito o aprisionamento; fizemos os arranjos para caracterizar a MOT, usando programas de computador para capturar e analisar as medidas. Caracterizamos a nuvem de átomos frios obtida, estimamos o número de átomos aprisionados, o tempo de carregamento e a temperatura da nuvem. 



\section{Abstract}

We built a magneto-optical trap (MOT) for rubidium as a first step for the trapping of a cloud of cold atoms in a periodic potential formed by light beams. This system will be used for experiments in atom physics, with possible applications in quantum information. A MOT is necessary to avoid the problems imposed by the thermal agitation of the atoms to the measurement of their properties. In this configuration, we combine the radiative pressure of laser beam with the effect of a magnetic field to cool and trap neutral atoms.

During the execution of this project, we built the lasers and the electronic system for their control of frequency, intensity and temperature. We also built the system for vacuum pumping and the vacuum chamber for the trapping, as well as the setup for the MOT characterization, with computer programs for capture and analyze the measurements. We characterize the cold atoms cloud, measuring the number of trapped atoms, their loading time in the MOT and their temperature. 



\section{Agradecimentos}

- Agradeço sinceramente ao meu orientador Prof. Marcelo Martinelli pela orientação, pelos incentivos e pelos ensinamentos durante meu mestrado. Não seria possível concluir este projeto sem o seu apoio e compreensão.

- Ao Prof. Paulo Alberto Nussenzveig por ter me aceitado no grupo e indicado ao Prof. Marcelo.

- Ao Paulo Valente que ajudou muito nos meus trabalhos, e com quem aprendi muito.

- Aos meus amigos e (ex-)colegas do grupo: Rodrigo e Laércio, que trabalharam diretamente comigo e me ajudaram muito, juntos tentamos explorar esta área fascinante e ao mesmo tempo desafiadora; ao Antônio, Fabio, Felippe e Jônatas com os quais aprendi diversos assuntos e passei muitos momentos agradáveis; ao Clodoaldo com quem sempre conversei muito sobre os estudos e a carreira, e que me incentivou muito na conclusão do mestrado; ao Douglas, Vitor e Pedro que me ajudaram no inicio do meu mestrado.

- Ao pessoal da oficina mecânica e da oficina eletrônica. Os seus trabalhos, sempre de alta qualidade, foram essenciais na construção do sistema.

- Às secretárias da FEP, Edi e Ivanei, sempre prontas para ajudar nos trabalhos burocráticos.

- Aos colegas do Curso de Ciências Moleculares, com os quais aprendi muito e cresci muito. Obrigado pelos momentos incríveis que passamos juntos e pelos apoios. 
- A todos os meus professores. Obrigado pelos ensinamentos, vocês me mostraram como a vida é cheia de maravilhas e possibilidades.

- Às pessoas mais importantes da minha vida, a minha família. Palavras são muito pouco para demonstrar todo o meu agradecimento e afeto.

- À Cristina Sayuri, obrigado por caminhar junto e me ajudar nos momentos mais difíceis.

- Aos meus amigos da Aliança Beneficente Universitária. Guardarei sempre junto comigo a amizade e o espírito de trabalho em equipe.

- À minha terapeuta, Simone, que me fez conhecer mais a mim mesmo.

- Há muitas pessoas para agradecer, mas infelizmente não dá para escrever para todas aqui. Agradeço a todos que me ajudaram um dia e que contribuíram para o meu crescimento.

- Por fim, agradeço à FAPESP pelo apoio financeiro e por acreditar em mim. 
"A vida é um piquenique e eu estou faminto!" do desenho Doug 



\section{Sumário}

1 Introdução $\quad 13$

1.1 Manipulação de átomos com a luz . . . . . . . . . . . . . . . . . . 13

1.2 Apresentação do trabalho . . . . . . . . . . . . . . . . . . . . 17

2 Teoria do Aprisionamento e Resfriamento Atômico 20

2.1 Pressão de radiação . . . . . . . . . . . . . . . . . . . . . . 21

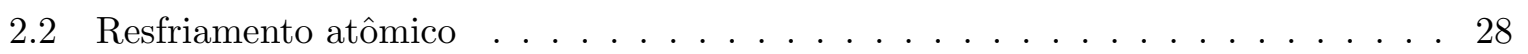

2.2 .1 Temperatura Doppler . . . . . . . . . . . . . . . . 34

2.3 Adicionando o aprisionamento . . . . . . . . . . . . . . 36

2.3 .1 Campo magnético . . . . . . . . . . . . . . . . . . 40

2.4 Resfriamento sub-Doppler . . . . . . . . . . . . . . . . . 43

2.4.1 Configuração $\sigma^{+}-\sigma^{-} \ldots \ldots \ldots \ldots \ldots$. . . . . . . . . . . 44

2.4 .2 Resfriamento Sísifo . . . . . . . . . . . . . . . . . . . 46

2.5 A estrutura hiperfina do átomo de rubídio . . . . . . . . . . . . . . . . . 47

3 Experimento $\quad 50$ 
3.1 Câmara de vácuo . . . . . . . . . . . . . . . . . . 50

3.2 Lasers . . . . . . . . . . . . . . . . . . . . . . . 61

3.3 Eletrônica de controle . . . . . . . . . . . . . . . . . . . 67

3.4 Controle da freqüência do laser mestre . . . . . . . . . . . . . . . . 71

3.5 Controle da freqüência dos lasers escravos . . . . . . . . . . . . . . . . . . 74

3.6 Modulador acusto-ótico $(\mathrm{AOM}) \ldots \ldots \ldots \ldots \ldots$. . . . . . . . . . . 77

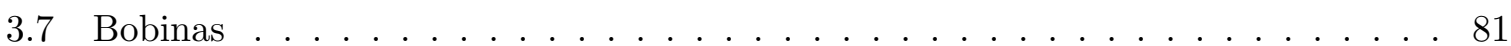

3.8 Software de controle e análise . . . . . . . . . . . . . . . . . . 83

4 Resultados $\quad 90$

4.1 Número de átomos . . . . . . . . . . . . . . . . . . . . . . . . . . 90

4.2 Tempo de carga . . . . . . . . . . . . . . . . . . . . . . 93

4.3 Temperatura da nuvem . . . . . . . . . . . . . . . . . . . 93

4.4 Rede ótica . . . . . . . . . . . . . . . . . . . . . . . 97

4.4.1 Montagem planejada . . . . . . . . . . . . . . . . . . . . 98

5 Conclusões e Perspectivas $\quad 100$

A Especificações do laser de diodo $\quad 102$

B Laser com cavidade externa $\quad 106$ 


\section{Capítulo 1}

\section{Introdução}

\subsection{Manipulação de átomos com a luz}

A luz pode trocar momento linear com os átomos ao incidir sobre estes, e com isso exercer uma força dita radiativa. Entre os exemplos da observação deste efeito, temos que há muito tempo já se percebeu que a cauda de cometas sempre se direciona para a direção oposta ao Sol. Kepler tentou explicar este fato curioso conjecturando que a luz solar desempenha uma força sobre a matéria. No entanto, o entendimento da pressão de radiação só se tornou quantitativo com a teoria de eletromagnetismo de Maxwell. Ele mostrou que o campo eletromagnético exerce uma pressão igual a sua energia por unidade de volume. Um grande passo para o entendimento da pressão de radiação veio com a mecânica quântica, quando em 1917 Einstein apontou a natureza quântica desta força [1]. Um quantum de luz, ou fóton, possui energia $h v$. Um átomo ao absorver um fóton recebe um momento $p=h v / c=h / \lambda$ na direção do movimento da luz ( $h$ é a constante de Planck, $v, c, \lambda$ são, respectivamente, a frequência, velocidade e comprimento 
de onda da luz). E se o átomo emitir um fóton, pela conservação do momento, irá recuar na direção oposta. Assim, as interações entre fótons e o átomo mudam o momento atômico o que causa mudança do movimento atômico.

No começo do século XX era difícil observar os efeitos da pressão de radiação nos laboratórios pois não haviam fontes de luz intensas. Mesmo assim as experiências de Lebedev em 1901 [2] e de Nichols e Hull em 1903 [3] forneceram pela primeira vez a demonstração laboratorial e medida quantitativa da pressão de radiação sobre objetos macroscópicos. Em 1933, Frish mostrou o efeito da luz sobre átomos ao desviar um feixe de átomos de sódio $(\mathrm{Na})$ com radiação ressonante de uma lâmpada [4].

Enfim, com a invenção do laser (década de 60), conseguiu-se uma poderosa ferramenta para criar luz colimada e com alta potência. E além disso a luz emitida é coerente, facilmente sintonizável em frequência e com largura de linha muito estreita. Com o laser, tornou-se possível o controle e a manipulação direta de átomos. Estes avanços sempre foram objetivos perseguidos pelos físicos para poder estudar mais profundamente a matéria.

Em 1975, Hänsh e Schawlow [5], e Wineland e Dehmelt [6] propuseram respectivamente o resfriamento de átomos neutros e íons usando o efeito Doppler. Empregando radiação laser, Wineland, Drullinger e Walls conseguiram resfriar uma nuvem de íons de magnésio ( $\mathrm{Mg})$ contida numa armadilha eletromagnética de Penning, em 1978, a temperatura da amostra atingiu abaixo de $40 \mathrm{~K}$ [7]. Os primeiros sucessos experimentais com átomos neutros vieram bem mais tarde pois, como não há força eletrostática, é mais díficil sua manipulação. Apenas em 1982, com os trabalhos de W. Phillips e H. Metcalf [8], foi conseguido desacelerar átomos de sódio utilizando um feixe laser contra-propagante e um campo magnético não homogêneo. Em 1985, um grupo 
da Bell Laboratories liderado por S. Chu conseguiu resfriar átomos de sódio usando apenas feixes de luz laser [9]. Eles utilizaram três pares de feixes contra-propagantes, um em cada eixo. Como a força é altamente viscosa no cruzamento dos feixes, foi dado o nome de melaço ótico (optical molasses) à região de cruzamento dos feixes no qual se situa a nuvem resfriada. Este experimento não incluiu forças de aprisionamento, que precisam de uma dependência com a posição dos átomos. A primeira armadilha magneto-ótica (MOT - Magneto-optical trap) capaz de resfriar e aprisionar átomos foi demonstrada dois anos mais tarde pelo mesmo grupo [10]. Este sistema combinou o arranjo do melaço ótico com o efeito de um campo magnético externo para manipular os átomos, devido à sua simplicidade e robustez é utilizado amplamente desde então.

A temperatura teórica da nuvem de átomos aprisionados é da ordem de centenas de $\mu \mathrm{K}$. Isto corresponde ao limite teórico da Temperatura Doppler [11]. No entanto, depois de experiências com técnicas mais precisas, o grupo de W. Philips, do NIST (National Institute of Standards and Technology), mediu temperaturas muito mais baixas (1988), da ordem de dezenas de $\mu \mathrm{K}$ [12]. Este resultado surpreendente atraiu atenção de muitos pesquisadores. Descobriu-se que a diferença era devida à simplicidade do modelo de átomo de dois níveis usado até então. Novas teorias foram formuladas levando em consideração os múltiplos subníveis atômicos e também a existência de um gradiente de polarização criado por feixes contra-propagantes. A formulação mais usada atualmente é a proposta por J. Dalibard e C. Cohen-Tannoudji [13]. Revisões gerais sobre o desenvolvimento da área de manipulação de átomos com laser pode ser encontradas em $[14,15,16]$

O prêmio Nobel de Física de 1997 foi dividido por Steven Chu, Cohen-Tannoudji e William 
D. Phillips "por desenvolvimento de métodos de resfriamento e aprisionamento de átomos com luz laser" (for development of methods to cool and trap atoms with laser light). Os artigos escritos especialmente para o prêmio são excelentes introduções para esta área [17, 18, 19].

Nas experiências iniciais com sódio, para estudo de muitos átomos eram necessários fornos para gerar os átomos que dão origem às amostras atômicas. Isto implicava em um sistema de vácuo relativamente grande e tornava o trabalho mais complexo. Em 1990, C. Monroe et al. conseguiram produzir uma armadilha para césio em uma célula de vidro pequena contendo vapor em baixa presão [20]. A técnica simplificou muito a obtenção de certos tipos de amostras atômicas frias com montagens mais simples.

Estes avanços importantes permitiram a criação de condensados de Bose-Einstein (BEC Bose-Einstein Condensate) pela primeira vez em 1995 pelo grupo de Eric Cornell e Carl Wieman [21]. Utilizando a MOT juntamente com outros processos de resfriamento e aprisionamento, eles conseguiram produzir um condensado de átomos de rubídio 87 cuja temperatura é perto de 170 nK, levando ao tão procurado "quinto estado da matéria". No mesmo ano o grupo do Wolfgang Ketterle no MIT criou um condensado com átomos de sódio [22]. Os feitos renderam aos três pesquisadores o prêmio Nobel de física de 2001.

As técnicas de resfriamento e aprisionamento permitiram a produção de átomos frios. Os átomos perdem energia cinética e são confinados em um ambiente com pouquíssimas perturbações. Estas condições são excelentes para muitas aplicações como espectroscopia de alta precisão, relógios atômicos - de fundamental importância para o sistema GPS (Global Positioning System) - ou mesmo estudos de moléculas biológicas, como o enrolamento de moléculas de DNA [17, 23]. A tabela 1.1 mostra as faixas de temperatura e as técnicas empregadas para 


\begin{tabular}{|c|c|}
\hline Escala de temperatura & Técnica empregada \\
\hline $300 \mathrm{~K}$ & temperatura ambiente \\
\hline $3 \mathrm{~K}$ & hélio líquido \\
\hline $3 \mathrm{mK}$ & resfriamento ótico \\
\hline $300 \mu \mathrm{K}$ & limite Doppler \\
\hline $3 \mu \mathrm{K}$ & resfriamento evaporativo \\
\hline $30 \mathrm{nK}$ &
\end{tabular}

Tabela 1.1: Escala de temperatura das técnicas de resfriamento.

atingi-las.

O recorde de temperatura continua sendo vencido. Por exemplo, em setembro de 2003 o grupo de W. Ketterle no MIT conseguiu atingir $450 \mathrm{pK}$, medida num BEC de sódio [24]. Para atingir esta marca eles utilizaram uma nova técnica de confinamento chamada armadilha gravito-magnética. Para o efeito de comparação, na natureza o lugar mais frio já medido fora de laboratório é localizado na Nebulosa de Boomerang na constelação de Centauros onde a temperatura é de $1 \mathrm{~K}$.

\subsection{Apresentação do trabalho}

Construímos uma armadilha magneto-ótica para resfriar e aprisionar átomos de rubídio que serão utilizados em estudos de rede ótica. Uma rede ótica é formada pela sobreposição de feixes contra-propagantes que criam um potencial periódico. Os átomos frios podem ser carregados na rede ótica formando uma estrutura com posicionamento periódico que lembra os cristais 
descritos pela teoria do estado sólido.

As amostras da armadilha são da forma gasosa, contidas numa câmara de vácuo de baixíssima pressão. Utilizando a pressão de radiação de feixes de luz laser e força magnética, podemos resfriar e confinar as amostras no centro da armadilha. Forma-se uma nuvem de tamanho da ordem de 1 milímetro e com cerca de $10^{8}$ átomos.

No capítulo 2 apresentaremos a parte teórica envolvida nas experiências. Descreveremos a interação da luz com átomo, os efeitos de absorção e emissão de fótons. O processo de resfriamento e a importância do efeito Doppler serão apresentados. Também escreveremos sobre o aprisionamento de átomos apresentando a armadilha magneto-ótica. Posteriormente analisaremos os mecanismos de resfriamento sub-Doppler incluindo a configuração Corkscrew e o efeito Sísifo. No fim mostraremos a estrutura hiperfina do átomo de rubídio.

No capítulo 3 apresentaremos a parte experimental do projeto. Isto engloba principalmente os lasers de diodo: a construção dos lasers; a sintonização dos feixes; o sistema de controle em freqüência e em amplitude dos feixes através de moduladores acústo-óticos (AOM - acousticoptical modulator); o sistema de travamento em freqüência dos feixes (lock) e a espectroscopia de absorção saturada. E além disso descreveremos o sistema de vácuo e as bobinas para geração de campo magnético.

No capítulo 3 descreveremos ainda os programas de computador de controle, de aquisição e de tratamento de dados. Desenvolvemos os programas em LabVIEW. Através de uma interface conversor analógico-digital podemos controlar a maior parte das experiências.

Apresentaremos os resultados no capítulo 4 . Caracterizamos a nuvem de átomos aprisionados, medimos o tamanho, o tempo de carregamento, o número de átomos e a temperatura da 
nuvem. Os dados foram tirados através de um detector com multiplicador de ganho e de uma câmera CCD.

No final, descrevemos resumidamente as aplicações do sistema desenvolvido e as perspectivas abertas por este trabalho. 


\section{Capítulo 2}

\section{Teoria do Aprisionamento e}

\section{Resfriamento Atômico}

Apresentamos a seguir uma descrição concisa da teoria envolvendo a técnica de resfriamento e aprisionamento atômico magneto-ótico. Apesar desta teoria ser extensamente coberta na literatura, resolvemos reproduzi-la aqui em seus detalhes visando a consistência desta dissertação, cobrindo todos os passos da construção da armadilha magneto-ótica. O tratamento será baseado nas descrições apresentadas em [25, 26, 27].

Neste capítulo começamos por descrever a interação entre radiação e matéria com um modelo de átomo de dois níveis, não degenerado e sem spin. Escolhemos os auto-estados $|g\rangle$ e $|e\rangle$ ortonormais. Mostramos como a absorção e a emissão de fótons alteram o movimento atômico. Fazemos uma descrição semi-clássica na qual o átomo é quantizado e o campo é clássico. Este modelo é uma base para entendimento das forças envolvidas nos processos de resfriamento e de aprisionamento. 


\subsection{Pressão de radiação}

O operador Hamiltoniano total do sistema em estudo na descrição semi-clássica é dado por $\mathbf{H}=\mathbf{H}_{0}+\mathbf{V}$, onde $\mathbf{H}_{0}$ é o Hamiltoniano do átomo livre e $\mathbf{V}$ é o operador de interação. Temos para o átomo livre o hamiltoniano envolvendo tanto a parte cinética quanto a parte eletrônica

$$
\mathbf{H}_{0}=\frac{\mathbf{p}^{2}}{2 M}+\hbar \omega_{0}|e\rangle\langle e|
$$

onde $\mathbf{p}$ é o momento linear do átomo e $\omega_{0}$ é a frequência de ressonância da transição entre os níveis $|g\rangle$ e $|e\rangle$. Para um campo com o comprimento de onda muito maior que o comprimento de onda de de Broglie do átomo, $\lambda \gg \lambda_{A}$, o momento linear do fóton é muito menor que o do átomo, portanto o processo de absorção e emissão de um único fóton não consegue alterar significativamente a velocidade atômica. Podemos desprezar o termo cinético $p^{2} /(2 M)$ na energia total do átomo livre numa primeira aproximação, e reduzir o hamiltoniano a $\mathbf{H}_{0}^{\prime}=\hbar \omega_{0}|e\rangle\langle e|$.

$\mathrm{O}$ operador de interação $\mathbf{V}=-\mathbf{d} \cdot \mathcal{E}$ é proporcional ao campo elétrico $\mathcal{E}$. O operador momento dipolo elétrico $\mathbf{d}$ é definido como $\mathbf{d}=-e \mathbf{r}$, onde $e$ é a carga do elétron e $\mathbf{r}$ o operador da posição eletrônica. O operador momento de dipolo elétrico possui paridade ímpar, com isto seus elementos diagonais são nulos,

$$
\mathbf{d}=d_{e g}(|e\rangle\langle g|+| g\rangle\langle e|)
$$

$\operatorname{com} d_{e g}=\langle e|\mathbf{d}| g\rangle=\langle g|\mathbf{d}| e\rangle$

Consideremos inicialmente uma onda eletromagnética clássica plana monocromática,

$$
\mathcal{E}(\mathbf{r}, t)=\mathbf{E}_{0} \cos (\omega t-\mathbf{k} \cdot \mathbf{r})
$$

com vetor de polarização $\mathbf{E}_{0}$, frequência angular $\omega$ e vetor de onda $\mathbf{k}$. 
Colocando a função cosseno na forma exponencial, obtemos:

$$
\begin{aligned}
\mathbf{V}= & -\mathbf{d} \cdot \mathcal{E} \\
=-\frac{d_{e g} \cdot \mathbf{E}_{0}}{2} & {\left[e^{-i(\omega t-\mathbf{k} \cdot \mathbf{r})}|e\rangle\left\langle g\left|+e^{i(\omega t-\mathbf{k} \cdot \mathbf{r})}\right| g\right\rangle\langle e|+\right.} \\
& \left.\quad+e^{-i(\omega t-\mathbf{k} \cdot \mathbf{r})}|g\rangle\left\langle e\left|+e^{i(\omega t-\mathbf{k} \cdot \mathbf{r})}\right| e\right\rangle\langle g|\right] .
\end{aligned}
$$

Nesta expressão os últimos dois termos, $e^{-i(\omega t-\mathbf{k} \cdot \mathbf{r})}|g\rangle\langle e|$ e $e^{i(\omega t-\mathbf{k} \cdot \mathbf{r})}|e\rangle\langle g|$, são termos antiressonantes, que representam os processos atômicos, respectivamente, de absorção de fóton ao descer de nível e de emissão de fóton ao subir de nível. Na Aproximação de Ondas Girantes (RWA Rotating Wave Approximation) [26] estes termos não ressonantes são desprezados, e o operador de interação pode ser descrito apenas pelos termos ressonantes

$$
\begin{aligned}
\mathbf{V} & \approx-\frac{d_{e g} \cdot \mathbf{E}_{0}}{2}\left[e^{-i(\omega t-\mathbf{k} \cdot \mathbf{r})}|e\rangle\left\langle g\left|+e^{i(\omega t-\mathbf{k} \cdot \mathbf{r})}\right| g\right\rangle\langle e|\right] \\
& =\frac{\hbar \Omega(\mathbf{r}, t)}{2}\left[e^{-i(\omega t-\mathbf{k} \cdot \mathbf{r})}|e\rangle\left\langle g\left|+e^{i(\omega t-\mathbf{k} \cdot \mathbf{r})}\right| g\right\rangle\langle e|\right]
\end{aligned}
$$

onde definimos a frequência de Rabi, proporcional à amplitude do campo elétrico: $\Omega(\mathbf{r}, t) \equiv-\frac{d_{e g} \cdot \mathbf{E}_{0}}{\hbar}$.

Nosso objetivo é deduzir qual a força exercida pelo campo clássico sobre o átomo quantizado. Para podermos falar de força na mecânica quântica, usamos o teorema de Ehrenfest, que estabelece o valor esperado de um operador quântico como sendo igual ao seu correspondente clássico. Portanto, a força $\mathcal{F}$ sobre um átomo deve ser igual ao valor esperado do operador de força F. Escrevendo a versão quântica da equação de Newton temos que

$$
\mathcal{F}=\langle\mathbf{F}\rangle=\frac{d}{d t}\langle\mathbf{p}\rangle
$$

onde $\mathbf{p}$ é o operador de momento linear do átomo. 
A evolução temporal do valor médio do operador quântico independente de tempo é dada por

$$
\frac{d}{d t}\langle\mathbf{p}\rangle=\frac{i}{\hbar}\langle[\mathbf{H}, \mathbf{p}]\rangle=-\langle\nabla \mathbf{H}\rangle,
$$

lembrando que $[\mathbf{H}, \mathbf{p}]=i \hbar \nabla \mathbf{H}$. Portanto, a força exercida sobre o átomo é

$$
\mathcal{F}=-\langle\nabla \mathbf{H}\rangle=-\langle\nabla \mathbf{V}\rangle,
$$

onde eliminamos o Hamiltoniano livre no segundo passo, o qual não depende da posição do átomo. O resultado é análogo à expressão clássica na qual a força é igual ao negativo do gradiente de um potencial. Usando o fato do comprimento de onda ótica ser normalmente algumas centenas de nm enquanto o tamanho de átomo é tipicamente menor que $1 \mathrm{~nm}$, podemos desprezar a variação da amplitude do campo elétrico na dimensão do átomo. Com esta aproximação de dipolo elétrico podemos inverter a ordem entre o valor esperado e o gradiente para obter a relação entre a força e a hamiltoniana de interação

$$
\mathcal{F}=-\nabla\langle\mathbf{V}\rangle \text {. }
$$

Introduzimos agora o operador de densidade do átomo $\boldsymbol{\rho}=|\Psi\rangle\langle\Psi|$. Utilizando a propriedade de que o valor médio de um operador $\mathbf{A}$ é igual ao traço da matriz $\boldsymbol{\rho} \mathbf{A},\langle\mathbf{A}\rangle=\operatorname{Tr}(\boldsymbol{\rho} \mathbf{A})[28]$, temos que,

$$
\mathcal{F}=-\nabla[\operatorname{Tr}(\boldsymbol{\rho} \mathbf{V})]
$$

Partindo do operador densidade

$$
\boldsymbol{\rho}=\rho_{g g}|g\rangle\left\langle g\left|+\rho_{e e}\right| e\right\rangle\left\langle e\left|+\rho_{e g}\right| e\right\rangle\left\langle g\left|+\rho_{e g}^{*}\right| g\right\rangle\langle e|,
$$


$\operatorname{com} \rho_{i j}=\langle i|\rho| j\rangle$ e $\rho_{g e}=\rho_{e g}^{*}$, temos que,

$$
\operatorname{Tr}(\boldsymbol{\rho} \mathbf{V})=\frac{\hbar \Omega}{2}\left[e^{i(\omega t-\mathbf{k} \cdot \mathbf{r})} \rho_{e g}+e^{-i(\omega t-\mathbf{k} \cdot \mathbf{r})} \rho_{e g}^{*}\right]
$$

substituindo de volta na equação da força (2.10) teremos

$$
\mathcal{F}=-\frac{\hbar}{2}\left[\nabla\left(\Omega e^{-i \mathbf{k} \cdot \mathbf{r}}\right) e^{i \omega t} \rho_{e g}+\nabla\left(\Omega e^{i \mathbf{k} \cdot \mathbf{r}}\right) e^{-i \omega t} \rho_{e g}^{*}\right] .
$$

Como os dois termos da soma são complexos conjugados, podemos simplificar a expressão ( $\Re$ denota parte real e $\Im$, parte imaginária) :

$$
\begin{aligned}
\mathcal{F} & =-\hbar \Re\left[\nabla\left(\Omega e^{-i \mathbf{k} \cdot \mathbf{r}}\right) e^{i \omega t} \rho_{e g}\right] \\
& =-\hbar \Re\left[\left(\nabla \Omega e^{-i \mathbf{k} \cdot \mathbf{r}}-i \mathbf{k} \Omega e^{-i \mathbf{k} \cdot \mathbf{r}}\right) e^{i \omega t} \rho_{e g}\right] \\
& =-\hbar \Omega\left\{\left(\frac{\nabla \Omega}{\Omega}\right) \Re\left[e^{i(\omega t-\mathbf{k} \cdot \mathbf{r})} \rho_{e g}\right]+\mathbf{k} \Im\left[e^{i(\omega t-\mathbf{k} \cdot \mathbf{r})} \rho_{e g}\right]\right\},
\end{aligned}
$$

onde temos um termo envolvendo o gradiente do campo elétrico e a parte real do termo de coerência da matriz densidade na descrição de onda girante, e um termo propocional ao vetor de onda do campo $\mathbf{k}$ e à parte imaginária do termo de coerência. O primeiro dá origem a forças conservativas sobre o átomo, enquanto que o segundo dará origem a um termo dissipativo.

Para melhor descrevermos os efeitos, vamos definir novas variáveis:

$$
\begin{aligned}
& s_{1} \equiv \Re\left[e^{i(\omega t-\mathbf{k} \cdot \mathbf{r})} \rho_{e g}\right], \\
& s_{2} \equiv \Im\left[e^{i(\omega t-\mathbf{k} \cdot \mathbf{r})} \rho_{e g}\right], \\
& s_{3} \equiv \frac{1}{2}\left(\rho_{e e}-\rho_{g g}\right) .
\end{aligned}
$$

Os três termos formam o vetor de Bloch $\mathbf{s}=\left(s_{1}, s_{2}, s_{3}\right)$, que fornece uma representação geométrica do estado atômico. Substituindo estes termos na equação (2.14) chegamos a

$$
\mathcal{F}=-\hbar \Omega\left[\frac{\nabla \Omega}{\Omega} s_{1}-\mathbf{k} s_{2}\right]
$$


Neste ponto, para obter as expressões para $s_{1}$ e $s_{2}$, precisamos saber a evolução temporal do operador matriz densidade. Partindo da equação de Schrödinger temos que [27],

$$
i \hbar \dot{\rho}=[\mathbf{H}, \boldsymbol{\rho}]
$$

Expandindo esta equação na base $\{|g\rangle,|e\rangle\}$, denotando $\beta \equiv \omega t-\mathbf{k} \cdot \mathbf{r}$, obtemos:

$$
\begin{aligned}
& \dot{\rho}_{g g}=-\frac{i \Omega}{2}\left(e^{i \beta} \rho_{e g}-e^{-i \beta} \rho_{e g}^{*}\right) \\
& \dot{\rho}_{e e}=-\frac{i \Omega}{2}\left(-e^{i \beta} \rho_{e g}+e^{-i \beta} \rho_{e g}^{*}\right) \\
& \dot{\rho}_{e g}=-i \omega_{0} \rho_{e g}+i \frac{\Omega}{2} e^{-i \beta}\left(\rho_{e e}-\rho_{g g}\right)
\end{aligned}
$$

onde $\omega_{0}$ é a frequência angular da transição atômica.

Agora, como partimos de um tratamento semi-clássico, não há termos de relaxação nestas equações, que surgem naturalmente ao tratarmos quanticamente o campo eletromagnético [29]. Precisamos adicionar a constante de decaimento $\Gamma$ relacionada a emissão espontânea de forma fenomenológica ${ }^{1}[26]$ levando às equações de Bloch:

$$
\begin{aligned}
& \dot{\rho}_{g g}=\Gamma \rho_{e e}-\frac{i \Omega}{2}\left(e^{i \beta} \rho_{e g}-e^{-i \beta} \rho_{e g}^{*}\right) \\
& \dot{\rho}_{e e}=-\Gamma \rho_{e e}-\frac{i \Omega}{2}\left(-e^{i \beta} \rho_{e g}+e^{-i \beta} \rho_{e g}^{*}\right) \\
& \dot{\rho}_{e g}=-\left(\frac{\Gamma}{2}+i \omega_{0}\right) \rho_{e g}+i \frac{\Omega}{2} e^{-i \beta}\left(\rho_{e e}-\rho_{g g}\right)
\end{aligned}
$$

Podemos observar que a conservação populacional $\dot{\rho}_{g g}+\dot{\rho}_{e e}=0$ é satisfeita.

Este conjunto de equações é conhecido como as equações de Bloch Óticas, em analogia às equações de Bloch da ressonância magnética nuclear.

\footnotetext{
${ }^{1} \mathrm{Na}$ seção sobre Resfriamento descreveremos mais sobre os processos de relaxação e a diferença entre emissão espontânea e emissão estimulada.
} 
Diferenciando (2.15) e usando (2.19) obtemos

$$
\begin{aligned}
& \dot{s}_{1}=-\frac{\Gamma}{2} s_{1}+\delta s_{2} \\
& \dot{s}_{2}=-\delta s_{1}-\frac{\Gamma}{2} s_{2}-\Omega s_{3} \\
& \dot{s}_{3}=\Omega s_{2}-\Gamma s_{3}-\frac{\Gamma}{2}
\end{aligned}
$$

onde definimos $\delta \equiv \omega-\omega_{0}$ como a dessintonia do feixe laser em relação à transição atômica.

No estado estacionário, temos a condição $\dot{\mathbf{s}}=0$. Aplicando isto nas equações (2.20) obtemos a solução estacionária

$$
\begin{aligned}
s_{1} & =\frac{\delta}{2} \frac{\Omega}{\delta^{2}+\Omega^{2} / 2+\Gamma^{2} / 4}, \\
s_{2} & =\frac{\Gamma}{2} \frac{\Omega / 2}{\delta^{2}+\Omega^{2} / 2+\Gamma^{2} / 4}, \\
s_{3} & =\frac{\Omega}{2} \frac{\Omega}{\delta^{2}+\Omega^{2} / 2+\Gamma^{2} / 4}-\frac{1}{2} .
\end{aligned}
$$

Substituindo (2.21a) e (2.21b) na equação (2.16), obtemos a expressão da força média sobre o átomo

$$
\begin{aligned}
\mathcal{F} & =-\hbar \nabla \Omega \frac{\delta}{2} \frac{\Omega}{\delta^{2}+\Omega^{2} / 2+\Gamma^{2} / 4}+\hbar \mathbf{k} \frac{\Gamma}{2} \frac{\Omega^{2} / 2}{\delta^{2}+\Omega^{2} / 2+\Gamma^{2} / 4} \\
& =\mathcal{F}_{\text {dip }}+\mathcal{F}_{s p}
\end{aligned}
$$

Nesta expressão, o primeiro termo representa a força de dipolo elétrico, proporcional ao gradiente do campo $\nabla \Omega$, sendo um termo conservativo. Esta força só será apreciável quando a intensidade do feixe variar consideravelmente numa distância da ordem do comprimento de onda. Como no nosso experimento utilizamos feixe laser colimado e aproximadamente Gaussiano, o perfil de intensidade do feixe é bastante homogêneo, portanto podemos desprezar este termo $(\nabla \Omega \approx 0)$. Para outras aplicações, envolvendo o aprisionamento atômico em gradientes 
de campo elétrico (armadilhas tipo FORT - Far off resonance trap [30] ou redes óticas [31]), este termo será relevante. O segundo termo da equação representa a força da pressão da radiação, gerada pela absorção seguida de emissão espontânea de fótons. Este termo dissipativo dará origem ao processo de resfriamento atômico.

Pela definição de $s_{3}$ e usando a propriedade $\rho_{g g}+\rho_{e e}=1$, temos que $\rho_{e e}=s_{3}+1 / 2$. Comparando com a equação (2.21c), temos que:

$$
\mathcal{F}_{s p}=\hbar \mathbf{k} \Gamma \rho_{e e} .
$$

A força é igual ao momento de um fóton $\hbar \mathbf{k}$ multiplicado pela taxa de relaxação atômica $\Gamma$ e pela probabilidade do átomo estar no estado excitado $\rho_{e e}$ cujo valor máximo é $1 / 2$.

Para mostrar mais claramente o sentido da equação, usamos a relação entre a frequência de Rabi e a intensidade do campo, dada por

$$
2 \frac{\Omega^{2}}{\Gamma^{2}}=\frac{I}{I_{s}}
$$

onde $I$ é a intensidade do feixe e $I_{s}$ é a intensidade de saturação do átomo, que é dada por $I_{s} \equiv \pi h c \Gamma /\left(3 \lambda^{3}\right) \quad[27]$. Assim temos que a força que uma onda monocromática plana exerce sobre o átomo corresponde a

$$
\mathcal{F} \simeq \mathcal{F}_{s p}=\hbar \mathbf{k} \frac{\Gamma}{2} \frac{I / I_{s}}{1+I / I_{s}+(2 \delta / \Gamma)^{2}}=\hbar \mathbf{k} \Gamma \rho_{e e}
$$

No caso de um feixe intenso, $I / I_{s} \gg 1$, vemos que a força tende a um limite:

$$
\mathcal{F}_{\text {max }} \simeq \hbar \mathbf{k} \Gamma / 2
$$

A força não cresce continuamente com o aumento da intensidade do campo, posto que a transição atômica é saturada pelo feixe. Esta pressão exercida pela radiação será empregada para efetuar o resfriamento atômico na armadilha magneto-ótica. 


\subsection{Resfriamento atômico}

Para muitas experiências, queremos evitar a agitação térmica dos átomos, resfriando-os e mantendo-os ainda individualmente isolados, na forma de vapor. Precisamos de uma amostra fria, localizada e isolada da interferência do ambiente, o que é feito normalmente dentro de uma câmara de vácuo. Para resfriar a amostra, ou seja, obter uma distribuição de velocidade comprimida perto do zero, não podemos simplesmente resfriar a câmara, pois isto faria com que toda a amostra se condensasse nas paredes internas. Assim, para resfriar mas sem tocar diretamente os átomos, precisamos utilizar as propriedades da interação entre átomos e fótons.

A interação ressonante entre fóton e átomo é gerada pela absorção e emissão. Há dois tipos de emissão: espontânea e estimulada. Somente o primeiro é responsável pelo resfriamento de átomo.

A emissão estimulada ocorre no mesmo sentido da absorção, o momento transferido para átomo pela emissão estimulada possui o sentido oposto e o módulo igual ao do momento recebido na absorção do fóton. Portanto, os momentos se cancelam e a força resultante é nula.

Já a emissão espontânea é diferente, esta não possui direção preferencial, o fóton é emitido aleatoriamente. Sendo assim, a cada emissão espontânea há transferência de momento para o átomo, mas se somarmos a contribuição de várias emissões seguidas, por uma questão de simetria, a soma dos momentos deve ser nula. Portanto, na média, a emissão espontânea não altera o movimento do átomo, e apenas a absorção do fóton transfere momento para este. Este processo é que gera o resfriamento.

Como a força da pressão de radiação é gerada pela transferência do momento do fóton, $\hbar k$, para o átomo, para que o fóton tenha maior probabilidade de ser absorvido, ele precisa estar 
sintonizado numa frequência de transição do átomo. Também precisamos considerar que os átomos estão se movendo continuamente e com velocidades aleatórias devido às interações com o ambiente. Por causa disso, a frequência do fóton no referencial do átomo é deslocada pelo efeito Doppler. Seja v a velocidade atômica, a frequência angular da radiação é transformada em $\omega \rightarrow \omega-\mathbf{k} \cdot \mathbf{v}$, onde $\mathbf{k}$ é o vetor de onda do feixe. Se o átomo está se movendo contra a luz, a frequência aumenta, e se o átomo está se movendo no mesmo sentido da luz a frequência diminui. Assim o feixe da luz pode estar fora da ressonância na maior parte do tempo por causa do deslocamento atômico. Portanto, a pressão de radiação da equação (2.25) no referencial do átomo, dependendo do sentido da propagação do feixe, é modificada para

$$
\begin{aligned}
\mathcal{F}_{ \pm} & = \pm \hbar \mathbf{k} \frac{\Gamma}{2} \frac{I / I_{s}}{1+I / I_{s}+[2(\delta \mp \mathbf{k} \cdot \mathbf{v}) / \Gamma]^{2}} \\
& = \pm \hbar \mathbf{k} R_{ \pm}
\end{aligned}
$$

onde foi definida a taxa de espalhamento de fótons para cada feixe $R_{ \pm}$.

Nesta expressão assumimos que a velocidade do átomo não varia muito durante alguns ciclos de absorção e emissão de fótons, ou seja, $k v_{r e c} \ll \Gamma$, onde $v_{r e c}=\hbar k / M$ é a velocidade de recuo do átomo ao absorver ou emitir um fóton. Isto permite falarmos em força "média" (média sobre alguns ciclos) para uma dada velocidade atômica [32].

Em 1975, de forma independente, Hänsh e Schawlow [5] , e Wineland e Dehmelt [6] sugeriram uma idéia muito elegante de usar a pressão de radiação de feixe laser para resfriar átomos aproveitando esta dessintonia causada pelo efeito Doppler. A seguir apresentaremos os princípios do resfriamento Doppler.

Considerando um modelo unidimensional, um átomo viajando na direção $+\hat{z}$ com a veloci- 

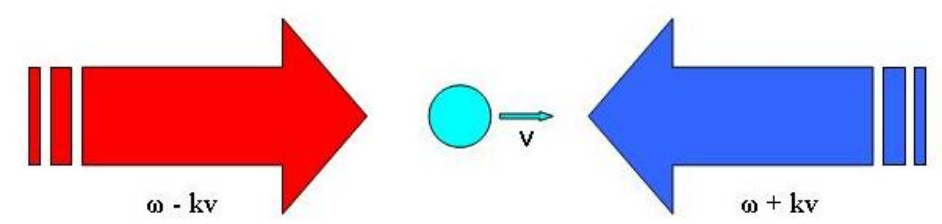

Figura 2.1: Um átomo se movendo no meio de dois feixes contra-propagantes com a mesma frequência. Devido ao efeito Doppler, no referencial do átomo, os feixes sofrem deslocamentos diferentes.

dade $v$ é irradiado pelos dois lados com um par de feixes contrapropagantes $(+k$ e $-k)$ e com a frequência $\omega$ sintonizada abaixo da frequência natural da transição do átomo $\omega_{0}(\delta<0)$. No referencial do átomo a frequência do feixe oposto ao seu movimento é aumentada para $\omega+k v$ logo aproxima-se da frequência da ressonância, e o feixe copropagante é deslocado para mais longe da ressonância $\omega-k v$, sendo que $k=2 \pi / \lambda$ e $\lambda$ é o comprimento de onda (ver a figura 2.1). Consequentemente, o átomo absorve mais os fótons do primeiro feixe, que são opostos ao seu movimento e mais ressonantes, perde momento e, portanto, é freado nesta direção. O mesmo fenômeno acontece se o átomo mover para o outro lado. Então os átomos sempre espalham mais os fótons do lado contra o qual estão se movendo e portanto são freados e resfriados. Para obter resfriamento tridimensional, precisa posicionar um par de feixes em cada direção.

Note porém que o deslocamento Doppler pode ser grande demais caso a velocidade de um átomo é muito alta, portanto os feixes não conseguem frear qualquer átomo. Os átomos precisam estar mais lentos que a velocidade de captura do sistema para sentir os efeitos. Normalmente isto corresponde a velocidade atômica média de dezenas de metros por segundo ou à temperatura de 
$1 \mathrm{~K}$. Mas como os átomos da amostra encontram-se numa distribuição de velocidades, sempre há uma pequena porção de átomos que satisfazem esta condição.

Levando em consideração os dois feixes contrapropagantes e os deslocamentos Doppler, e desprezando a emissão estimulada (de resultante média nula), a força total sobre o átomo é dada através da equação (2.27) por

$$
\begin{aligned}
\mathcal{F}_{t} & =\mathcal{F}_{+}+\mathcal{F}_{-} \\
& =\hbar k \frac{\Gamma}{2} \frac{I}{I_{s}}\left[\frac{1}{1+I / I_{s}+4(\delta-k v)^{2} / \Gamma^{2}}-\frac{1}{1+I / I_{s}+4(\delta+k v)^{2} / \Gamma^{2}}\right]
\end{aligned}
$$

A figura 2.2 mostra a relação entre a força resultante e a velocidade atômica. Os gráficos foram construídos usando a equação (2.28) com intensidade dos feixes igual a $I_{s}$. Estão apresentadas curvas de quatro valores de dessintonias diferentes. Podemos perceber que, próximo de $v=0$, a força varia mais rapidamente quando $\delta=-\Gamma / 2$ e com isto teremos um resfriamento mais eficiente. Além disso, perto da origem, a força varia quase que linearmente.

Para velocidades atômicas baixas que satisfaçam a condição $|k v| \ll|\delta|$, podemos simplificar a expressão, obtendo

$$
\begin{aligned}
\mathcal{F}_{t} & \approx \hbar k \frac{\Gamma}{2} \frac{I}{I_{s}} \frac{k v}{\Gamma} \frac{16 \delta}{\Gamma} \frac{1}{\left[1+I / I_{s}+(2 \delta / \Gamma)^{2}\right]^{2}} \\
& =4 \hbar k \frac{I}{I_{s}} \frac{2 \delta / \Gamma}{\left[1+I / I_{s}+(2 \delta / \Gamma)^{2}\right]^{2}} k v \\
& =-\alpha_{D} v
\end{aligned}
$$

onde definimos o coeficiente de fricção

$$
\alpha_{D} \equiv 4 \hbar k \frac{I}{I_{s}} \frac{2 k|\delta| / \Gamma}{\left[1+I / I_{s}+(2 \delta / \Gamma)^{2}\right]^{2}}
$$




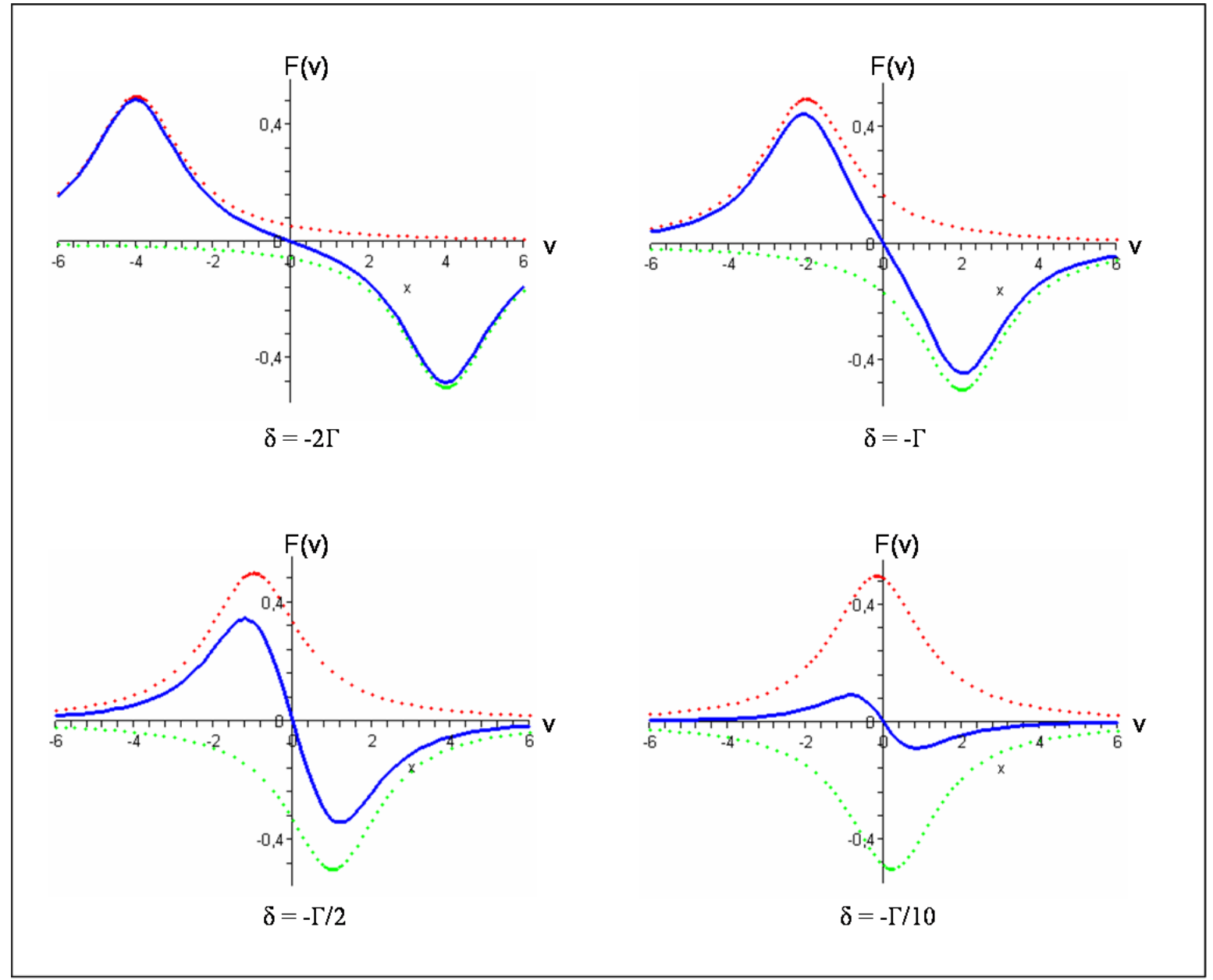

Figura 2.2: Força Doppler x velocidade atômica. As linhas pontilhadas representam forças de um feixe só e as linhas cheias representam a força resultante da soma. São mostradas quatro situações com dessintonias $\delta$ diferentes. 
Podemos ver que a pressão de radiação neste limite é como uma força de atrito, linearmente proporcional ao negativo da velocidade. É importante notar que isto só vale para $\delta=\omega-\omega_{0}<0$, caso contrário a força não será mais de resfriamento.

A equação (2.29b) é dependente de vários fatores: o primeiro é o momento do fóton, o segundo é a intensidade normalizada, o terceiro depende da dessintonia normalizada $2 \delta / \Gamma$ (onde $\Gamma / 2$ é a metade da largura da transição) e por fim temos o efeito do deslocamento Doppler. Podemos ver que a força total tende a zero se a dessintonia tender a zero ou ao infinito. Para uma dada intensidade do feixe, a força é máxima para $\delta=-\Gamma / 2 \sqrt{\left(I+I_{s}\right) / 3 I_{s}}$.

A força de resfriamento é proporcional à velocidade dos átomos, assim como o deslocamento Doppler é proporcional à velocidade. Nesse sentido a pressão de radiação exerce uma força de fricção como se fosse um fluido, atenuando a velocidade do átomo. A primeira experiência de resfriamento tridimensional de átomos neutros foi realizada pelos pesquisadores do Bell Laboratórios, EUA em 1985 [9]. Observando o comportamento dos átomos resfriados, eles deram o nome de melaço ótico (optical molasses) para "o fluido viscoso de fótons" no qual os átomos são resfriados. Neste tipo de resfriamento os átomos percorrem uma distância muito curta a cada absorção ou emissão de fóton e as velocidades dos átomos envolvidos são rapidamente diminuídas. O movimento dos átomos no centro do cruzamento dos feixes (dentro da nuvem) é muito parecido com o movimento Browniano de partículas em um líquido. 


\subsubsection{Temperatura Doppler}

Nesta seção nós baseamos no artigo [33] para descrever o limite de temperatura do resfriamento Doppler. A temperatura da nuvem de átomos frios é resultado do equilíbrio entre o resfriamento a laser e o processo de aquecimento devido à absorção e emissão de fótons. A absorção e emissão espontânea aleatória de fótons causa a mudança constante do momento do átomo. Embora a média do momento $p$ (média da velocidade) tenda a zero, a média quadrática do momento $p^{2}$ não é nula e é aumentada por este processo aleatório o que leva ao aquecimento.

A taxa de variação de $p^{2}$ é igual ao momento do fóton ao quadrado vezes a taxa de espalhamento total de fótons $R$ multiplicado por fator 2 devido a contagem da absorção e emissão:

$$
\frac{d p^{2}}{d t}=2 R(\hbar k)^{2}
$$

A taxa total $R$ é obtido por $R=R_{+}+R_{-}$, onde $R_{+}$e $R_{-}$são definidos na equação (2.27). Com a aproximação de $|k v| \ll|\delta|$, temos que [34]:

$$
R=\frac{\Gamma\left(I / I_{s}\right)}{1+I / I_{s}+[2 \delta / \Gamma]^{2}}
$$

Como a energia cinética é $E=p^{2} / 2 M$, com a aproximação de $|k v| \ll|\delta|$ e $|k v| \ll \Gamma$, e no limite de baixa intensidade, temos que a variação de energia devida ao aquecimento é:

$$
\frac{d E_{A}}{d t}=\frac{(\hbar k)^{2}}{M} \Gamma \frac{I / I_{s}}{1+(2 \delta / \Gamma)^{2}}
$$

Este termo representa a variação da energia cinética devido ao aquecimento. A variação devido ao resfriamento é

$$
\frac{d E_{R}}{d t}=\mathcal{F}_{t} v=-\alpha_{D} v^{2} .
$$


No equilíbrio a soma dos dois termos deve ser zero, portanto, usando as equações $(2.30),(2.33)$

e (2.34), podemos obtemos:

$$
v^{2}=\frac{\hbar \Gamma}{4 M} \frac{1+(2 \delta / \Gamma)^{2}}{2|\delta| / \Gamma} .
$$

Como este termo é calculado usando taxas médias, podemos interpretá-lo como a velocidade média quadrática de um grupo de átomos ou a média temporal da velocidade quadrática de um único átomo. Pela teorema da equipartição da energia [35] temos que $M v_{r m s}^{2} / 2=k_{B} T / 2$, onde $k_{B}$ é a constante de Boltzmann. Portanto temos:

$$
k_{B} T=\frac{\hbar \Gamma}{4} \frac{1+(2 \delta / \Gamma)^{2}}{2|\delta| / \Gamma} .
$$

A temperatura é mínima quando $2 \delta / \Gamma=-1$ que corresponde a $k_{B} T_{\min }=\hbar \Gamma / 2$. Esta temperatura é chamada de limite de resfriamento Doppler. O limite de resfriamento Doppler $T_{D}$ para átomo de ${ }^{85} \mathrm{Rb}$ é $143 \mu \mathrm{K}$ que corresponde a velocidade média de $V_{D}=11,9 \mathrm{~cm} / \mathrm{s}$. Para ${ }^{23} \mathrm{Na}, T_{D}=240 \mu \mathrm{K}$ com $V_{D}=29,5 \mathrm{~cm} / \mathrm{s}[27]$.

Os desenvolvimentos apresentados aqui são teóricos, no entanto, as primeiras medidas de temperatura obtidas a partir de átomos resfriados mostraram temperaturas inferiores a este limite. Para compreender a origem deste resfriamento sub-Doppler, é necessário levar em conta os diferentes subníveis dos estados fundamental e excitado, e a polarização do campo eletromagnético. Neste caso, o limite fundamental é dado pelo recuo do átomo na emissão de um único fóton. Apesar da média da emissão espontânea não interferir no momento do átomo, cada emissão de fóton altera momentaneamente a velocidade do átomo. Esta natureza aleatória da emissão estabelece um limite mínimo para a largura da distribuição de velocidade sendo que a temperatura mínima correspondente é chamada de limite de recuo do fóton. Para ${ }^{85} \mathrm{Rb}$, 
$T_{r}=0,370 \mu \mathrm{K}$ e $V_{r}=0,60 \mathrm{~cm} / \mathrm{s}$, e para ${ }^{23} \mathrm{Na}, T_{r}=2,399 \mu \mathrm{K}$ e $V_{r}=2,95 \mathrm{~cm} / \mathrm{s}[27]$, representando o limite inferior de resfriamento possível usando feixes laser.

\subsection{Adicionando o aprisionamento}

O resfriamento é apenas a diminuição da velocidade média atômica, diferentemente do aprisionamento, que implica em confinamento espacial. No melaço ótico, como a pressão de radiação não depende da posição, os átomos com a velocidade $v$ sofrem a mesma força onde estiverem, portanto não são presos numa região fixa. Em consequências de choques com outros átomos, eles podem ser ejetados da região de resfriamento. Além disso, o processo de emissão espontânea irá produzir ao final um movimento aleatório dos átomos dentro do feixe, levando a um processo difusivo no qual o átomo finalmente sai da região de melaço ótico.

Enquanto a força de resfriamento é proporcional à velocidade atômica, a de aprisionamento precisa ser proporcional à posição. No entanto, uma armadilha baseada somente em absorção e emissão espontânea numa configuração estática de feixes lasers não é estável, isto é conhecido como Teorema ótico de Earnshaw [36] em analogia ao teorema em eletrostática que estabelece a instabilidade de aprisionamento de partículas carregadas num campo estático. Mas se algum campo externo altera a força de espalhamento do feixe com uma dependência posicional, uma armadilha estável é possível de se criar.

Foi criada a armadilha magneto-ótica (Magneto-Optical Trap - MOT) que combina o resfriamento de melaço ótico com o efeito de um campo magnético. A ideia básica é usar o momento angular da luz circularmente polarizada para explorar a estrutura magnética do átomo. Um campo magnético especial é adicionado na configuração do melaço ótico para gerar uma força 
dependente da posição atômica dentro do campo, obtendo assim resfriamento e aprisionamento. Normalmente o campo magnético da MOT é criado por um par de bobinas (quadrupolo), é estático e não-homogêneo. No centro do campo a intensidade possui variação aproximadamente linear com a posição: no eixo de simetria das bobinas $\hat{z}, \mathbf{B}(z)=b z \hat{e}_{z}$, onde $b$ é o gradiente do campo [ver mais detalhes sobre o campo magnético na próxima seção].

Para compreender o processo de aprisionamento, devemos sair do modelo simplificado de átomo de dois níveis, e levar em conta os níveis Zeeman identificados com diferentes valores de número quântico magnético $m_{F}$, que pode assumir apenas valores inteiros entre $+F$ e $-F$ e cujo produto $m_{F} \hbar$ é a projeção do momento angular total $F$ no eixo de quantização.

Usamos o exemplo da transição de dois níveis $g$ e $e$ com variação do momento angular total $F_{g}=0 \rightarrow F_{e}=1$, que possui 3 níveis Zeeman no estado excitado com $m_{F_{e}}=(-1,0,1)$. Embora poucos átomos têm esta transição simples, a descrição também é aplicável para qualquer transição $F_{g} \rightarrow F_{e}=F_{g}+1$.

O efeito do campo magnético é quebrar a degenerescência das 3 componentes Zeeman do átomo, criando uma separação entre os níveis que depende da posição espacial. Considerando apenas o eixo $\hat{z}$, o deslocamento da energia de um nível com momento magnético $\mu$ pelo campo é dado por

$$
\Delta E=-\mu \cdot B(z)=\mu_{B} g F \cdot B(z)=m_{F} \hbar \mu_{B} g b z
$$

onde $\mu_{B}$ é o magneton de Bohr e $g$ é o fator giromagnético de Landé do estado excitado. A frequência de ressonância da transição $\left|F_{g}=0, m_{F_{g}}=0\right\rangle$ para $\left|F_{e}=1, m_{F_{e}}\right\rangle$ é alterada para:

$$
\omega_{0} \rightarrow \omega_{0}+m_{F_{e}} \mu_{B} g b z
$$

lembrando que, pela regra de seleção, $\Delta m_{F}$ pode assumir apenas os valores $\{-1,0,1\}$, onde 
$\Delta m_{F} \equiv m_{F_{e}}-m_{F g}=m_{F_{e}}$. Será explicado mais adiante que, devido à orientação da polarização dos feixes laser, o feixe $+\mathbf{k}$ promove transição para $m_{F_{e}}=+1$ e o feixe contrário, para $m_{F_{e}}=-1$. Assim, incluindo o efeito Doppler, a dessintonia $\delta=\omega-\omega_{0}$ do feixe $+\mathbf{k}(-\mathbf{k})$ é modificado no eixo $\hat{z}$ para a dessintonia real $\delta_{+}\left(\delta_{-}\right)$:

$$
\begin{aligned}
\delta_{ \pm} & =(\omega \mp k v)-\left(\omega_{0} \pm \mu_{B} g b z\right) \\
& =\delta \mp k v \mp \mu_{B} g b z
\end{aligned}
$$

Substituindo na equação (2.25) e somando as contribuições dos dois feixes contrapropagantes obtemos a expressão da força total de radiação na armadilha no eixo $\hat{z}$ :

$$
\mathcal{F}_{T}=\hbar \mathbf{k} \frac{\Gamma}{2} \frac{I}{I_{s}}\left[\frac{1}{1+I / I_{s}+\left(2 \delta_{+} / \Gamma\right)^{2}}-\frac{1}{1+I / I_{s}+\left(2 \delta_{-} / \Gamma\right)^{2}}\right]
$$

Para um átomo com baixa velocidade e perto do centro do campo magnético, podemos fazer uma aproximação de primeira ordem em $v$ e $z$, e obtemos que a força depende linearmente destes parâmetros:

$$
\mathcal{F}_{T}=-\alpha_{D} v-K_{D} z
$$

onde $\alpha_{D}$ é dado pela fórmula (2.30) e

$$
K_{D} \equiv \alpha_{D} m_{F} \mu_{B} g b / k
$$

é chamado de constante de mola e é ligado à força de restauro para a posição $z=0$.

A figura 2.3 esquematiza o mecanismo de aprisionamento da MOT. Fixamos a origem do eixo $\vec{z}$ no centro do campo, onde a amplitude deste é nula. Para $z>0$ as energias dos níveis hiperfinos aumentam de $\Delta m_{F}=-1$ até $\Delta m_{F}=+1$; para $z<0$ a situação se inverte devido ao sinal do campo. A separação de energia entre os níveis cresce com o aumento do $|z|$. Incidimos sobre 


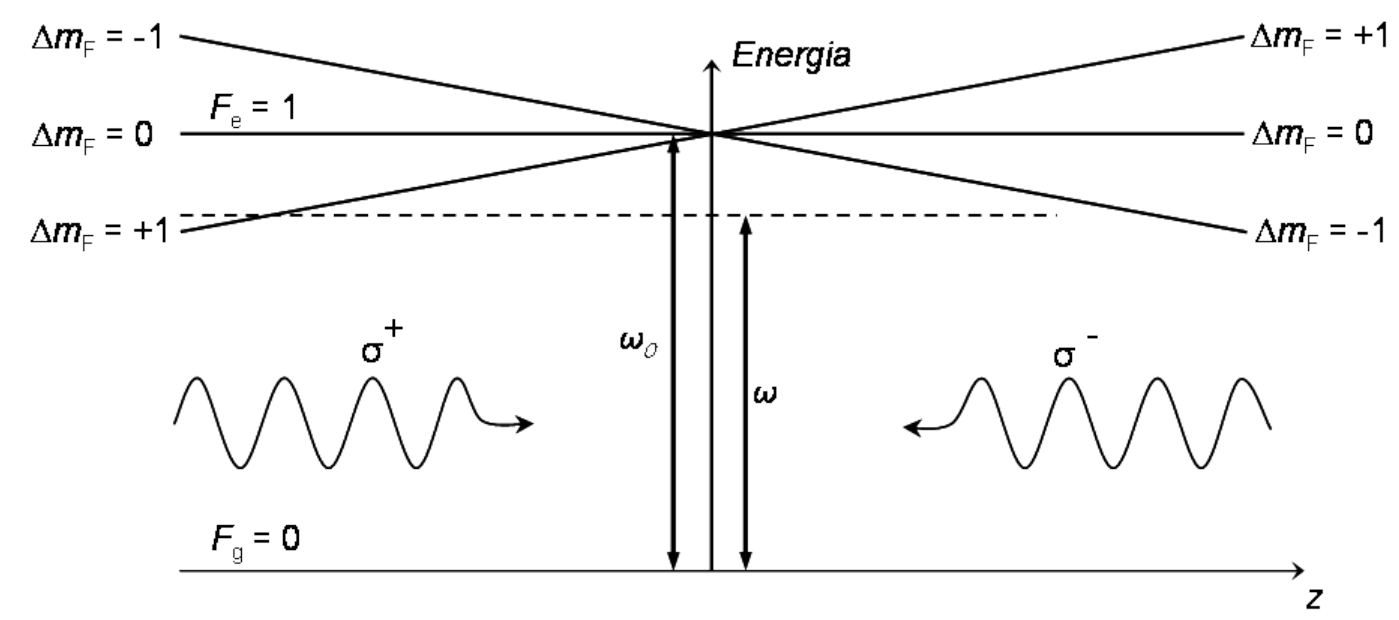

Figura 2.3: Aprisionamento, combinando campo magnético e feixes laser (retirado de [37].)

o átomo dois feixes contrapropagantes sintonizados abaixo da linha de transição atômica, cuja valor na ausência do campo magnético é igual à energia do nível $m_{F}=0$. O feixe da orientação $+\hat{z}$ possui polarização circular $\sigma^{+}$, e o do sentido contrário possui polarização circular $\sigma^{-}$. Os fótons do feixe $\sigma^{+}$possuem momento angular $+\hbar$ e promovem transição com $\Delta m_{F}=+1$ e os fótons do feixe $\sigma^{-}$possuem momento $-\hbar$ e promovem transição com $\Delta m_{F}=-1$. Se o átomo estiver na região $z>0$, a transição $\Delta m_{F}=-1$ através do feixe $\sigma^{-}$é a mais ressonante, e o resultado é uma pressão de radiação que empurra o átomo para o centro. Se estiver na região $z<0$, a transição $\Delta m_{F}=+1$ com espalhamento dos fótons do feixe $\sigma^{+}$é a preferencial e que também tende devolver o átomo para o origem. Portanto, com a soma dos efeitos, o átomo é efetivamente confinado na região ao redor do centro do campo magnético. 


\subsubsection{Campo magnético}

Na armadilha magneto-ótica, o campo magnético é criado por duas bobinas iguais na configuração anti-Helmholtz. As bobinas são coaxiais e formadas por espiras, em cada uma delas circula correntes com a mesma amplitude mas em sentidos opostos ${ }^{2}$. O esquema do conjunto dentro da armadilha magneto-ótica é mostrado na figura 2.4. O campo magnético no eixo da simetria $\hat{z}$ com a origem fixada entre as bobinas situadas em $\pm b$, que possuem raio $r$ e são formadas por $N$ espiras, pode ser obtido aplicando a lei de Biot e Savart [38], a equação é:

$$
B_{z}(z)=\frac{N \mu_{0} I r^{2}}{2\left[(z-b)^{2}+r^{2}\right]^{3 / 2}}-\frac{N \mu_{0} I r^{2}}{2\left[(z+b)^{2}+r^{2}\right]^{3 / 2}}
$$

onde $\mu_{0} \equiv 4 \pi \cdot 10^{-7} \mathrm{~N} / \mathrm{A}^{2}$ em unidade do sistema MKS.

A configuração anti-Helmholtz é utilizada pois o centro é o único ponto onde o campo é nulo e a partir deste ponto o campo cresce de forma aproximadamente linear em todas as direções até certa distância. Este arranjo é simples de construir e a geometria não atrapalha o acesso de feixes. Normalmente usa-se para a separação entre as bobinas a proporção $2 b / r=1,25$ pois nesta medida a profundidade do campo é igual nas direções radial (plano x-y) e longitudinal (eixo $\hat{z})[39,40]$. A simulação computacional do campo criado pelas bobinas nesta configuração é mostrada na figura 2.5. Devido ao tamanho específico da nossa câmara de vácuo, esta proporção não é usada na nossa armadilha (ver no Capítulo Experimental sobre as bobinas).

\footnotetext{
${ }^{2}$ A configuração Helmholtz é composta por duas bobinas iguais com correntes iguais circulando no mesmo sentido, o raio das bobinas é igual à separação entre elas. Nesta configuração o campo é bastante homogêneo perto do centro (na meia distância entre as bobinas).
} 


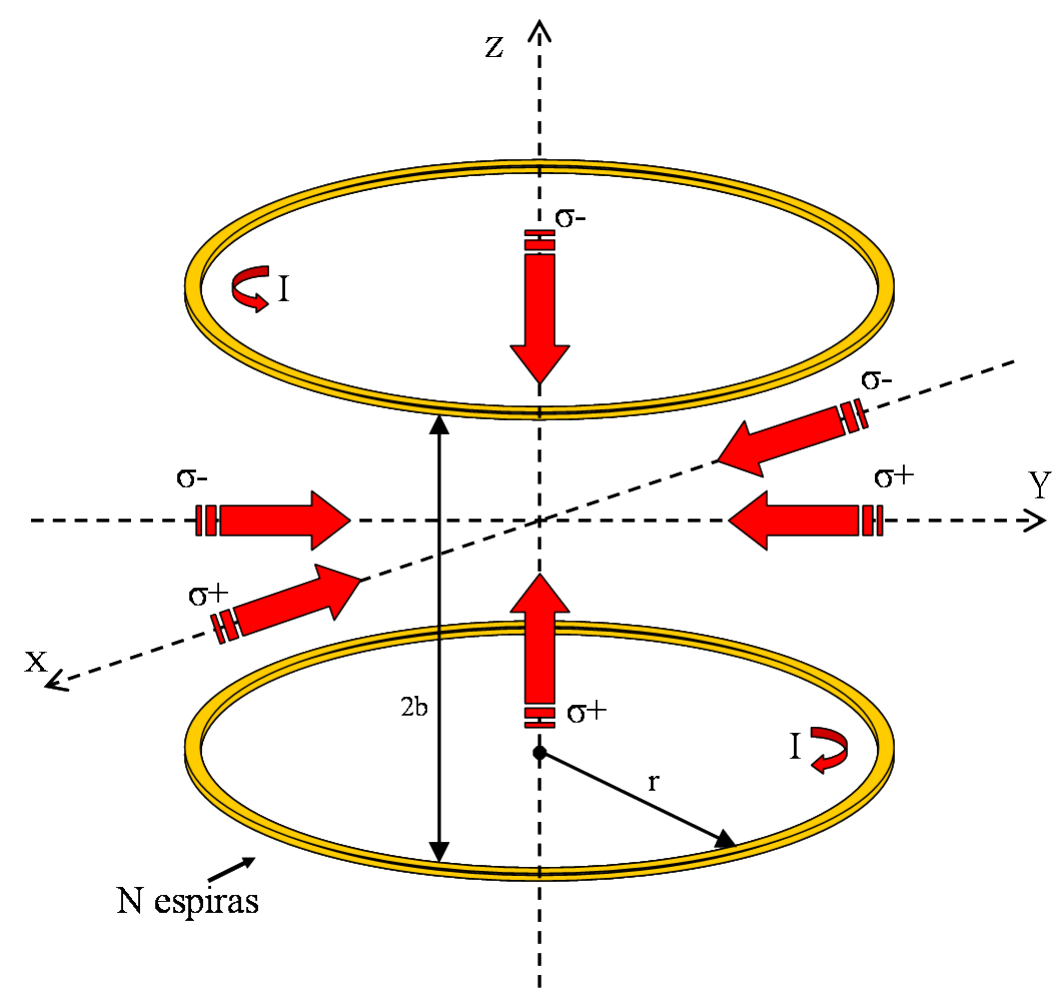

Figura 2.4: Esquema da armadilha magneto-ótica. Está mostrado as bobinas em configuração anti-Helmholtz e os feixes lasers.

Na primeira experiência de aprisionamento magnética de átomos neutros foram utilizadas bobinas na configuração anti-Helmholtz [39]. Os átomos de Na eram resfriados anteriormente com feixe laser para perderem energia e ser capturados pela armadilha. É importante notar que na MOT o campo magnético é bastante fraco [10] o que é diferente de uma armadilha puramente magnética. 


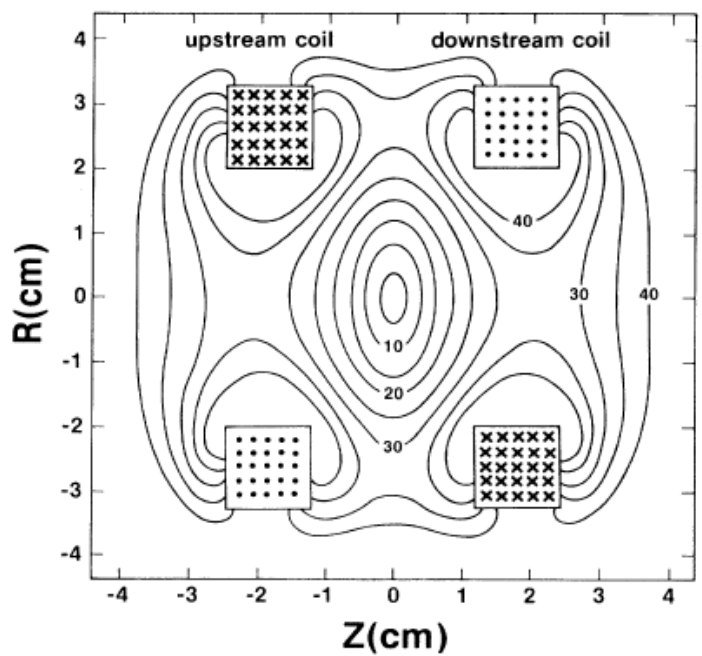

Figura 2.5: Curvas equipotenciais em unidade de militeslas (que possuem a mesma magnitude de campo) no plano que contem o eixo da simetria das bobinas. Figura retirada do artigo [39]. Nota que, no nosso caso, o eixo de simetria fica no plano horizontal e a proporção entre a distância entre as bobinas e o raio das bobinas é diferente de 1,25. 


\subsection{Resfriamento sub-Doppler}

Tendo átomos resfriados é importante saber a temperatura do sistema. Uma das técnicas mais utilizadas é a medida de temperatura por tempo de vôo (Time Of Flight - TOF). Nesta técnica, os átomos são primeiro capturados por uma MOT, depois são soltos desligando os feixes de laser. A nuvem de átomos expande balisticamente de acordo com a distribuição da velocidade atômica. Quando os átomos encontram-se com um feixe de prova localizado perto do melaço ótico, eles fluorescem, e a distribuição da fluorescência no tempo fornece a distribuição do tempo de vôo para os átomos chegarem até o feixe de prova. Com esse dado, a temperatura pode ser deduzida. Usando esta técnica, surpreendentemente o grupo de W. Phillips achou a temperatura de átomos de Na resfriados num melaço ótico igual a $40 \mu \mathrm{K}$ [12], muito mais frio que o limite Doppler teórico, que é $240 \mu \mathrm{K}$.

Vários grupos se dedicaram sobre o fenômeno e rapidamente descobriram que o modelo de átomo de dois níveis usado na teoria Doppler é simplificado demais e a natureza multinível dos átomos precisa ser considerada. E além disto, gradiente de polarização, bombeamento ótico e deslocamento de energia (light shift) atuam em conjunto desempenhando funções importantes nos mecanismos de resfriamento [13, 41, 42].

Há dois tipos de resfriamento sub-Doppler diferentes: um chama resfriamento Corkscrew que emprega feixes contrapropagantes com polarizações circulares opostas, denominado de configuração $\sigma^{+}-\sigma^{-}$e o outro chamado de resfriamento Sísifo usa feixes com polarizações lineares perpendiculares conhecido como configuração lin $\perp$ lin [43]. Os limites de resfriamento dos dois mecanismos são próximos. 


\subsubsection{Configuração $\sigma^{+}-\sigma^{-}$}

Na nossa MOT usamos a configuração $\sigma^{+}-\sigma^{-}$pois simplifica a montagem, os mesmos feixes para resfriamento são utilizados no aprisionamento. Nesta configuração, consideremos dois feixes contrapropagantes com polarizações circulares opostas, o feixe $\sigma^{+}$na direção $+\hat{z}$ e o feixe $\sigma^{-}$na direção $-\hat{z}$. As frequências e as amplitudes são iguais. Como no resfriamento Doppler, os feixes são sintonizados abaixo da frequência de transição, $\delta=\omega-\omega_{0}<0$. O vetor polarização total é linear com amplitude constante mas a orientação é rotacional no plano $x y$ sendo que ela descreve uma hélice no eixo $\hat{z}$ com periodicidade de $\lambda$.

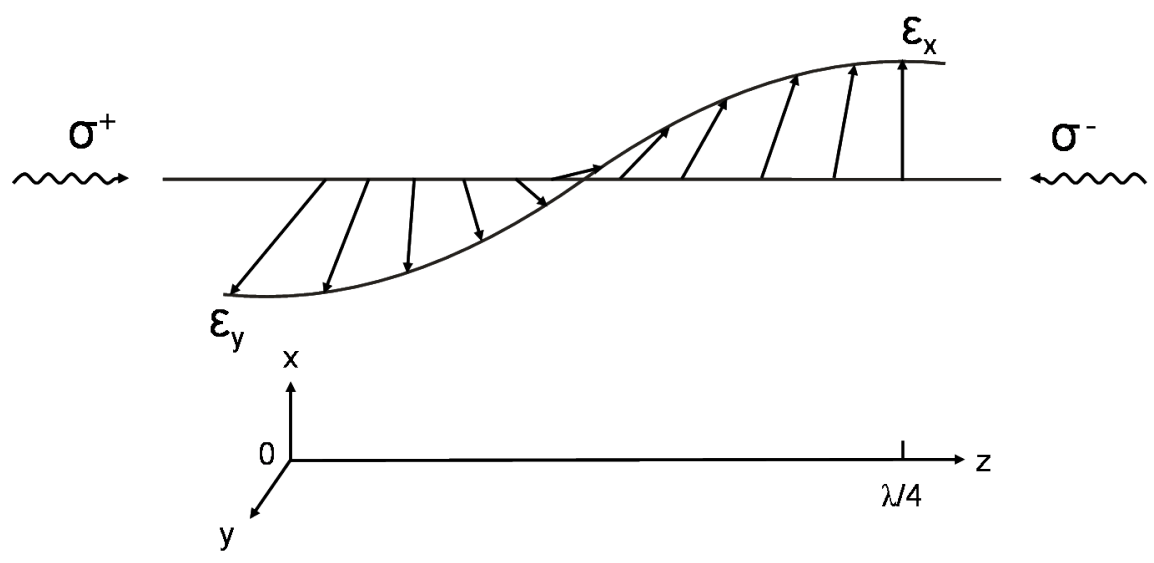

Figura 2.6: Polarização total da configuração $\sigma^{+}-\sigma^{-}$. A combinação dos dois feixes resulta numa polarização linear com amplitude constante mas a orientação é rotacional no eixo da propagação. A polarização gira uma volta inteira ao percorrer distância $\lambda$.

Devido ao gradiente da polarização total, num átomo, ao se mover no eixo $\hat{z}$, as populações dos subníveis do estado fundamental são alteradas pelo bombeamento ótico. Os subníveis mais populosos espalham mais fótons e assim os dois feixes são absorvidos diferentemente gerando uma força de fricção. 
Para ter uma diferença nas populações dos subníveis do estado fundamental é necessário que o momento angular total do estado fundamental seja maior que meio, $F_{g}>1 / 2$, porque os subníveis $g_{m}$ com valores de $|m|$ diferentes possuem light shift desiguais o que resulta em bombeamentos óticos com probabilidades desiguais. A situação mais simples que gera esta diferença de probabilidade é um sistema $F_{g}=1$ e $F_{e}=2$ com os subníveis $\left(g_{-1}, g_{0}, g_{+1}\right)$.

Suponha que o átomo esteja inicialmente em repouso na posição $z=0$ e que a polarização total no local tenha direção $\hat{y}$, os deslocamentos da energia gerados nos subníveis fundamentais $m_{y}= \pm 1$ e $m_{y}=0$ serão $\frac{3}{4} \Delta_{+1}=\frac{3}{4} \Delta_{-1}=\Delta_{0}$, e as populações no estado estacionário serão $\frac{4}{17}$, $\frac{4}{17}$ e $\frac{9}{17}$ respectivamente [13]. Lembrando que como os feixes são dessintonizados para vermelho $\Delta_{ \pm 1}$ e $\Delta_{0}$ são negativos.

O átomo ao se mover no eixo $\hat{z}$ com velocidade $v$ percebe a precessão da polarização com o ângulo $\varphi=-k z=-k v t$. Esta precessão gera um termo adicional no Hamiltoniano do sistema, $V_{\text {rot }}=k v F_{z}$.

Quando a velocidade atômica é baixa o suficiente, as populações dos subníveis do estado fundamental são variadas. O termo $V_{\text {rot }}$ cria diferença entre as populações do $g_{+1}$ e $g_{-1}$. Se o átomo está se movendo no sentido $+z$, contra o feixe $\sigma^{+}$, a população do subnível $g_{-1}$ é maior que do $g_{+1}$, e portanto espalhará mais fótons contrários ao seu movimento e é freado.

O resfriamento Doppler também depende do espalhamento de fótons opostos ao movimento atômico, a diferença é que no resfriamento Doppler o desbalanceamento entre os espalhamentos dos feixes opostos é induzido pela velocidade atômica que gera deslocamento Doppler, e no resfriamento Corkscrew a probabilidade de espalhamento é a mesma mas as populações do estado fundamental são diferentes. 


\subsubsection{Resfriamento Sísifo}

O resfriamento Sísifo é gerado na configuração lin $\perp$ lin de feixes.

Os átomos alcalinos como rubídio e sódio possuem sub-níveis de Zeeman no estado fundamental $g$. O bombeamento ótico pode transferir átomos de um sub-nível $g_{m}$ para um outro $g_{m \prime}$ através de ciclos de absorção e emissão espontânea. Cada ciclo leva um tempo de bombeio $T_{p}$ para ser completado. O resultado do bombeamento ótico é uma distribuição de população entre os vários sub-níveis $g_{m}$. Esta distribuição depende da polarização do laser.

O light shift é causado pelo acoplamento campo-átomo. Esta interação faz com que os dois estados vestidos repelirem um ao outro aumentando a separação entre eles. Light shift também depende da polarização da luz.

Outro ingrediente importante do resfriamento Sísifo é a existência de gradientes de polarização, que é inevitável em melaços tridimensionais. Por causa da interferência entre os feixes do laser, a polarização da luz varia rapidamente no intervalo de uma unidade de comprimento de onda. Portanto, a distribuição da população entre os vários sub-níveis $g_{m}$ e o light shift de cada sub-nível depende da posição do átomo na luz.

Considere um exemplo específico de um melaço ótico unidimensional. O esquema consiste em dois feixes contrapropagantes com polarizações lineares ortogonais e com a mesma freqüência e intensidade. Devido a interferência, a polarização total do campo varia de $\sigma^{+}$para $\sigma^{-}$e vice versa a cada intervalo de $\lambda / 4$. Considere agora um caso simples no qual o momento angular do estado fundamental é igual a $1 / 2$. Os dois sub-níveis $g_{+1 / 2}$ e $g_{-1 / 2}$ sofrem light shifts diferentes dependendo da polarização do laser, então a degenerescência é removida sem a presença de campo magnético. Isto produz uma modulação espacial nas energias dos dois sub-níveis com 
período igual $\lambda / 2$. Neste exemplo, as taxas do bombeamento ótico também são moduladas espacialmente pelo gradiente de polarização com período igual $\lambda / 2$. A direção da transferência entre os dois sub-níveis é de $g_{-1 / 2} \rightarrow g_{1 / 2}$ se a polarização for $\sigma^{+}$, e no sentido contrário se for $\sigma^{-}$. Podemos perceber claramente que há uma correlação entre as duas modulações. O bombeamento ótico sempre transfere átomos de um sub-nível mais alto para um mais baixo. Suponha que o átomo se move para o lado direito, começando pelo estado $g_{1 / 2}$ na posição onde a polarização é $\sigma^{+}$. Por causa do tempo de bombeio $T_{p}$, um átomo tem chances de subir a rampa do potencial antes de absorver um fóton e chegar até o topo do potencial, onde a probabilidade de ser bombeado opticamente para $g_{-1 / 2}$ é máxima. Se o átomo é transferido para $g_{-1 / 2}$, ele subirá novamente a rampa de potencial, e o processo se repetirá. Por causa do intervalo $T_{p}$, o átomo, sempre está escalando rampas de potencial, transformando parte da energia cinética em energia potencial. Assim a dissipação da energia ocorre porque o fóton emitido espontaneamente possui uma energia maior que o fóton absorvido. Esta situação lembra o Sísifo da mitologia Grega, condenado a empurrar eternamente uma rocha grande acima de uma montanha, e sempre que chegue no cume, a rocha rola morro abaixo.

\subsection{A estrutura hiperfina do átomo de rubídio}

É mais comum encontrar na literatura pesquisas com ${ }^{87} \mathrm{Rb}$ pois este é bóson e é possível de formar condensado de Bose-Einstein. Mas como não temos planos de estudar condensados a curto prazo, no nosso projeto atual trabalharemos com ${ }^{85} \mathrm{Rb}$. A vantagem de pesquisar com o isótopo ${ }^{85} \mathrm{Rb}$ é que ele é naturalmente mais abundante $(72 \%)$, os sinais de resposta com a luz são mais intensos e portanto é mais fácil de se trabalhar. Se quisermos futuramente trabalhar 


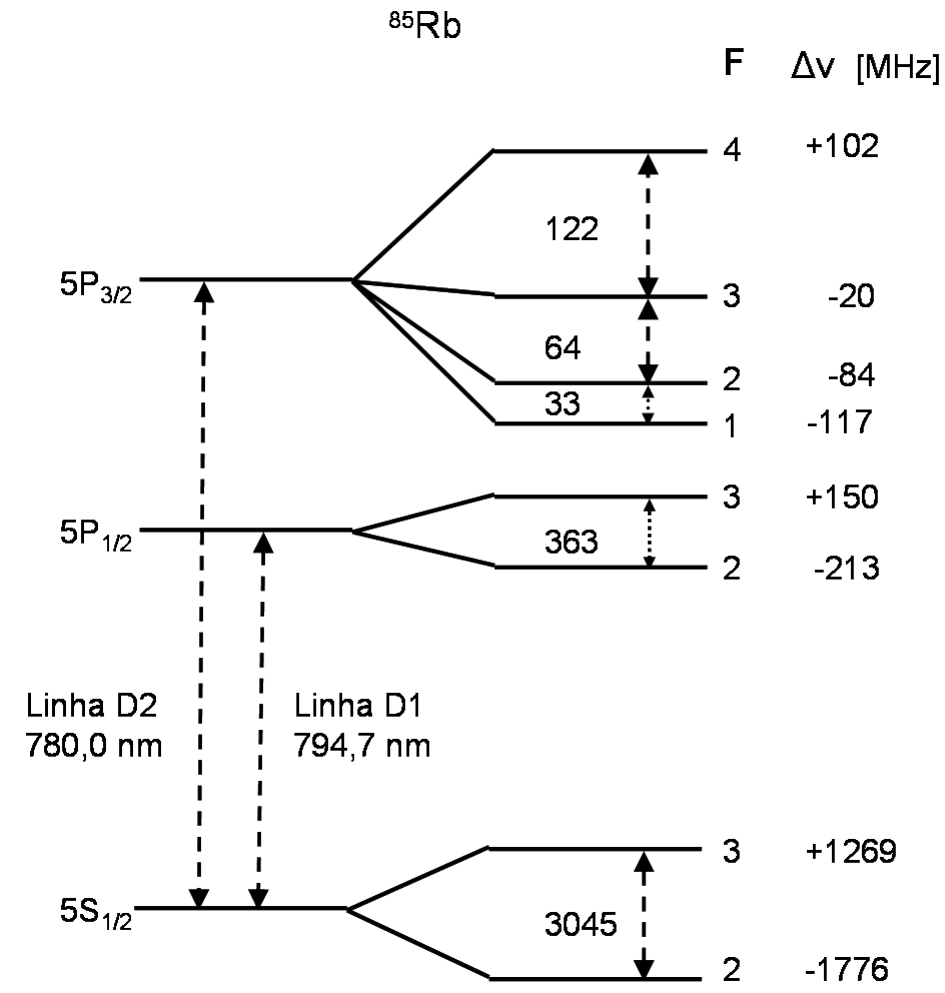

Figura 2.7: As energias dos níveis hiperfinos da linha $\mathrm{D}_{2}$ e $\mathrm{D}_{1}$ do Rubídio 85 (fora de escala).

com o rubídio 87 basicamente só precisamos alterar os parâmetros de frequência dos lasers.

São mostrados os níveis hiperfinos do rubídio 85 no diagrama 2.7. Trabalhamos com a transição $5 \mathrm{~S}_{1 / 2} \rightarrow 5 \mathrm{P}_{3 / 2}$, conhecido como a linha $\mathrm{D}_{2}$. Na nossa experiência três lasers, chamados de aprisionamento, são sintonizados na frequência da transição $F_{g}=3 \rightarrow F_{e}=4$ e são responsáveis pelo resfriamento e aprisionamento dos átomos. Além deste precisamos de um outro laser chamado de rebombeio sintonizado na transição $F_{g}=2 \rightarrow F_{e}=3$ da linha $\mathrm{D}_{2}$. O rebombeio é muito importante pois sem ele a nuvem perderia os átomos muito rapidamente. A razão disto é que, pela regra da seleção, apenas transições com $F_{e}-F_{g}=\{-1,0,1\}$ são permitidas, como os níveis $F_{e}=4$ e $F_{e}=3$ são muito próximos, com diferença de apenas $120 \mathrm{MHz}$, 
um átomo ao ser excitado pelo laser de aprisionamento pode eventualmente pular para o nível $F_{e}=3$ (ao invés do $F_{e}=4$ ) e de lá decair eventualmente para o estado fundamental $F_{g}=2$. Como este nível é muito distante dos outros níveis, o laser de aprisionamento não conseguirá excitar novamente este átomo. O laser de rebombeio é sintonizado de tal modo que bombeia átomos deste nível para o $F_{e}=3$ e de lá o átomo poderá decair de volta para $F_{g}=3$ e entrar em ressonância com o laser de aprisionamento. 


\section{Capítulo 3}

\section{Experimento}

No capítulo anterior apresentamos os fundamentos teóricos da armadilha magneto-ótica. Neste capítulo explicaremos os arranjos experimentais da armadilha que construímos durante o mestrado, detalhando os desafios técnicos que foram vencidos nesta montagem. Começaremos pela descrição do sistema de vácuo onde se garante que a câmara está preenchida basicamente por um vapor de fundo de átomos de rubídio.

\subsection{Câmara de vácuo}

Para obter uma amostra de átomos frios estável por um período longo, que permita a realização de experiências, é necessário diminuir drasticamente a quantidade de colisões dos átomos externos com os átomos aprisionados na nuvem. Um ambiente de alto vácuo é requerido para este fim. Montamos uma câmara de vácuo, incluindo o sistema de bomba de vácuo e um gauge de ionização. 


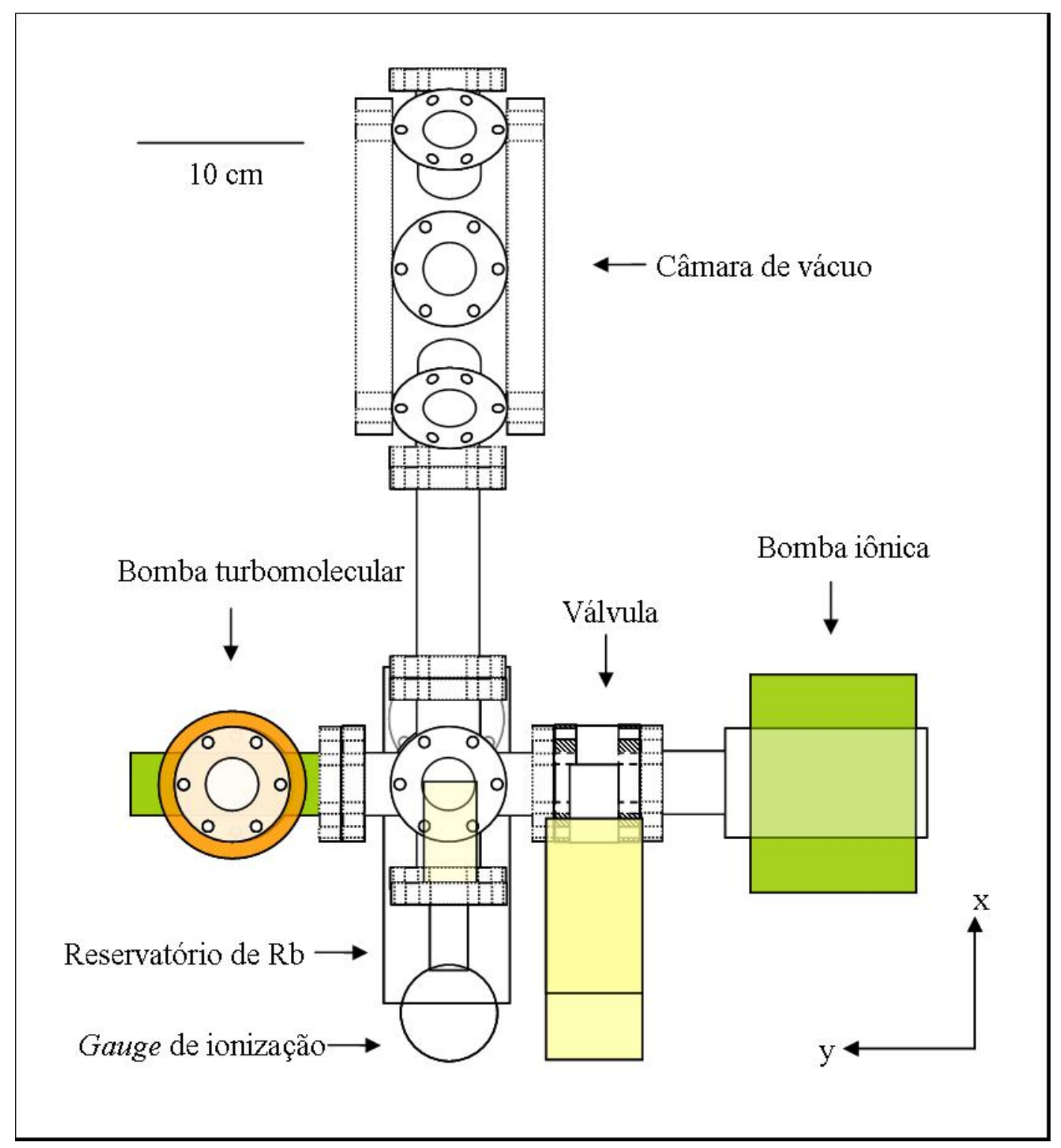

Figura 3.1: Conjunto da câmara de vácuo. Vista de cima. 
O tubo do gauge de ionização é fabricado pela empresa Varian, modelo 572, do tipo BayardAlpert. Um filamento de resistência ioniza o gás de fundo dentro da câmara de vácuo, e a pressão é medida indiretamente através da corrente iônica circulando entre os eletrodos mantido sem alta tensão. Esta corrente é muito fraca e o seu valor precisa ser calibrado de acordo com o tipo de gás. O limite de resolução é dados pelos os elétrons ionizados, que geram raios-X ao colidir com os componentes internos do medidor e produzir uma emissão fotoelétrica no coletor de íons. Isto estabelece um limite mínimo da pressão que é possível medir, conhecido como limite de raios-X, que é $2 \cdot 10^{-10}$ mbar para o nosso modelo [44].

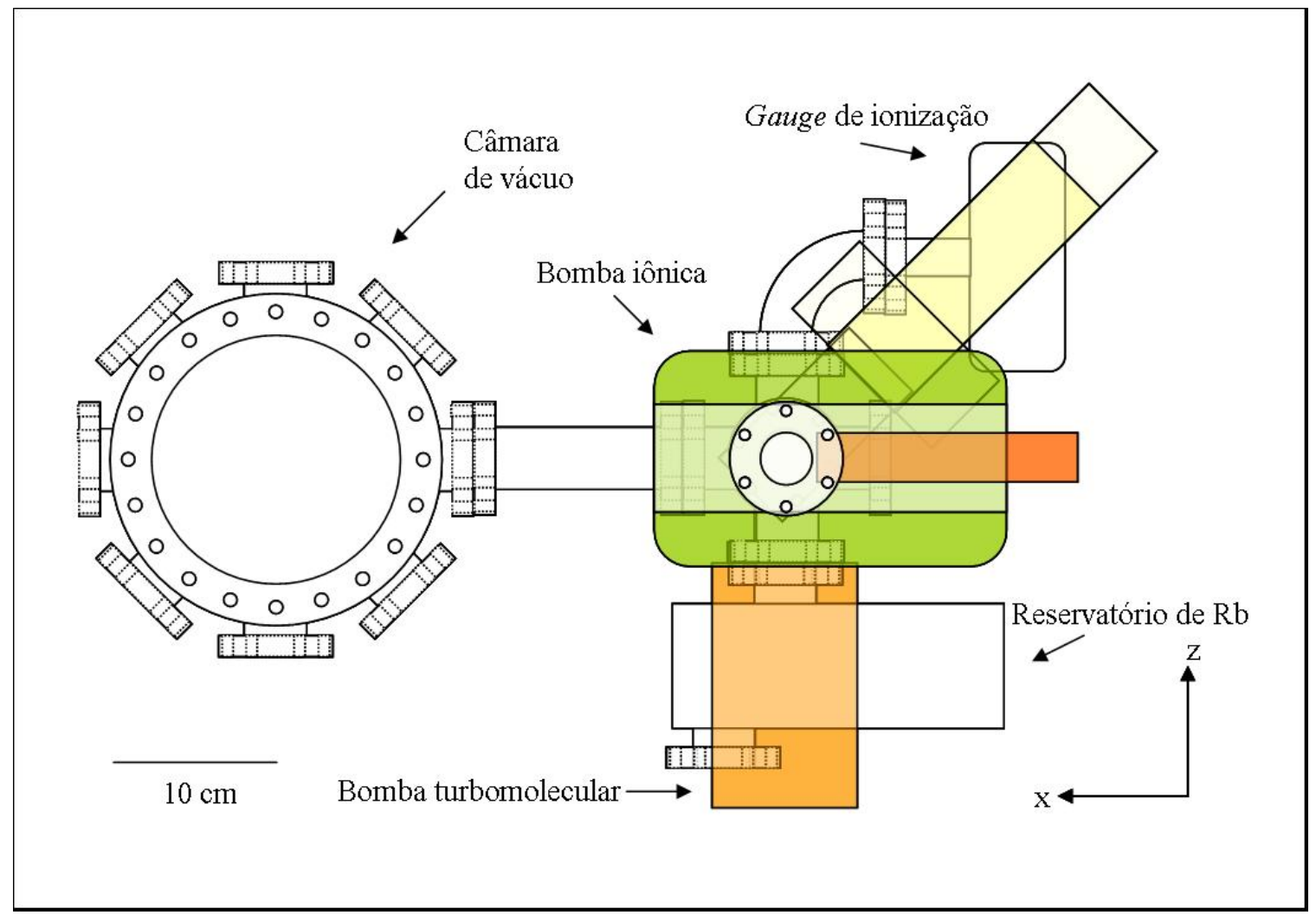

Figura 3.2: Conjunto da câmara de vácuo. Vista lateral. 
A estrutura metálica da câmara e os parafusos utilizados são todos de aço inoxidável para minimizar a geração de campo magnético permanente espúrio, o que poderia interferir na formação da nuvem atômica. As janelas de observação são fabricadas pela empresa $B O C$ Edwards. São oito janelas pequenas $(\varnothing=4 \mathrm{~cm})$ e duas janelas grandes $(\varnothing=14 \mathrm{~cm})$ (vide figuras $3.1,3.2 \mathrm{e}$ 3.3), todas possuem coating anti-refletor (AR) produzidos pela Oficina de Ótica do Instituto de Física de São Carlos da Universidade de São Paulo (IFSC-USP).

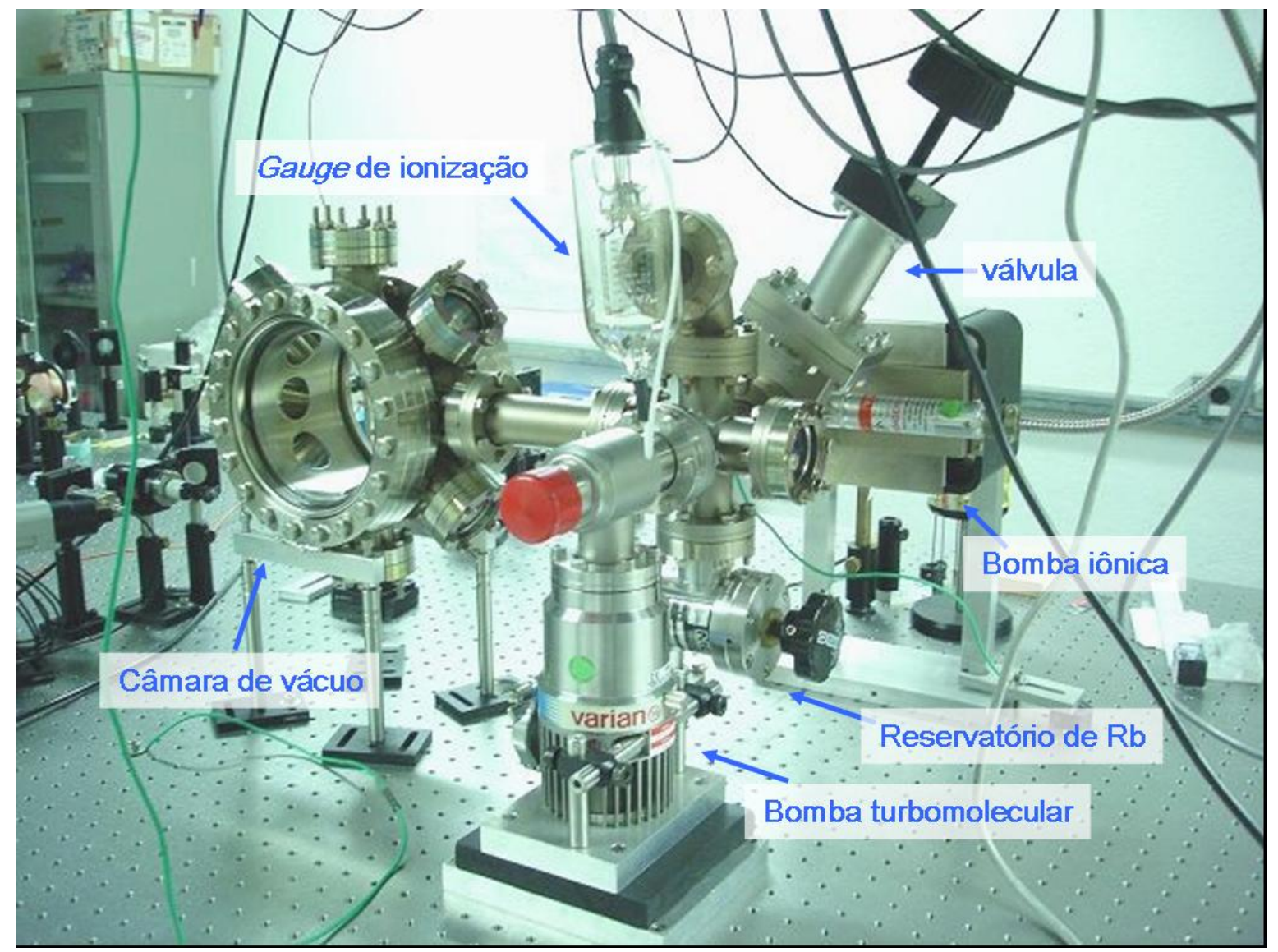

Figura 3.3: Foto do conjunto da câmara de vácuo.

Para determinar a qualidade do coating anti-refletor fizemos medidas de transmitância e refletância da janela principal. Assim, fixamos a janela verticalmente numa base giratória 
e fizemos medidas variando o ângulo de incidência do feixe com relação ao eixo normal da janela. Fizemos medidas, separadamente, com feixe laser linearmente polarizado na vertical e no horizontal. Incidimos o feixe laser com a potência conhecida no centro da janela e medimos as potências do feixe transmitido e do feixe refletido ${ }^{1}$. Repetimos o procedimento para vários ângulos, e ao final os dados foram normalizados e apresentados nos gráficos 3.4 e 3.5. Os resultados demonstram que há pouca perda de potência de feixe para um ângulo de incidência de até $40^{\circ}$ em relação à normal e, neste intervalo, a diferença entre as reflexões para as polarizações horizontal e vertical é menor que $2 \%$. Podemos concluir que o coating possui uma boa qualidade e é adequado para a armadilha, bem como para as aplicações de redes óticas e as investigações de manipulação coerente de estados luminosos empregando a transparência induzida nos átomos $[45,46,47]$.

Durante a montagem, tomamos diversos cuidados para obter um vácuo de alta qualidade (baixa pressão de fundo). As peças foram lavadas rigorosamente, primeiro com sabão neutro e em seguida com acetona. Depois foram enxaguadas com água destilada e secas numa estufa. Sempre utilizamos luvas cirúrgicas para manuseio das peças limpas. As flanges das conexões dos componentes são do tipo ConFlat, que utilizam um anel achatado de cobre (O-ring) para selar a conexão. O anel de cobre é prensado entre as facas das flanges, e estas por sua vez são fechadas com parafusos. Este tipo de ligação sustenta vácuo de até $10^{-13}$ mbar e pode ser aquecida até $450^{\circ} \mathrm{C}$. Apertamos os parafusos lentamente e sempre em pares diametralmente opostos para que a pressão se distribua uniformemente sobre o anel evitando possíveis vazamentos.

O reservatório de rubídio, que está conectado com a câmara de vácuo, permaneceu fechado

\footnotetext{
${ }^{1}$ Lembrando que há dois feixes refletidos, um por cada face da janela, e a potência medida é a soma das duas.
} 


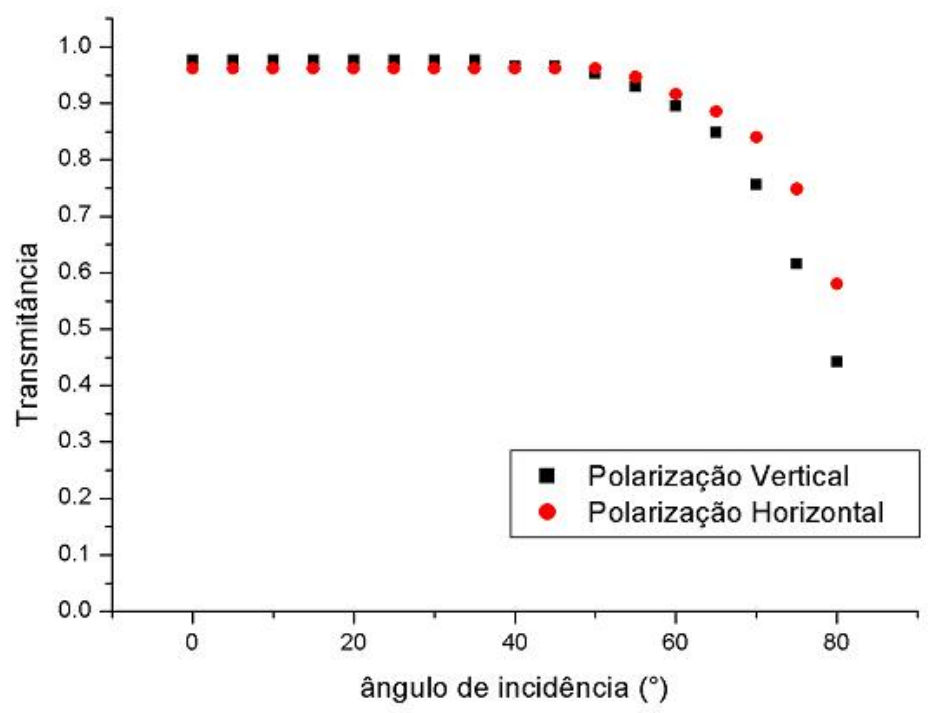

Figura 3.4: Transmitância da janela principal.

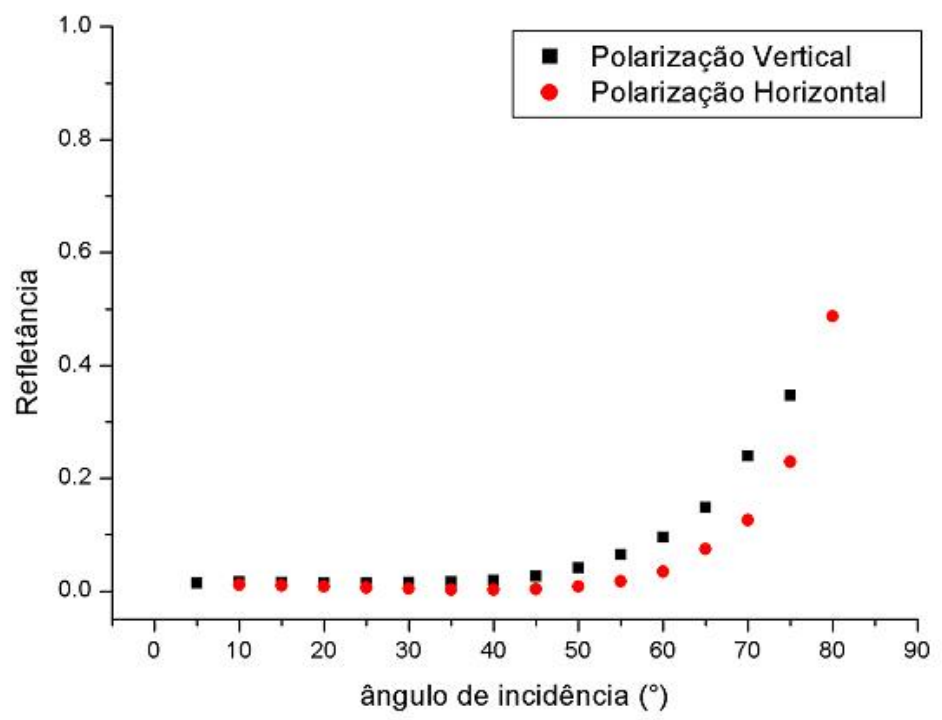

Figura 3.5: Refletância da janela principal. 
através de uma válvula durante o tempo todo. Dentro do reservatório há uma ampola contendo rubídio. Este material já foi utilizado numa montagem de armadilha magneto-ótica antiga do nosso laboratório, por isto a ampola já tinha sido quebrada para liberar os átomos. A quantidade de $\mathrm{Rb}$ é inferior a $1 \mathrm{~g}$, mas é suficiente para realizar experiências, como pode ser verificado posteriormente. É necessário deixar a válvula fechada pois o rubídio é altamente reativo, entrando em combustão no ar espontaneamente. Além disso, como a pressão de vapor de $\mathrm{Rb}$ é muito baixa, perderíamos material ao fazer vácuo na câmara. Só abrimos a válvula quando atingimos uma pressão muito baixa.

Feito a montagem da câmara começamos fazer o vácuo. Foram utilizadas três bombas de vácuo fabricadas pela Varian: a mecânica, a turbomolecular e a iônica.

A bomba mecânica (modelo Varian SD 40) retira uma grande quantidade de ar. Sua função é criar o pré-vácuo para permitir o funcionamento da bomba turbomolecular, por isso é ligada na saída de ar da bomba turbo que, por sua vez, é conectada diretamente na câmara de vácuo. A taxa de sucção é de aproximadamente dois metros cúbicos de ar por minuto [48]. A pressão final é da ordem de $10^{-3}$ mbar. Esta bomba mecânica é do tipo bomba de paleta rotatória com dois estágios. Basicamente, um rotor gira dentro de uma câmara cilíndrica e através de um par de paletas móveis o ar do recipiente é retirado, transferido, comprimido e finalmente expelido. É utilizado um óleo especial para garantir a lubrificação interna, manter as peças móveis ajustadas e retirar o calor produzido. Como gotículas deste óleo são expelidos juntamente com o ar, o que poderiam sujar as peças óticas, tomamos o cuidado de filtrar a saída de ar com um filtro de carvão ativo.

Depois de atingir a pressão mínima da bomba mecânica acionamos a bomba turbomolecular, 
série Turbo-V 70, modelo 969-9360. Esta bomba é utilizada para criar alto e ultra-alto vácuo. Em condições ideais a pressão mínima chega a $10^{-9}$ mbar [49]. O efeito de bombeamento é obtido através de uma turbina rotativa (com velocidade máxima de $75000 \mathrm{rpm}$ ) movida por um motor elétrico de alto rendimento. A velocidade de bombeamento é $45 \mathrm{l} / \mathrm{s}$ para $N_{2}$.

Com o objetivo de obter uma pressão final muito baixa, enquanto a bomba turbo começou operar, fizemos ao mesmo tempo o aquecimento da câmara (baking). Este processo consiste em aquecer o conjunto do sistema de vácuo para liberar as partículas aderidas (adsorvidas) nas paredes internas da câmara e também para aumentar a velocidades dos átomos acelerando o processo de bombeamento. Para aquecer todo o conjunto usamos quatro fitas térmicas controladas por um autotransformador ajustável (variac), que fornece a tensão conforme o nosso controle. Além disso cobrimos todo o conjunto com papel alumínio por fora para distribuir melhor o calor (foto 3.6), incluindo a bomba iônica, da qual retiramos os magnetos para tornar o aquecimento mais eficiente. Elevamos a temperatura lentamente, pois como as conexões da câmara contêm vários tipos de materiais que possuem índice de dilatação diferentes, uma variação abrupta poderia causar (micro)deformações nas ligações da câmara e criaria vazamentos. A câmara (que é feita de aço inoxidável e vidro especial) e a bomba iônica suportam temperaturas altas, mantivemo-as aquecidas em torno de $250^{\circ} \mathrm{C}$. As válvulas da bomba iônica e do reservatório de Rb contêm materiais mais delicados (por exemplo borracha ou Viton) por isto não deixamos as temperaturas passarem de $120^{\circ} \mathrm{C}$ e $70^{\circ} \mathrm{C}$ respectivamente, conforme especificado nos manuais. Monitoramos a pressão interna da câmara com o gauge de ionização. Mantivemos o aquecimento por mais de uma semana, a bomba turbo e a bomba mecânica estiveram em funcionamento ininterrupto nesta etapa. A pressão interna deveria chegar em $10^{-8}$ mbar, no 
entanto, nossas medidas mostraram que a pressão não abaixou aquém de $10^{-6}$ mbar. Suspeitamos de um possível vazamento no conjunto. Desligamos o aquecimento e fizemos um teste pingando acetona em todas as junções do sistema. Como a acetona evapora rapidamente, se houver algum ponto mal selado a pressão interna subiria de imediato. No final detectamos que havia um pequeno vazamento no conector de corrente elétrica da bomba iônica. Este conector tem uma junção metal-cerâmica, a ligação se deteriorou com o tempo e surgiram micro-fissuras. Consertamos o problema usando um líquido selante da Kurt J. Lesker Company. Voltamos ao aquecimento e desta vez a pressão chegou a $7 \cdot 10^{-8}$ mbar (sem o uso de bomba iônica).

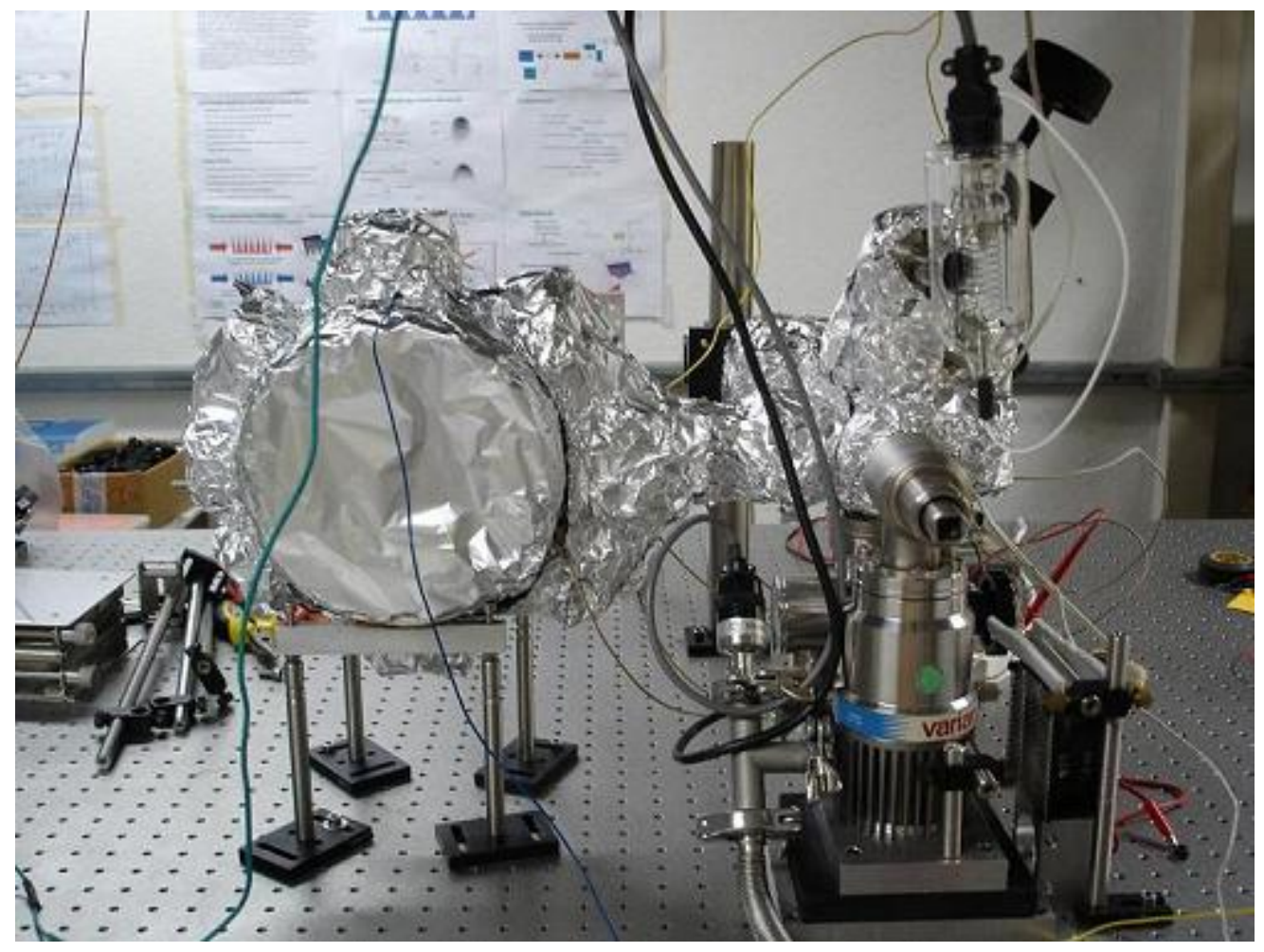

Figura 3.6: A câmara de vácuo durante o processo de baking.

Tendo a certeza de que a câmara está toda selada, o sistema de vácuo funcionando bem e a 
pressão interna estando muito baixa, abrimos e fechamos rapidamente a válvula do reservatório de $\mathrm{Rb}$ para igualar a pressão lá dentro. Pois como ainda não tínhamos aberto a válvula, a pressão dentro do reservatório era várias ordens de grandeza maior que o resto da câmara. Verificamos isto ao notar que, ao abrir a válvula, a pressão medida saltou de $10^{-8}$ mbar para $10^{-2}$ mbar. Mas logo a pressão abaixou e voltou ao valor antigo. Depois de alguns segundos o reservatório foi fechado novamente para preservar o rubídio durante o processo da criação do vácuo.

Com esta condição, interrompemos o aquecimento da bomba iônica e ligamo-la, mantendo o aquecimento do resto do conjunto. A bomba iônica é de diodo, série VacIon Plus 25 modelo 911-5036. A velocidade nominal de bombeamento para $N_{2}$ é $24 \mathrm{l} / \mathrm{s}$. A pressão inicial máxima recomendada para o funcionamento é $1 \cdot 10^{-3}$ mbar, mas usamos uma pressão inicial bem mais baixa para evitar a saturação da capacidade de absorção da bomba. O limite de pressão mínima que a bomba consegue atingir em condições ideais é $10^{-11}$ mbar. Utilizando uma fonte de alta tensão, a bomba ioniza os gases residuais para que estes possam ser absorvidos pelo material especial dentro da bomba. A bomba iônica contem ímãs que criam um campo magnético muito forte e que poderia causar interferência no aprisionamento de átomos. Para minimizar isto isolamos a bomba com uma placa de blindagem magnética.

Também fizemos a desgaseificação dos filamentos do gauge de ionização. O controlador do aparelho automaticamente aquece os filamentos por mais de uma hora para liberar as sujeiras aderidas no filamento. Isto garante maior precisão das medidas.

Depois de dois dias de aquecimento desligamos todas as fitas térmicas e selamos a válvula da bomba turbomolecular. No final, apenas com a bomba iônica funcionando, a pressão atingiu 
$7 \cdot 10^{-9}$ mbar, medida pelo gauge de ionização e também pela corrente consumida pela bomba iônica. A bomba iônica funciona ininterruptamente para retirar constantemente a quantidade ínfima de sujeiras restantes e os gases que eventualmente penetram para dentro da câmara (principalmente gás hidrogênio e hélio).

Com a câmara de vácuo pronta, abrimos a válvula do reservatório de rubídio para liberar os átomos. No começo a pressão mudava muito pouco, então fechamos a válvula da bomba iônica, permitindo a pressão subir para $4 \cdot 10^{-7}$ mbar. Depois de horas de espera ainda não conseguíamos observar fluorescência na câmara. Como o reservatório é localizado a cerca de $50 \mathrm{~cm}$ do centro da câmara, os átomos levam bastante tempo para migrarem até lá. Isto deve-se à adsorção pelas paredes da câmara (metal e vidro). Como as paredes internas da tubulação e da câmara acabaram de passar por baking, as superfícies são muito limpas e ao entrarem em contato com os átomos de rubídio, as paredes adsorvem-nos de tal forma que a quantidade de átomos na armadilha só aumentará significativamente quando este processo atingir o equilíbrio. Para agilizar o processo aquecemos o conjunto. Os átomos de rubídio ganharam mais energia cinética com isso, e a pressão de vapor aumentou, o que contribuiu para que mais átomos sejam adsorvidos pelas paredes da câmara. Aquecemos o reservatório até $70^{\circ} \mathrm{C}$ e a tubulação até $100^{\circ} \mathrm{C}$ durante cerca de 3 horas. Embora a fluorescência ficasse mais forte, ela praticamente desapareceu assim que desligamos o aquecimento. Então aquecemos o reservatório por mais algumas vezes e deixamos a válvula aberta durante vários dias. No final conseguimos observar uma fluorescência fraca e estável (sem aquecimento) e com a pressão menor que $1 \cdot 10^{-8}$ mbar. Este valor é determinado pela corrente da bomba iônica, não conseguimos medir com precisão melhor que esta ordem pois durante o processo de saturação das paredes da câmara houve o acúmulo 
de um pouco de rubídio dentro da câmara do gauge de ionização. Ao ligar o medidor, o aquecimento do filamento de tungstênio libera os átomos e, conseqüentemente, aumenta a pressão, impossibilitando uma medida mais precisa. Mesmo fazendo uma desgaseificação automática do equipamento a medida não melhora muito. De qualquer forma, a bomba iônica mostra que conseguimos obter uma pressão interna da câmara muito baixa, menor que $1 \cdot 10^{-8}$ mbar, possibilitando o funcionamento da armadilha.

Tendo conseguido o controle do vácuo da câmara, nos dedicamos aos lasers empregados no aprisionamento dos átomos na armadilha.

\section{$3.2 \quad$ Lasers}

Para realizar as experiências, precisamos de lasers estáveis e fáceis de sintonizar na freqüência de transição. Além disso, os lasers precisam ter largura de banda fina o suficiente para distinguir as linhas hiperfinas do rubídio.

Construímos quatro lasers de diodo. Utilizamos diodos fornecidos pelas empresas Thorlabs e Toptica, modelo Sanyo DL7140-201S, com o comprimento de onda especificado para $785 \mathrm{~nm}$, mas pedimos dois lotes selecionados com o comprimento de onda de aproximadamente $780 \mathrm{~nm}$, que é a linha de transição D2 do ${ }^{85} \mathrm{Rb}$, a qual usaremos para resfriamento e aprisionamento ${ }^{2}$. Os modos de emissão de diodo são muito sensíveis a temperatura, e uma mudança de $1^{\circ} \mathrm{C}$ pode causar uma grande variação no comprimento de onda, portanto é muito importante garantir a estabilidade da temperatura. Usamos pastilhas termoelétricas (peltier) da marca Danvic para manter a temperatura fixa. A pastilha é um sanduíche de placas cerâmicas recheadas com uma

\footnotetext{
${ }^{2}$ As especificações do diodo estão incluídos no apêndice A na página 102.
} 
série de elementos semicondutores do tipo-p e tipo-n agrupados em pares (normalmente $\mathrm{Bi}_{2} \mathrm{Te}_{3}$, telureto de bismuto). Ao passar uma corrente através das junções metálicas da pastilha, uma diferença de temperatura é criada nas duas faces, e o calor é transferido de um lado para o outro (figura 3.7). A transferência do calor é proporcional à corrente, e este fenômeno é chamado de efeito Peltier [51, 52].

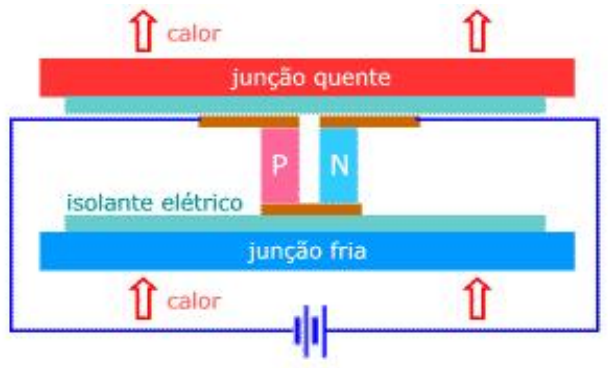

Figura 3.7: Detalhe do funcionamento da pastilha térmica.

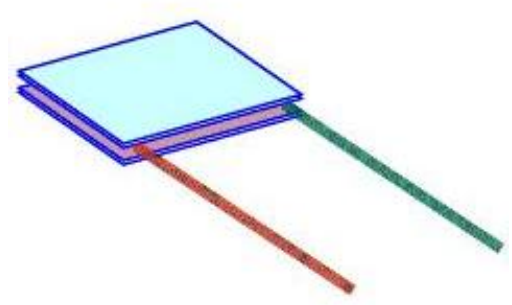

Figura 3.8: Um peltier típico.

Usando uma resistência sensível à temperatura (termistor) para medir a temperatura do diodo e emitir o sinal de retroalimentação para o circuito fornecedor de corrente, podemos controlar a temperatura do laser. A pastilha termoelétrica é fixada entre o suporte do diodo e a base do laser, e o conjunto todo é parafusado diretamente na mesa ótica. O suporte do diodo é feito de cobre, portanto com boa condução térmica, e a base em alumínio, funcionado como 
um reservatório à temperatura ambiente para o peltier

A colimação dos feixes dos diodos é feita através de um tubo colimador da Thorlabs, modelo LT230P-B ${ }^{3}$, com objetiva de $f=4,5 \mathrm{~mm}$. O resultado dos ajustes é muito satisfatório, os feixes são bem colimados até pelo menos 3 metros de distância. Visualmente os spots são bastante uniformes em intensidade e com perfil elíptico sendo que a razão de elipse de aproximadamente $3: 1$. A execução das peças de suporte do laser ficaram a cargo da oficina do nosso Instituto. Montamos quatro lasers livres (sem cavidade externa) e dois lasers com cavidade externa (lasers mestres $)^{4}$.

Testamos os lasers sem a cavidade externa e, para nossa surpresa, conseguimos observar o espectro da absorção saturada com boa resolução. Por batimento de freqüência entre dois laseres e verificamos que o diodo tem a largura de linha inferior a $10 \mathrm{MHz}$, limitado pelo sistema de detecção. Juntamente com a resolução obtida para as linhas de absorção saturada do rubídio (de $6 \mathrm{MHz}$ ), tivemos a garantia de que podemos usar estes lasers sem a cavidade externa para fazer aprisionamento e resfriamento. Assim a montagem do arranjo ficou mais simples e os lasers com a cavidade externa podem ser empregados nas experiências de redes óticas e de transparência induzida eletromagnéticamente (EIT - Electromagnetically Induced Transparency).

Temos dois métodos para sintonizar os lasers sem cavidade externa. O ajuste grosso é feito com a temperatura, e o ajuste fino com a corrente aplicada no diodo. Os lasers apresentam poucos saltos de modos ${ }^{5}$, possuem modos contínuos bem amplos, onde o comprimento de onda

\footnotetext{
${ }^{3}$ Especificações no apêndice A.

${ }^{4}$ O laser com cavidade externa é descrito no apêndice B na página 106.

${ }^{5}$ Comparado com os nossos antigos lasers de diodo da $S D L$ que foram utilizados na antiga armadilha do nosso
} 
pode ser variado pela corrente por dezenas de nanômetros sem aparecimento de saltos. Fizemos muitos testes para achar a temperatura ideal de funcionamento de cada laser. Variamos discretamente a temperatura entre $20^{\circ} \mathrm{C}$ a $35^{\circ} \mathrm{C}$. Para cada temperatura, esperamos a estabilização para depois ligar o laser. Procuramos a condição que permite o laser atingir a linha em menor tempo e com a potência do feixe razoavelmente alta, pelo menos acima de $40 \mathrm{~mW}$ (para isto a corrente fornecida precisa ser maior que $70 \mathrm{~mA}$ ). Normalmente é preciso variar a corrente num intervalo muito amplo, entre 50 a $110 \mathrm{~mA}$, aumentando e diminuindo a corrente algumas vezes até que o laser salte para o modo certo. Com tempo e prática, conseguimos sintonizar os lasers rapidamente. Atualmente o laser 1 é estabilizado em $30^{\circ} \mathrm{C}$ e os outros 3 lasers, em torno de $25^{\circ} \mathrm{C}$. Esta diferença de temperatura se deve às propriedades intrínsecas dos diodos. As correntes de trabalho são em torno de $90 \mathrm{~mA}$.

Depois de atingirem as freqüências pretendidas, os lasers são muito estáveis no sentido de que dificilmente pulam para fora do modo. Mas pequenas flutuações podem ocorrer em torno da linha de transição devido às perturbações do ambiente como mudança de temperatura. Para corrigir este problema utilizamos um circuito eletrônico com sinal de retroalimentação para travar os lasers na linha.

As figuras 3.9, 3.10 e 3.11 mostram os resultados obtidos com a espectroscopia de absorção saturada em vapor de rubídio. A primeira é de uma varredura mais ampla, englobando as transições de ${ }^{85} \mathrm{Rb}$ e ${ }^{87} \mathrm{Rb}$, e as outras duas mostram mais detalhatamente as transições utilizadas na armadilha. Os picos de absorção demonstram que os nossos lasers (sem cavidade externa) conseguem resolver os níveis hiperfinos do Rb.

laboratório [37]. 


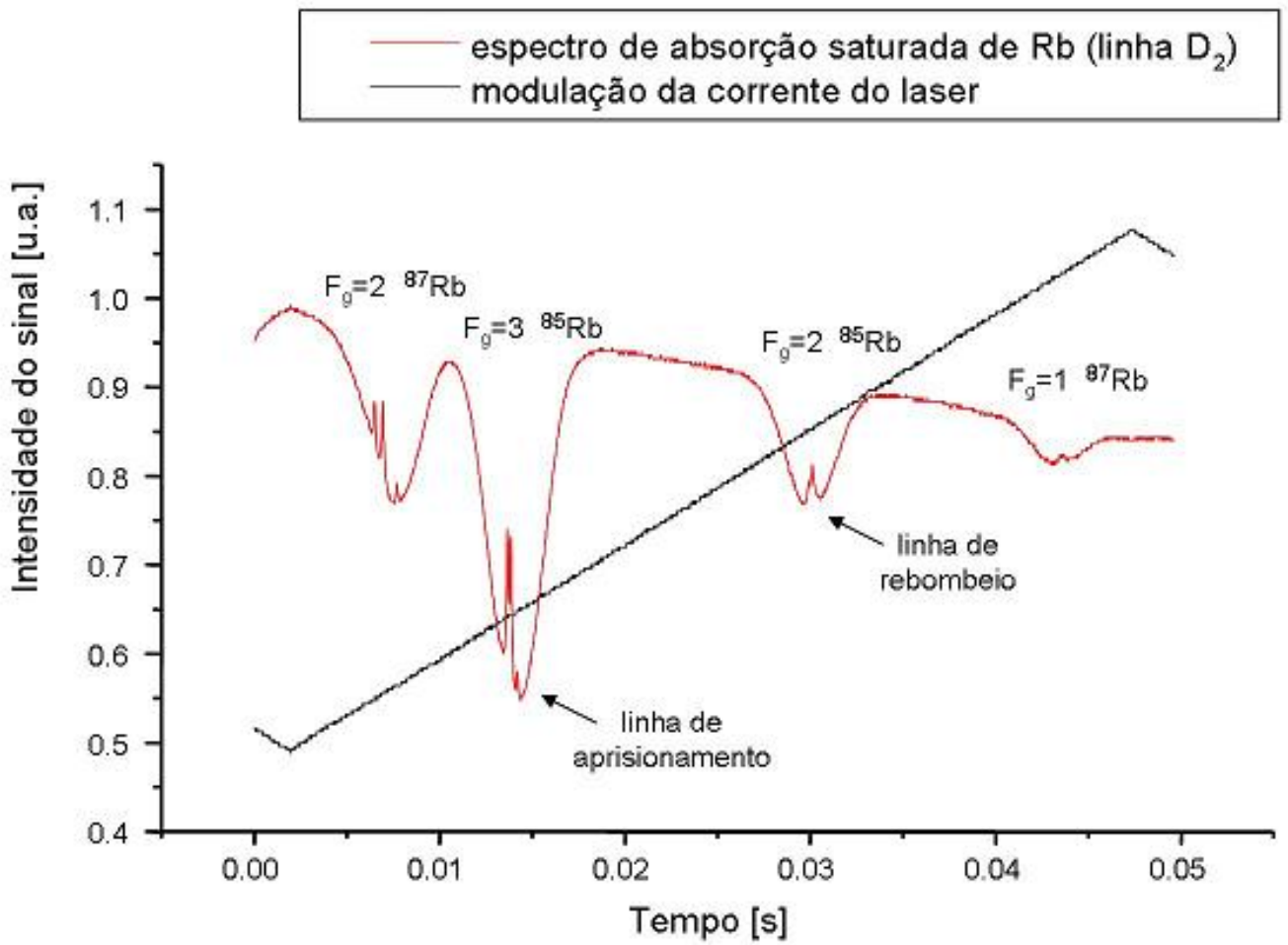

Figura 3.9: Espectro de absorção saturada de Rb. Medido com laser livre, sem cavidade externa. 


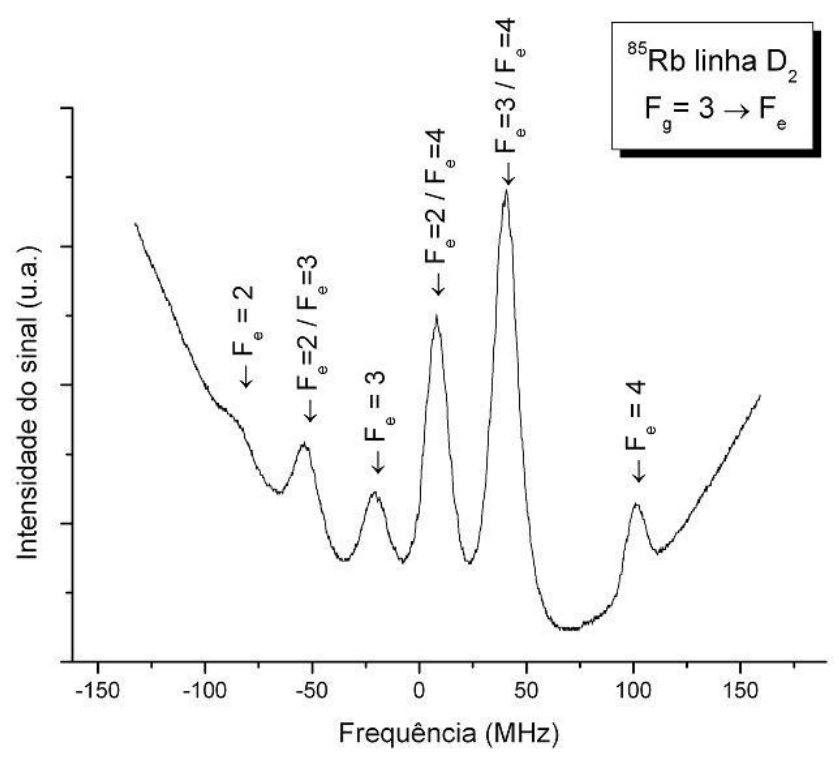

Figura 3.10: Espectro de absorção saturada das transições que partem do nível $F_{g}=3$ (linha de aprisionamento). Medido com laser livre, sem cavidade externa.

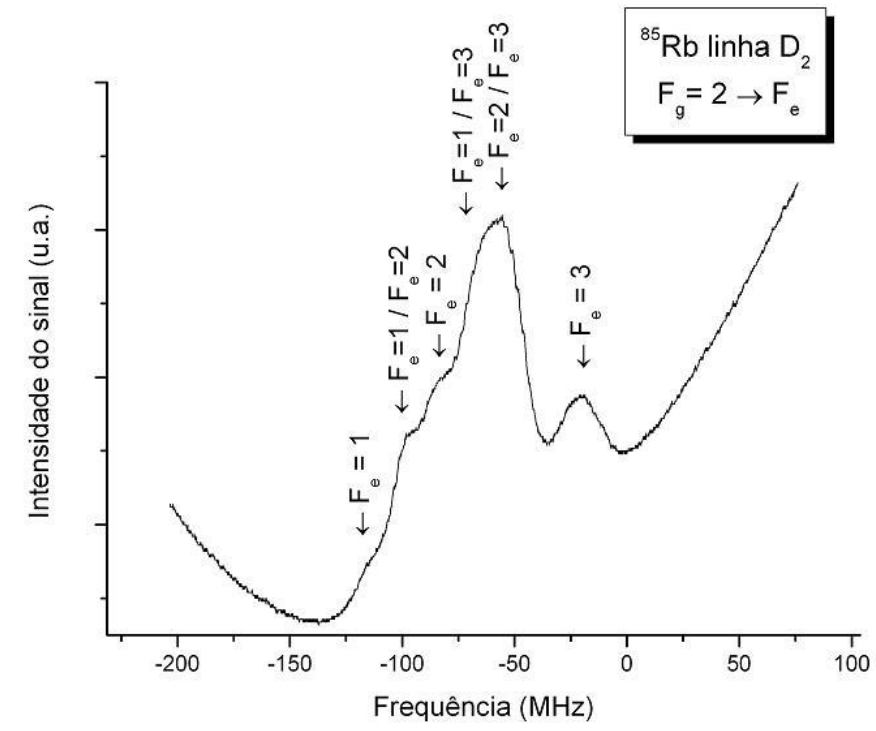

Figura 3.11: Espectro de absorção saturada das transições que partem do $F_{g}=2$ (linha de rebombeio). Medido com laser livre, sem cavidade externa. 
Utilizamos quatro lasers para a armadilha. Três são de aprisionamento (números 1, 2 e 3) e um de rebombeio (número 4), sendo que o laser 1 é mestre e os lasers 2 e 3 são lasers escravos. O laser mestre e o laser de rebombeio são sintonizados separadamente nas transições $F_{g}=3 \rightarrow F_{e}=4$ e $F_{g}=2 \rightarrow F_{e}=3$ da linha $\mathrm{D}_{2}$ do ${ }^{85} \mathrm{Rb}$, respectivamente. Cada um é monitorado independentemente por um arranjo de espectroscopia de absorção saturada.

\subsection{Eletrônica de controle}

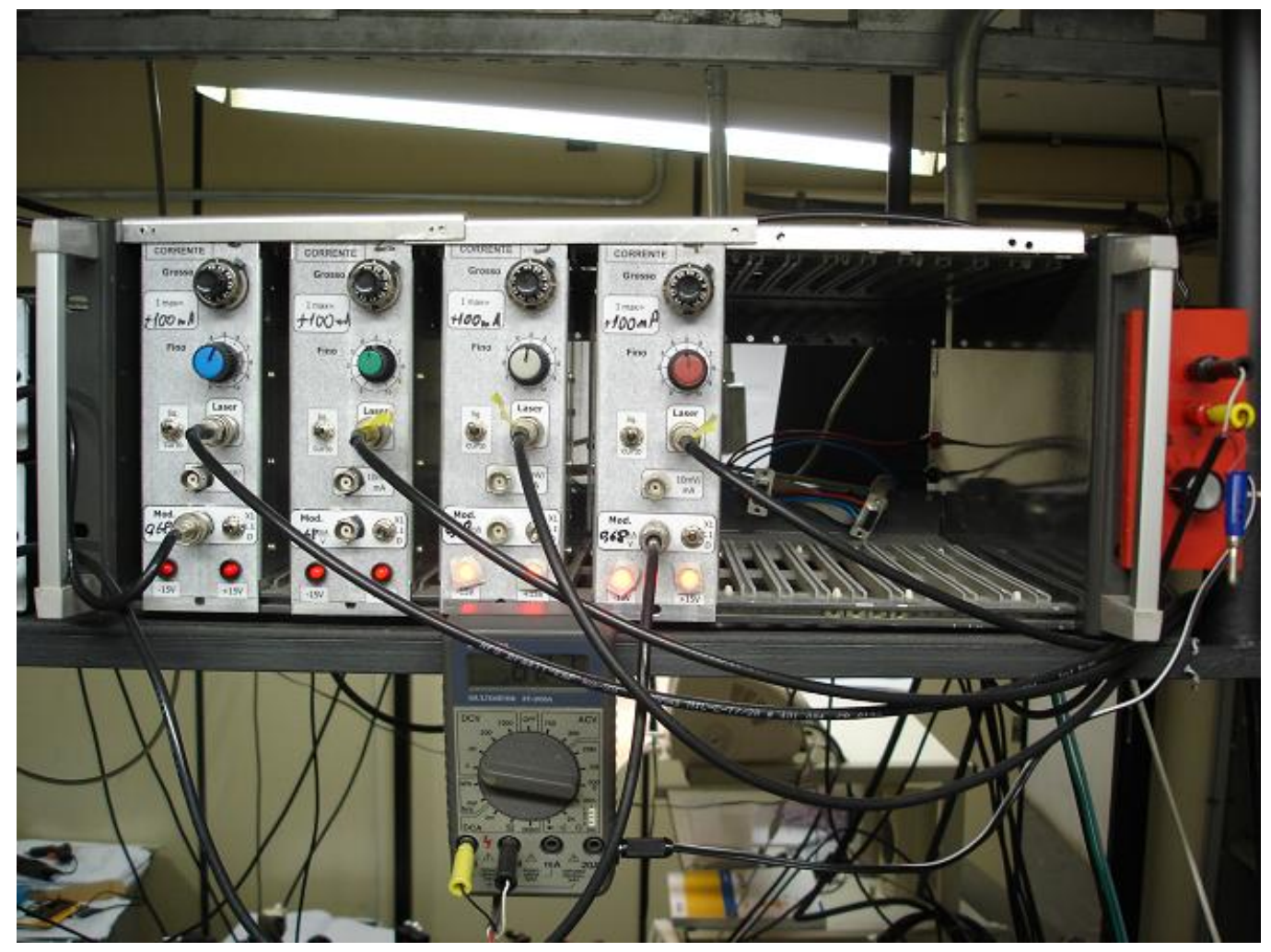

Figura 3.12: Controle de corrente dos lasers.

Construímos toda a eletrônica para fornecer corrente dos lasers (figuras 3.12 e 3.13) e para controlar a temperatura deles através de peltiers (figuras 3.14 e 3.15). Esta eletrônica é modular 


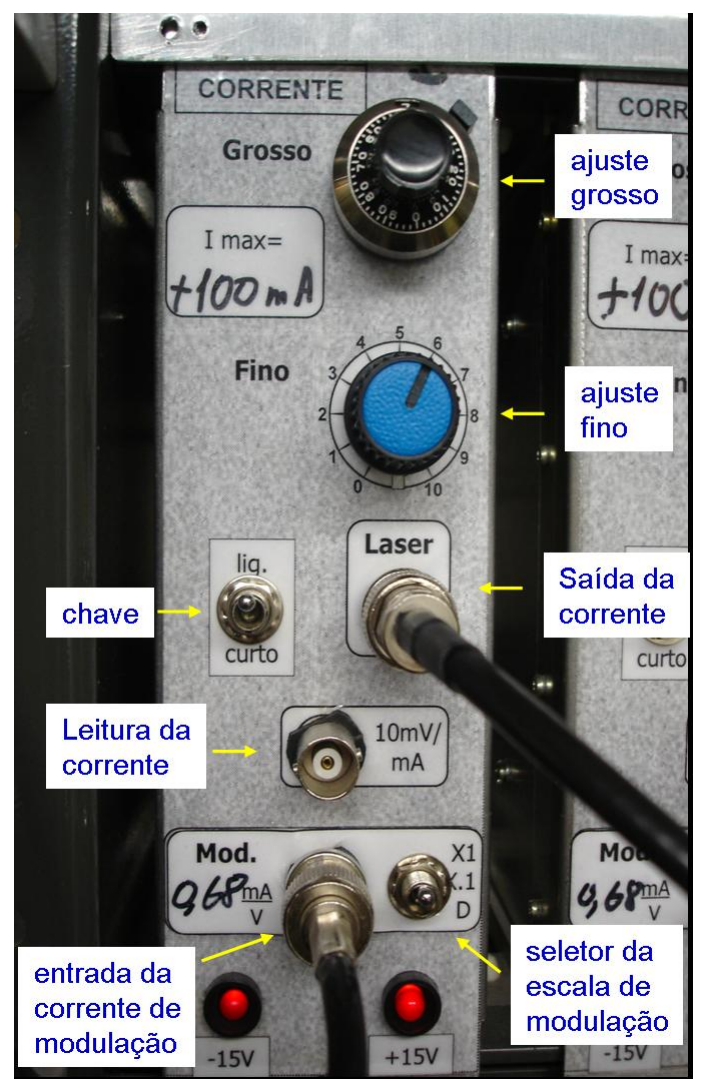

Figura 3.13: Detalhe do controle de corrente. 


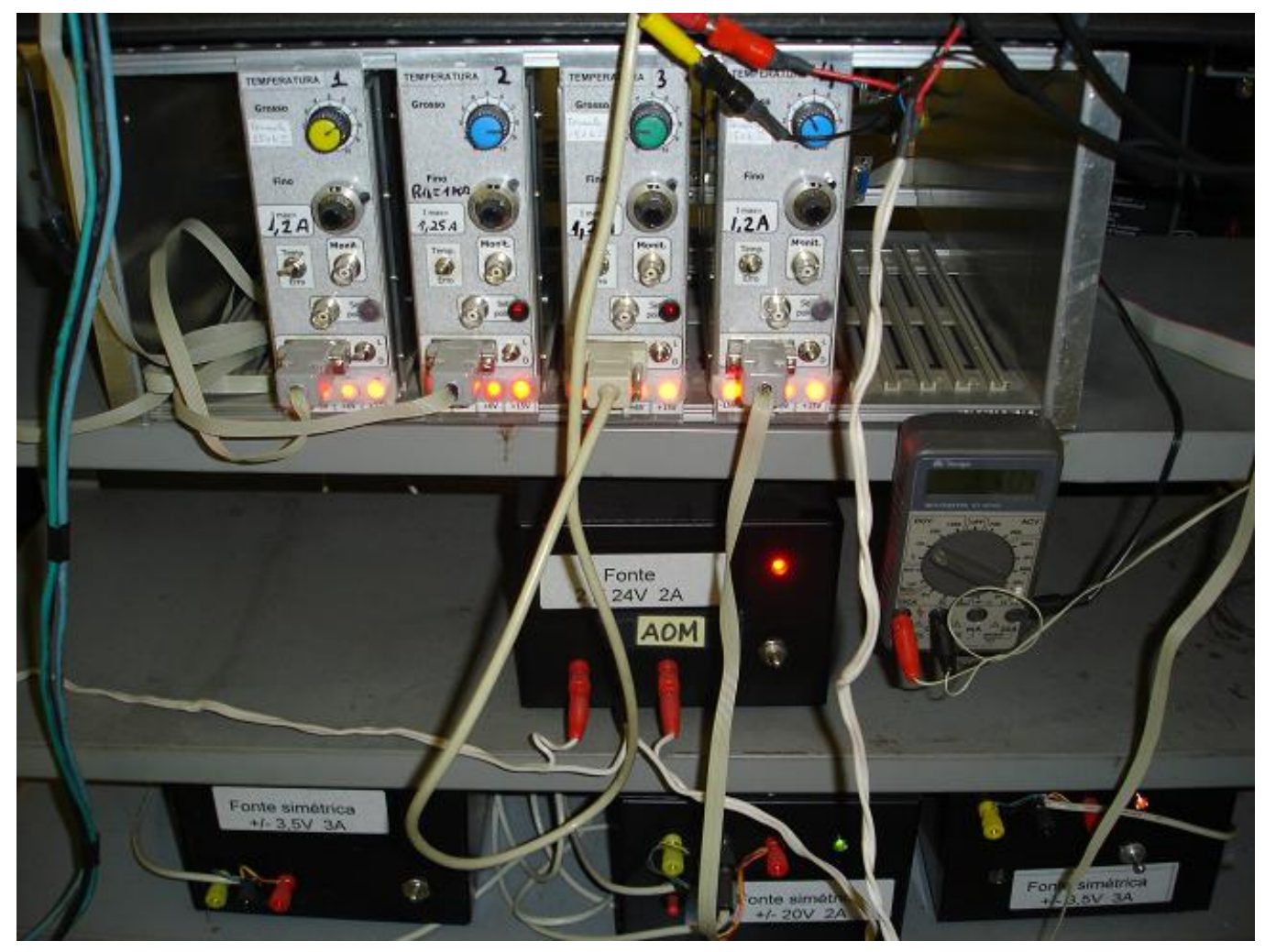

Figura 3.14: Controle da temperatura dos lasers e as fontes de tensão.

e é fácil de substituir as peças caso alguma parte apresente defeito. Também construímos as fontes de tensão. Toda a eletrônica tem se mostrado bastante robusta e confiável.

O controle de corrente permite ajustar o valor da corrente de saída com precisão menos que $0,1 \mathrm{~mA}$ e também pode sobrepor uma corrente de modulação externa na saída. Esta modulação é usada para varrer a freqüência do feixe laser e para fazer o controle do mesmo por realimentação, travando-o na transição desejada. 


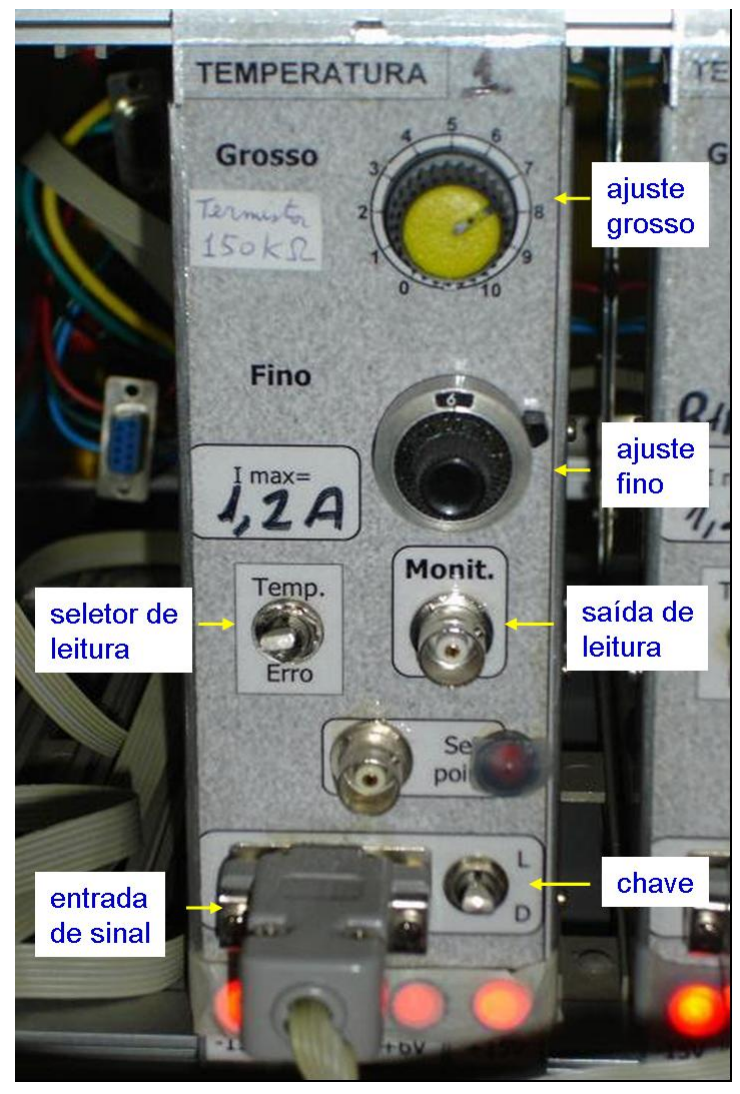

Figura 3.15: Detalhe do controle da temperatura. 


\subsection{Controle da freqüência do laser mestre}

Para o sucesso da armadilha é essencial ter controle preciso sobre a freqüência dos feixes laser. Isto é obtido através de moduladores acusto-óticos (Acoustic-optical modulator - AOM) ${ }^{6}$, espectroscopia de absorção saturada e travamento ativo em freqüência. A seguir explicaremos o esquema de controle (mostrada na figura 3.16).

O feixe do laser mestre, depois de passar por um isolador ótico, incide sobre um cubo divisor polarizado. Ajustando a polarização do feixe com uma lâmina de $\lambda / 2$, grande parte do feixe (>90\%) é transmitido (polarização vertical) pelo cubo e guiada para armadilha. A pequena parte do feixe refletida pelo cubo (polarização horizontal) é direcionada para o modulador acusto-ótico apelidado de AOM1a. Este feixe refletido é deslocado em freqüência pelo AOM1a, sendo o objetivo final fazer espectroscopia absorção saturada cujo sinal serve para travamento do laser mestre.

A dessintonia do feixe é realizada na dupla passagem pelo AOM1a (ida e volta). Primeiro, através de dois espelhos, direcionamos o feixe para AOM1a onde ele é difratado. Os feixes de saída (ordem 0 e ordem difratada) são colimados por uma lente plano-convexa com o foco no centro do modulador, e seguem então trajetos paralelos, porém cada um deles passa a convergir para uma cintura mínima no plano focal da lente. A distância focal da lente é $15 \mathrm{~cm}$. Depois da lente posicionamos um bloqueador de feixes que apenas permite a passagem do feixe difratado da ordem +1 . Mais adiante o feixe transmitido passa por uma lâmina de $\lambda / 4$, em seguida é retro-refletido por um espelho no plano focal da lente e volta pelo mesmo caminho. Ajustamos a $\lambda / 4$ de tal modo que a polarização do feixe é "girada" em $90^{\circ}$ depois da dupla passagem pela

\footnotetext{
${ }^{6}$ Descreveremos o funcinamento dos AOM na seção 3.6 na página 77
} 


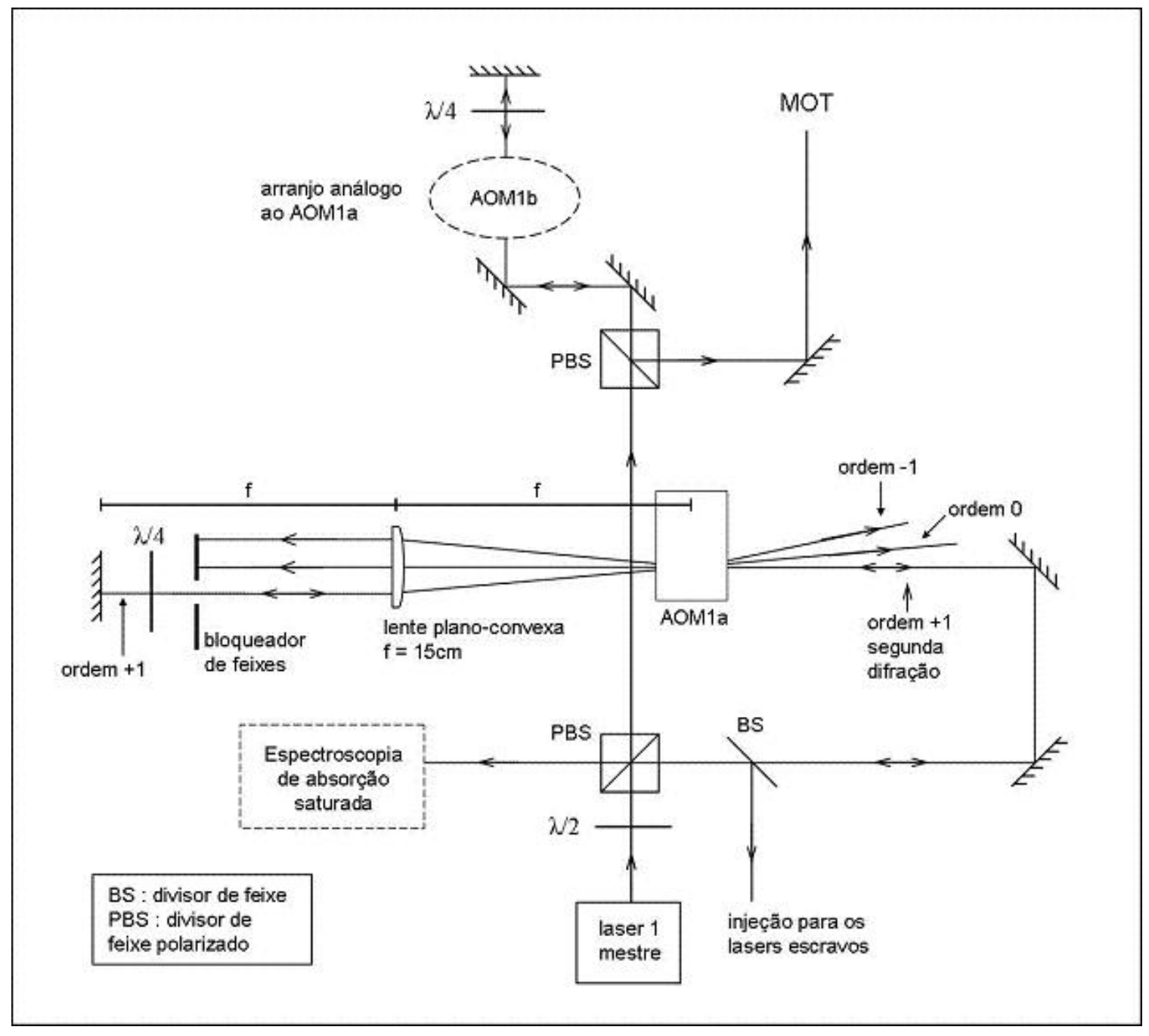

Figura 3.16: Arranjo ótico do laser 1 mestre. 
lâmina. Como o feixe de ida possui polarização horizontal, o de volta tem polarização vertical e quando incide novamente sobre o cubo é transmitido (não refletido) e é guiado para o arranjo da espectroscopia de absorção saturada.

O AOM que usamos é especificado para trabalhar em torno de $80 \mathrm{MHz}$. Podemos variar esta freqüência numa faixa de dezenas de MHz. Na configuração normal, um feixe difratado de ordem +1 tem a freqüência deslocada em $+80 \mathrm{MHz}$ em relação ao feixe de entrada. Como no nosso esquema o feixe é difratado duas vezes, a freqüência é deslocada duas vezes, ou seja, em $+160 \mathrm{MHz}$.

Na verdade, como o feixe difratado é usado na espectroscopia como referência para travamento do laser, se este feixe estiver na linha de transição, o feixe original é que possui deslocamento de $-160 \mathrm{MHz}$ com relação à transição atômica. Esta é a freqüência do feixe transmitido pelo cubo polarizador, que é direcionado para a armadilha. O feixe transmitido passa pelo arranjo de um outro modulador, AOM1b, semelhante ao arranjo do AOM1a. A função do AOM1b é deslocar a freqüência do feixe de volta para perto da linha de transição. O feixe difratado (também duas vezes) pelo AOM1b é usado como feixe de aprisionamento na armadilha.

Com este esquema de dois moduladores podemos, com precisão, variar finamente a dessintonia do feixe de aprisionamento relativo à transição atômica pela variação de freqüência do segundo modulador, de dezenas até apenas alguns MHz. Isto é uma condição importante para o bom funcionamento da armadilha.

A lente plano-convexa nos arranjos de moduladores facilita o alinhamento do feixe difratado em dupla passagem. O ângulo da difração é proporcional ao deslocamento da freqüência. Nas 
experiências, muitas vezes precisamos variar este deslocamento e isto gera variação na direção do feixe. Com a lente, cujo foco está no centro do modulador, os feixes saem paralelos com o feixe de ordem 0 (que não varia de direção) e o feixe de ordem +1 sempre incide com o mesmo ângulo ao espelho final e portanto sempre voltará ao AOM1a. O feixe não volta perpendicularmente ao AOM1a, mas como o feixe é difratado novamente, o desvio do feixe de ordem +1 da segunda difração compensa esse ângulo, e o feixe volta pelo mesmo caminho e elimina a necessidade de realinhamento a cada nova freqüência de trabalho.

\subsection{Controle da freqüência dos lasers escravos}

As freqüências dos lasers escravos 2 e 3 são controladas via injeção do feixe do laser mestre. Como o feixe injetado é dessintonizado para vermelho, os lasers 2 e 3 também o são. Posteriormente os feixes de cada laser passam pelos respectivos moduladores, AOM2 e AOM3, que deslocam a freqüência dos lasers escravo para azul, assim temos os mesmos controles de dessintonia do laser mestre, sendo que os três AOM's são alimentados pela mesma fonte.

Os diodos empregados possuem um fotodetector (fotodiodo) interno acoplado, o qual podemos utilizar para otimizar o alinhamento da injeção do feixe do laser mestre. Travamos a freqüência do laser mestre e adicionamos uma corrente triangular à alimentação do laser escravo para varrer o comprimento de onda do feixe emitido. Sem a injeção o sinal do detector ${ }^{7}$ também é triangular, mas quando o feixe de injeção for bem alinhado e o laser escravo estiver no modo correto, a curva apresenta um "platô"no meio. A faixa de captura é de alguns GHz.

\footnotetext{
${ }^{7}$ Visto no osciloscópio, usando uma terminação de 1 a $100 \mathrm{~K} \Omega$ ou com uma fonte externa polarizando reversamente e uma resistência de carga em série.
} 


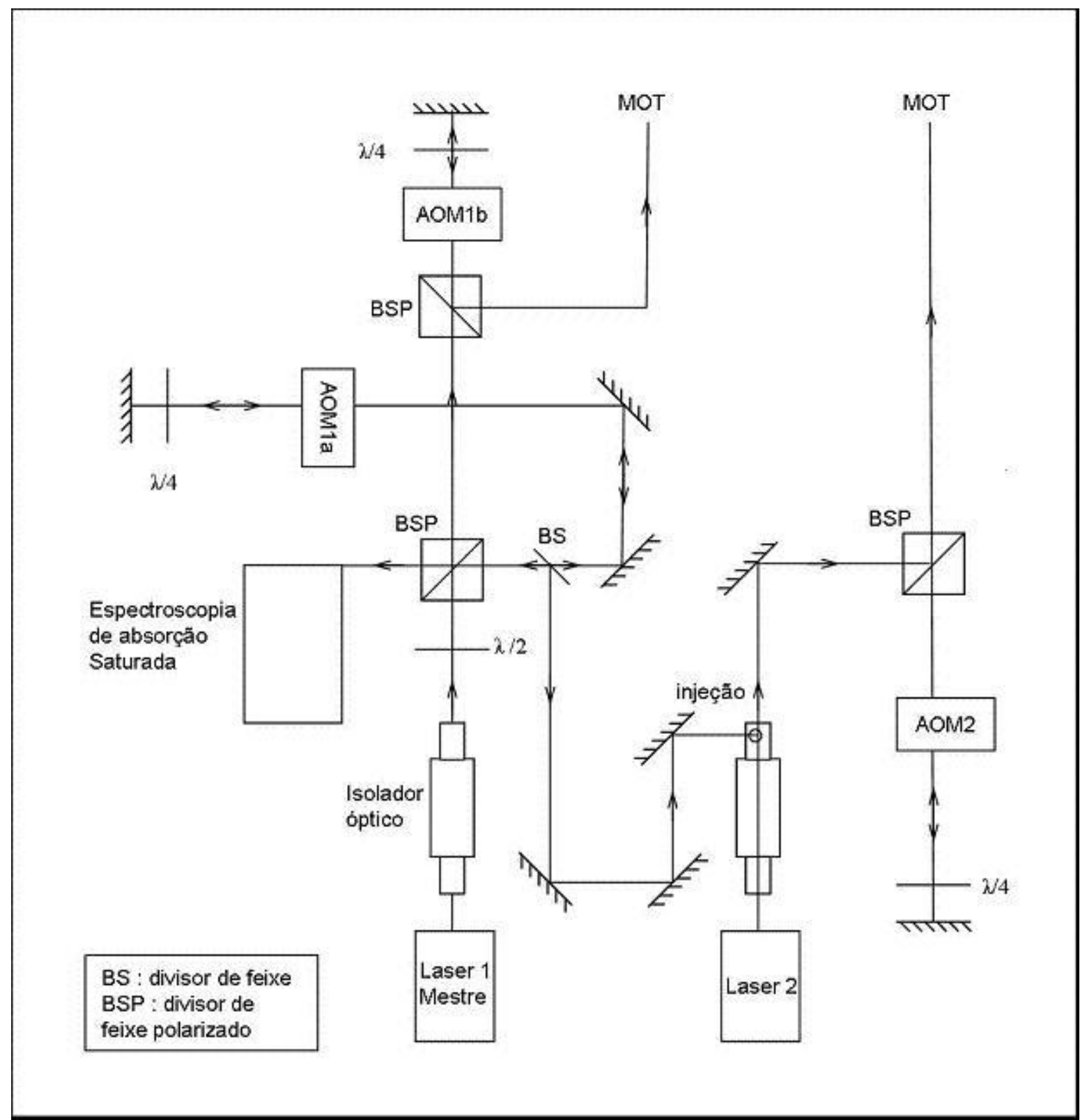

Figura 3.17: Controle dos feixes de laser 1 (mestre) e 2 (escravo). O esquema do laser 3 é igual do laser 2. Não está mostrado o laser de rebombeio. 
Durante as experiências as freqüências dos lasers escravos são fixadas pelo laser mestre. Monitoramos continuamente a injeção através de uma cavidade de Fabry-Perot, com a qual podemos perceber com precisão quando os lasers estão no modo correto.

Depois de passar pelos AOMs, cada feixe de laser é ampliado em tamanho através de um "telescópio" formado por duas lentes plano-convexas, uma de $8 \mathrm{~mm}$ de distância focal e outra de $15 \mathrm{~cm}$. As lentes são separadas por $15,8 \mathrm{~cm}^{8}$ e posicionadas com as faces planas voltadas para dentro para minimizar aberração esférica. O feixe ampliado possui o diâmetro de $16 \mathrm{~mm}$ aproximadamente e é elipsoidal com razão da ordem de 2:1. Este formato, no entanto, não é suficiente para justificar a inclusão de outros elementos ótico de correção do feixe.

Cada laser possui cerca de $50 \mathrm{~mW}$ de potência de saída, normalmente operando entre 75 e $90 \mathrm{~mA}$. A corrente máxima de operação do diodo é $140 \mathrm{~mA}$, de modo que a operação em corrente inferior à especificada garante um tempo de vida mais longo ao mesmo. A intensidade de cada feixe incidindo na armadilha é aproximadamente igual a $10 \mathrm{~mW} / \mathrm{cm}^{2}$ (a intensidade de saturação de ${ }^{85} \mathrm{Rb}$ é $1,64 \mathrm{~mW} / \mathrm{cm}^{2}$ ). Na nossa armadilha usamos a configuração de feixes retro-refletidos ao invés de feixes contrapropagantes separados, pois como as janelas da nossa câmara de vácuo possuem coating anti-refletor, o feixe transmitido perde muito pouca potência. Para travar em freqüência o laser mestre, utilizamos um arranjo de espectroscopia de absorção saturada. Deste arranjo temos dois sinais, um de absorção saturada e outro de absorção simples. Subtraímos um do outro para excluir o perfil Doppler e ficar apenas com os picos de absorção saturada. Travamos o sinal do feixe na rampa lateral do pico $\mathrm{F}_{g}=3 \longrightarrow \mathrm{F}_{e}=4$ da linha $\mathrm{D} 2$ do ${ }^{85} \mathrm{Rb}$, podendo ainda empregar a técnica de "dither and lock" para travá-lo na ressonância

\footnotetext{
${ }^{8} \mathrm{~A}$ distância precisa é ajustada de forma a obter um feixe colimado na saída do telescópio
} 
de uma linha de "cross over". Este última tem se mostrado mais robusta para o travamento, e menos sensível a efeitos espúrios, como a presença de luz ambiente. O rebombeio é travado na transição $\mathrm{F}_{g}=2 \longrightarrow \mathrm{F}_{e}=3$. É bem fácil de fazer o travamento em freqüência do laser mestre e do rebombeio. Uma vez travados os locks são bem robustos, podem ficar na linha durante horas. Os lasers 2 e 3 também são razoavelmente estáveis com a injeção, só precisamos eventualmente realizar pequenos ajustes nas correntes para corrigir possíveis flutuações de temperatura. A faixa da corrente de captura dos lasers escravos é cerca de $5 \mathrm{~mA}$, o que garante que mesmo com pequenas oscilações de temperatura os lasers continuem na linha.

\subsection{Modulador acusto-ótico (AOM)}

Moduladores acusto-óticos são usados para controlar a freqüência e a amplitude dos feixes óticos. Utilizamos AOM's da Crystal Technology, Inc, modelo 3080-122. Cada AOM contem um pequeno cubo de cristal de $\mathrm{TeO}_{2}$. Um feixe laser, ao passar pelo cristal, pode sofrer difração de Bragg [53]. A difração é causada pela passagem de uma onda acústica na direção quase perpendicular. Esta onda é gerada através de um transdutor acoplado a um sinal de radiofreqüência $(\mathrm{RF})$. A intensidade do feixe difratado depende da amplitude do sinal de $\mathrm{RF}$ e também do alinhamento. O deslocamento em freqüência do feixe depende da freqüência do sinal de RF.

Basicamente, um AOM é ligado num amplificador que por sua vez é conectado a um oscilador controlado por voltagem (voltage-controlled oscillator - VCO). O VCO é controlado por um circuito externo com entrada para sinal de modulação de amplitude (AM) e de freqüência (FM). Um sinal de saída do amplificador pode alimentar até três AOMs através de um divisor 
de potência. Este sistema é esquematizado na figura 3.18. Os componentes eletrônicos são da empresa Mini-Circuits.

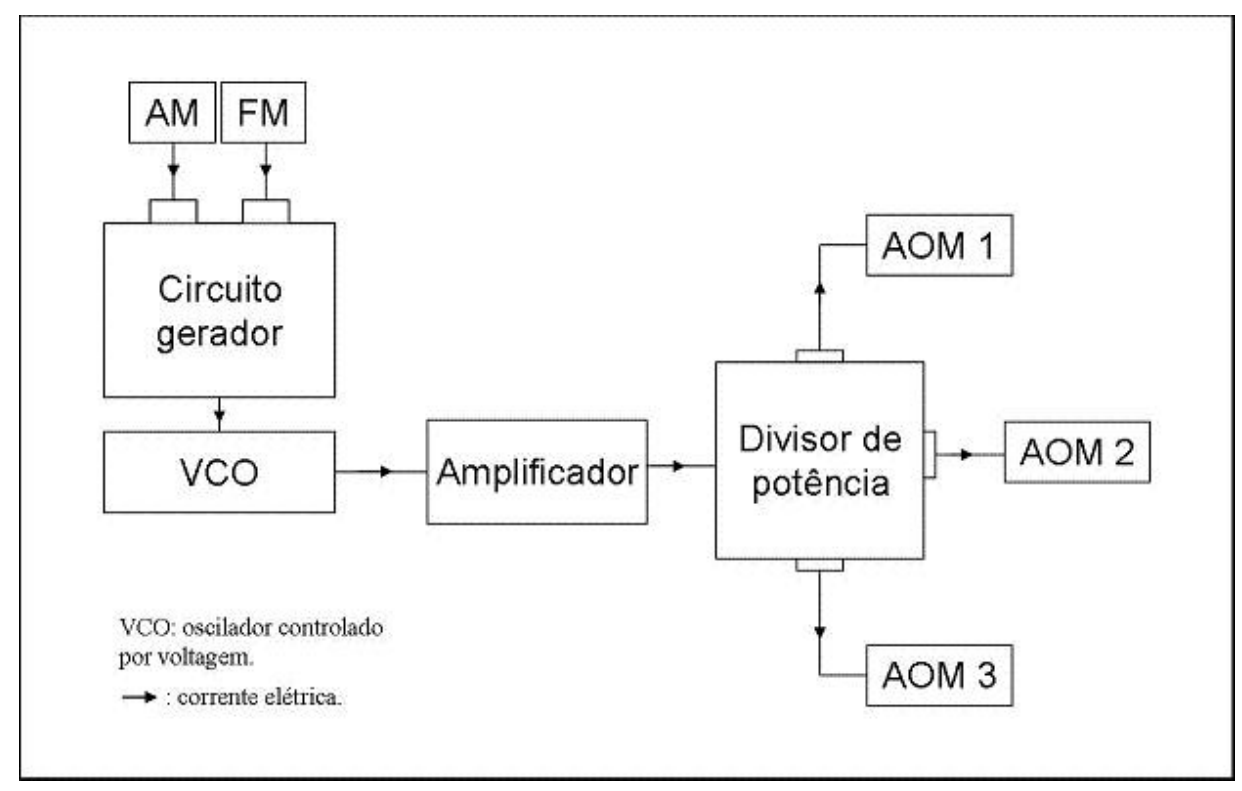

Figura 3.18: Alimentação dos moduladores acusto-ótico.

Fizemos o alinhamento de cada AOM para maximizar a intensidade do feixe difratado de primeira ordem, sendo que a eficiência atinge até $90 \%$ por passagem, para feixes grandes. Os feixes difratados de outras ordens são bloqueados. Controlando o sinal de RF podemos, rapidamente, deslocar a freqüência, modificar a amplitude e chavear a passagem do feixe de laser. Calibramos as variações do feixe passante com relação à tensão dos sinais de AM e de FM aplicados no gerador de sinal. Usando estes dados, podemos controlar a freqüência e a intensidade dos feixes de aprisionamento e de rebombeio via computador.

O gráfico 3.19 mostra a relação entre a amplitude do feixe difratado de primeira ordem e a tensão aplicada no controle AM de um dos AOMs. Para realizar esta medida mandamos para entrada AM uma rampa de tensão gerada pela placa NI PCI-6723 (National Instruments) e 
medimos a potência do feixe com um detector DET-100 (Thorlabs). Vemos que, para o arranjo especifico dessa medida, a potência do feixe difratado atinge o máximo com a tensão acima de, aproximadamente, 1,3V. Normalmente trabalhamos com tensão de 1,1V para este arranjo.

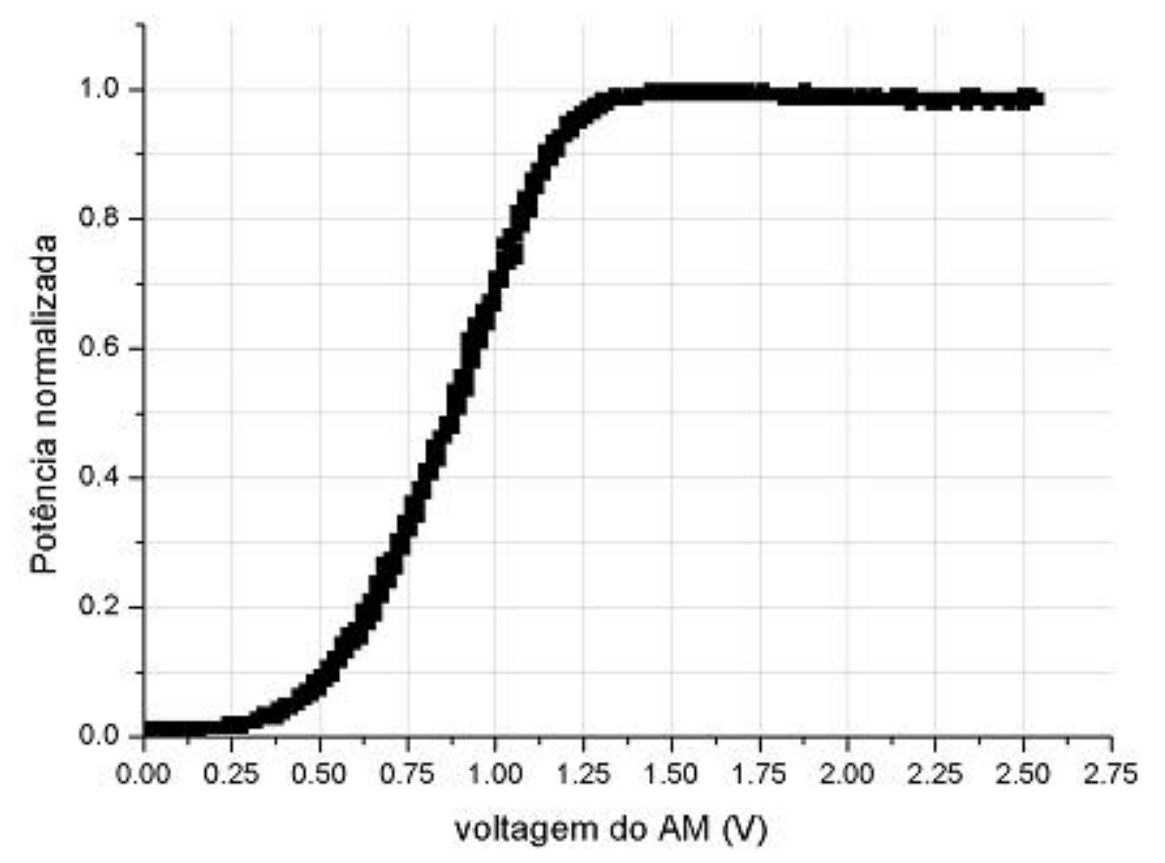

Figura 3.19: Potência normalizada do feixe difratado de primeira ordem vs. tensão do sinal de AM aplicado sobre o AOM.

A seguir, na figura 3.20, mostramos a relação do deslocamento da freqüência do feixe difratado com a tensão aplicada na entrada de sinal de FM de um dos AOMs. Como a difração no AOM é causada pela onda acústica em movimento, a freqüência do feixe difratado de ordem $n$ sofre o deslocamento Doppler por uma freqüência igual a $n f$, no qual $f$ é a freqüência da onda acústica [53]. No nosso caso $n$ é 1 , então o deslocamento é igual à $f$. Medimos esta freqüência 
usando uma ponta de prova na saída do VCO.

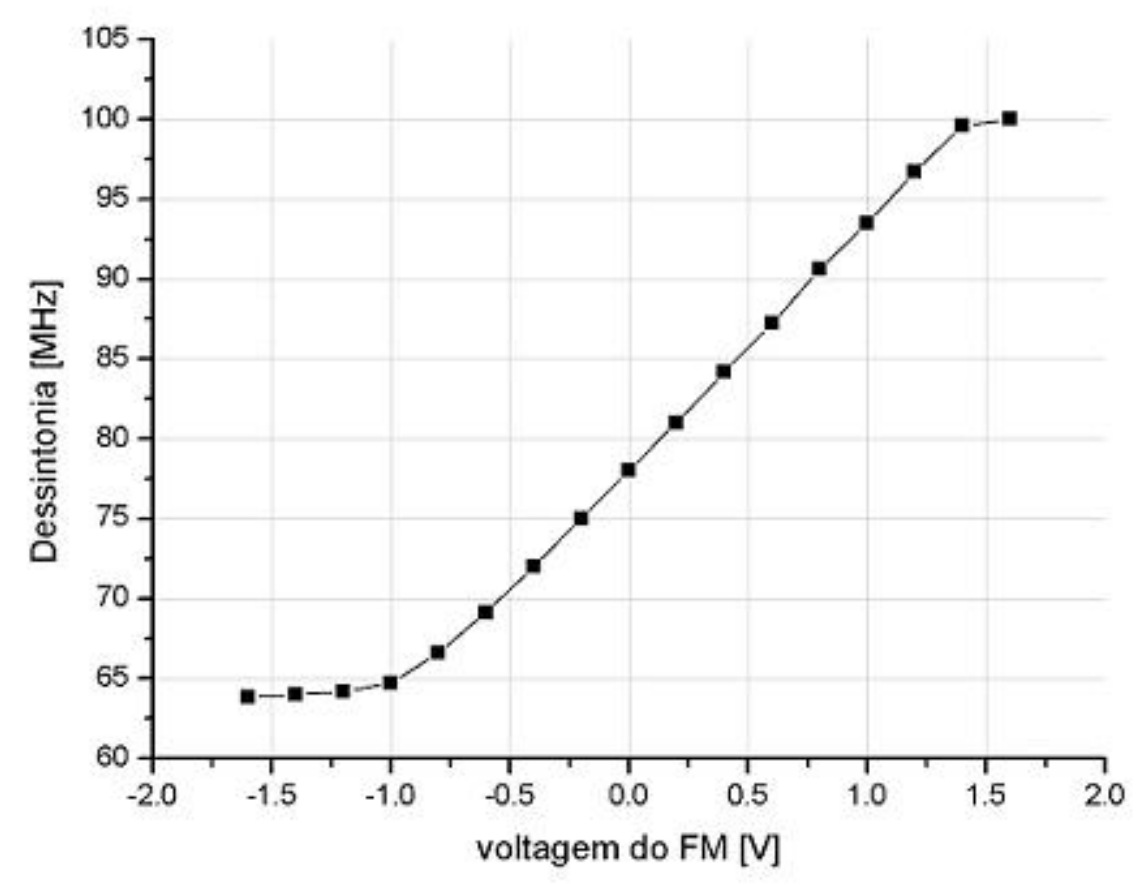

Figura 3.20: Dessintonia do feixe difratado de primeira ordem vs. tensão do sinal de FM aplicado sobre o AOM. A freqüência central do AOM é $80 \mathrm{MHz}$

Desta forma, combinando o travamento dos lasers, obtido através do controle de corrente e temperatura, com o controle da amplitude (de 0 a cerca de $20 \mathrm{~mW}$ ) e freqüencia (em uma faixa de $60 \mathrm{MHz}$ ) dos feixes através dos moduladores acusto-óticos, podemos controlar completamente a parte ótica da armadilha. Falta agora o controle do campo magnético, tema de nossa próxima seção. 


\subsection{Bobinas}

Para criar o campo magnético da armadilha utilizamos duas bobinas na configuração antiHelmholtz com o eixo no plano horizontal. Cada bobina possui raio médio de $r=9,25 \mathrm{~cm}$, a distância entre os centros das bobinas é $2 b=19,5 \mathrm{~cm}$ e a espessura é $3,5 \mathrm{~cm}$. A proporção $2 b / r$ é maior que o ideal de 1,25 [40]. Isto é devido ao tamanho da nossa câmara de vácuo; o raio das janelas de observação principal e a separação entre elas limitam as medidas das bobinas. No entanto, este fato não impede o trabalho da armadilha, as experiências têm demonstrado o funcionalidade do arranjo. As bobinas são feitas por 550 voltas de fio de cobre de 1,5 mm de diâmetro enroladas numa oficina especializada. Cada bobina possui resistência de $6 \Omega$ e não necessita de refrigeração pois em nossos testes a temperatura não passou de $60{ }^{\circ} \mathrm{C}$ com $3 \mathrm{~A}$ de corrente. Nas experiências usamos corrente em torno de 2 A o que fornece um gradiente de campo da ordem de 20 gauss/cm no centro da armadilha.

Já explicamos todos os componentes físicos da armadilha, a montagem atual é mostrada na foto 3.21. Na próxima seção será apresentados os softwares criados para caracterizar a MOT. 


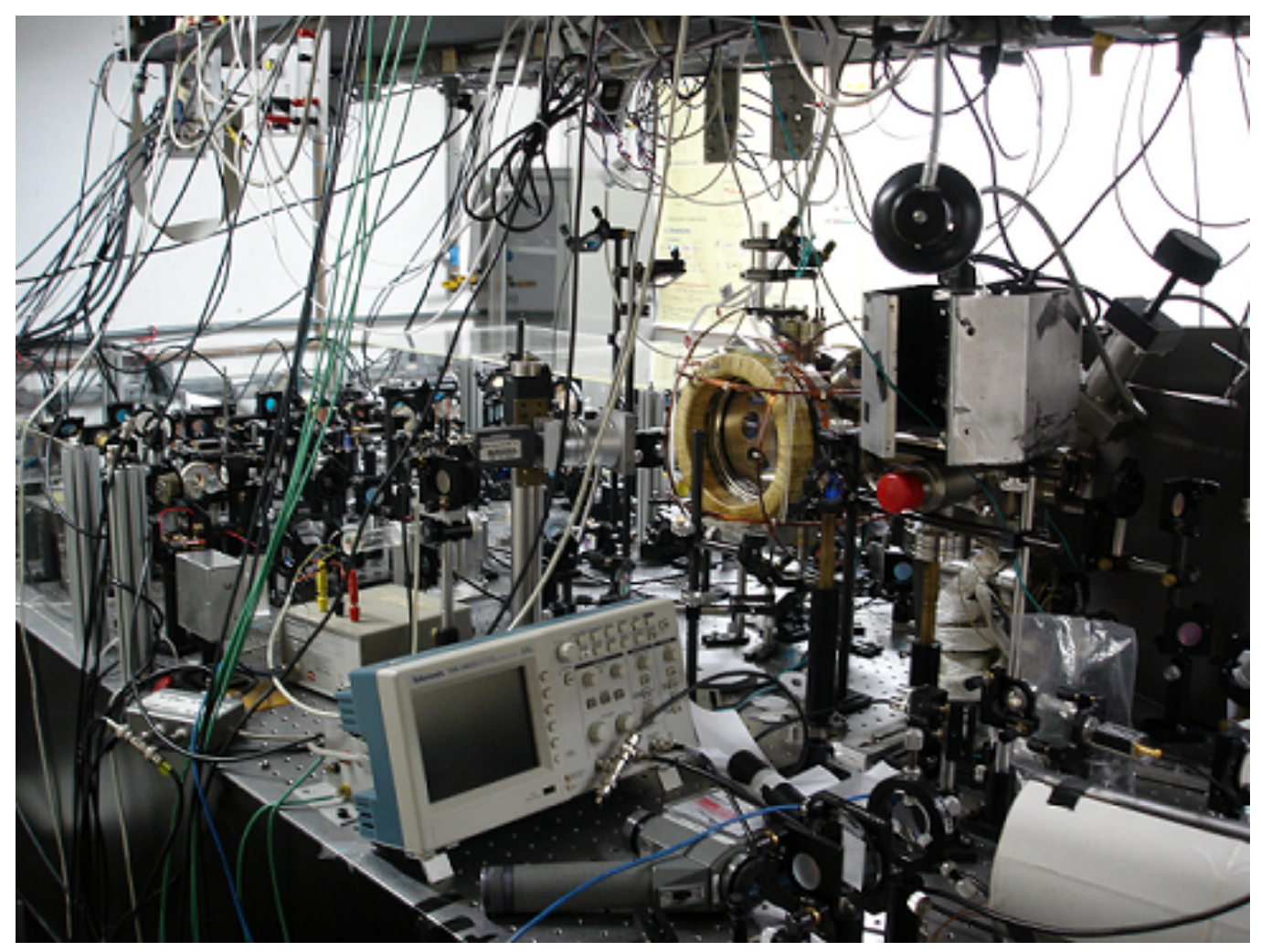

Figura 3.21: Montagem da armadilha magneto-ótica atual. 


\subsection{Software de controle e análise}

Vimos até aqui os detalhes técnicos da montagem do experimento, com o controle da ótica e do campo magnético providenciado por circuitos de controle acionados por tensão. Por si, eles já permitem o funcionamento da armadilha. No entanto, se queremos realizar experimentos de espectroscopia com a nuvem atômica resfriada, ou obter átomos em regime mais frio, ou nuvens mais densas, etc, precisamos controlar uma grande quantidade de componentes eletrônicos simultaneamente.

É necessário enviar sinais eletrônicos para ligar/desligar os campos óticos e magnéticos, variar os parâmetros dos AOM's, controladores de corrente, etc. Também precisamos controlar precisamente a execução das medidas e dos registros dos resultados. E frequentemente o tempo de execução dos controles são curtíssimos, impossibilitando qualquer controle manual. Por isto precisamos de controle eletrônico automatizado, o que inclui equipamentos e programas de computador.

Utilizamos a placa de conversão digital-analógica PCI-6723 produzida pela National Instruments para gerar sinais eletrônicos. Esta placa permite controlar até 32 canais ao mesmo tempo. A comunicação com a placa é feita através de programas em ambiente LabVIEW, da mesma empresa.

Durante o primeiro semestre do nosso projeto, com ajuda de um aluno de iniciação científica, criamos um programa básico de geração e controle de sinais. No entanto, durante os experimentos notamos que o programa era ineficiente. Ocupava uma quantidade excessiva de memória e tornava o computador muito lento. Isto impossibilitava a sincronização dos sinais, que é essencial para o sucesso das medidas. Posteriormente otimizamos várias etapas do pro- 
grama e eliminamos uso redundante de recursos computacionais. Atualmente o programa é bem mais eficiente, o uso de memória foi reduzido em mais de $70 \%$ e conseguimos gerar sinais multicanais nos tempos programados.

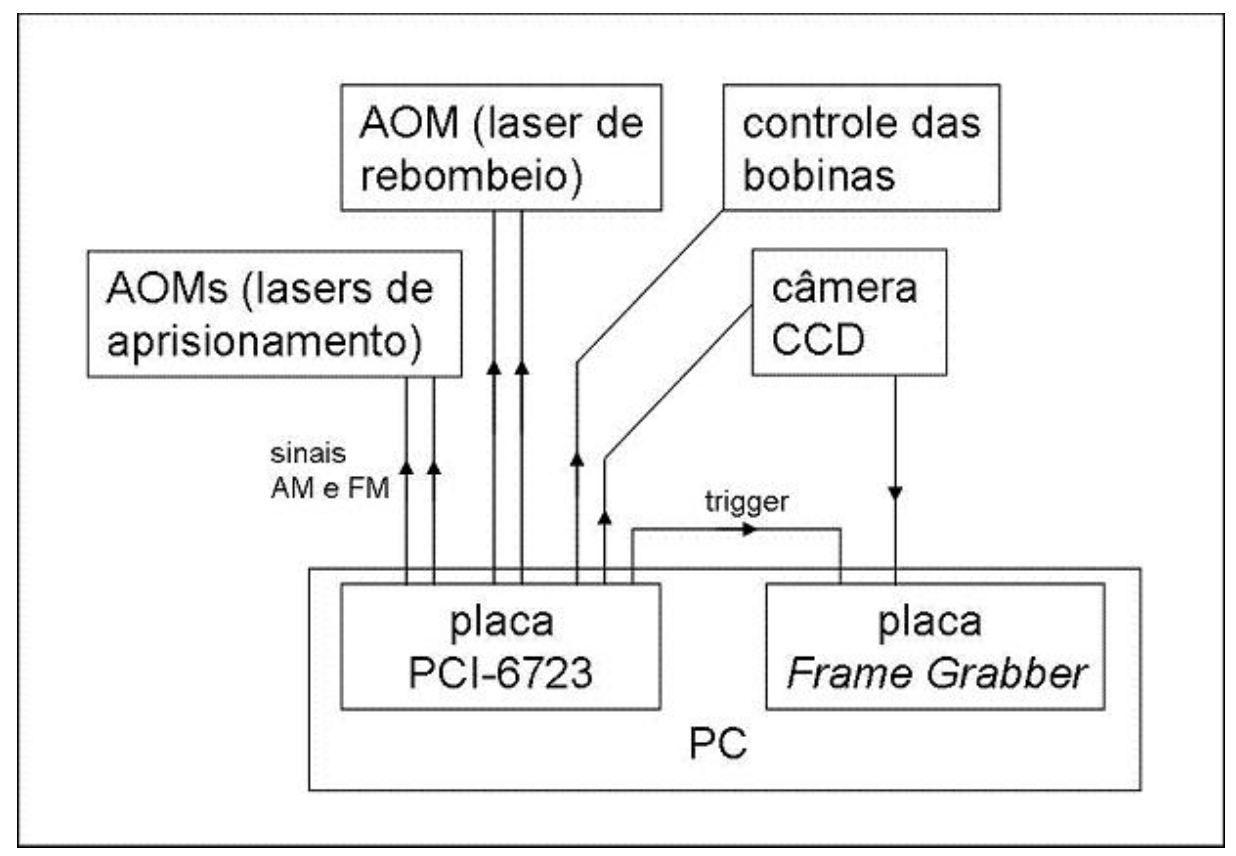

Figura 3.22: Esquema de ligação dos controle eletrônicos dos principais componentes.

Também implementamos o programa de aquisição de imagens. Usamos uma câmera CCD KP-M3 (Hitachi) para adquirir imagens da nuvem. As imagens são gravadas no computador pela placa de captura de video Frame Grabber DT-3152 da Data Translation. Como os programas de controle disponibilizados pela fabricante possuem funções muito limitadas, e nenhum em linguagem do LabVIEW, tivemos que criar o nosso programa. Utilizando a biblioteca de funções DT active open layers fornecida pela fabricante, conseguimos acessar e controlar a placa através do LabVIEW. No entanto, tivemos bastantes dificuldade para sincronizar as aquisições. Nas medidas de expansão precisamos adquirir fotos com precisão da ordem de milisegundos, 
se tiver qualquer dessincronia poderia gerar uma imagem distorcida ou com uma intensidade muito fraca ou simplesmente sem registro da nuvem. Depois de testar vários métodos de trigger (sinal de sincronização) e vários mecanismos de geração de sinal, chegamos num resultado muito satisfatório. A figura 3.22 mostra o esquema geral de controle eletrônico que construímos.

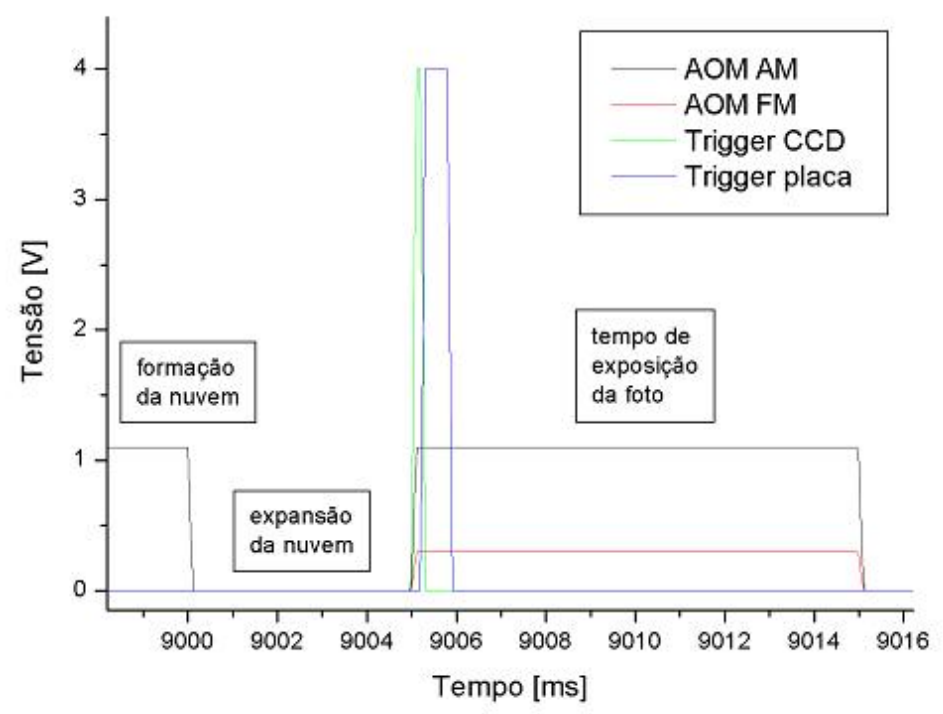

Figura 3.23: Sinais utilizados para a medida da expansão da nuvem.

Utilizando o programa em Labview podemos registrar imagens da nuvem em expansão. No gráfico 3.23 é possível ver a seqüencia dos procedimentos. Na ausência da luz ambiente, primeiro emitimos o sinal de AM do controlador dos AOMs por alguns segundos, isto permite a transmissão dos feixes de aprisionamento e a formação da nuvem de átomos frios. Depois cortamos os feixes de aprisionamento deixando a nuvem se expandir e religamo-los novamente depois de alguns milisegundos. Ao religar os lasers, simultaneamente é mandado um sinal de trigger (duração de 0,1 ms) para a câmera CCD para adquirir uma imagem da nuvem. Este 
sinal é seguido por um trigger $(0,5 \mathrm{~ms})$ para a placa Frame Grabber que espera até que a aquisição da foto termine e salva a imagem do CCD no computador em forma de bitmap.

Deixamos o sinal AM ligado por mais alguns milisegundos para a exposição da foto. Como o tempo de exposição é muito curto, e a nuvem expandida possui fluorescência fraca, a intensidade da imagem adquirida é normalmente muito baixa. Uma forma de melhorar isto é mandar um sinal adequado de FM para o controlador de AOM depois da expansão. O objetivo é deslocar a freqüência dos feixes laser para perto da ressonância da linha de transição fazendo com que a emissão de fótons seja aumentada.

Também criamos softwares para analisar as fotos. Podemos subtrair a luz de fundo de uma foto para deixar a imagem da nuvem mais limpa. Fizemos funções que normalizam a intensidade dos pontos da foto e que inverte a escala de cores para uma melhor visualização. Além disso, devido às particularidades da nossa câmera CCD, cada imagem adquirida é composta por dois campos (fields) sendo que um é mais intenso que o outro. O software pode extrair apenas o mais forte para obter uma imagem uniforme. O resultado é reprodutível a cada realização do experimento.

Para analisar o perfil de intensidade da nuvem, criamos outro programa. Cada imagem é composta por 240 linhas e 640 colunas, sendo o número de linhas reduzido devido ao fato de usarmos apenas um "frame". Somamos os valores dos pixels das linhas (ou das colunas) da imagem para traçar o perfil vertical (ou horizontal). É possível subtrair o background para diminuir os ruídos e também trabalhar apenas com uma região selecionada da foto. Calibramos o tamanho do pixel usando a foto de uma folha milimetrada tirada sob as mesmas condições óticas. Um pixel corresponde a $16 \mu \mathrm{m}$. Posteriormente ajustamos as curvas com gaussianas 


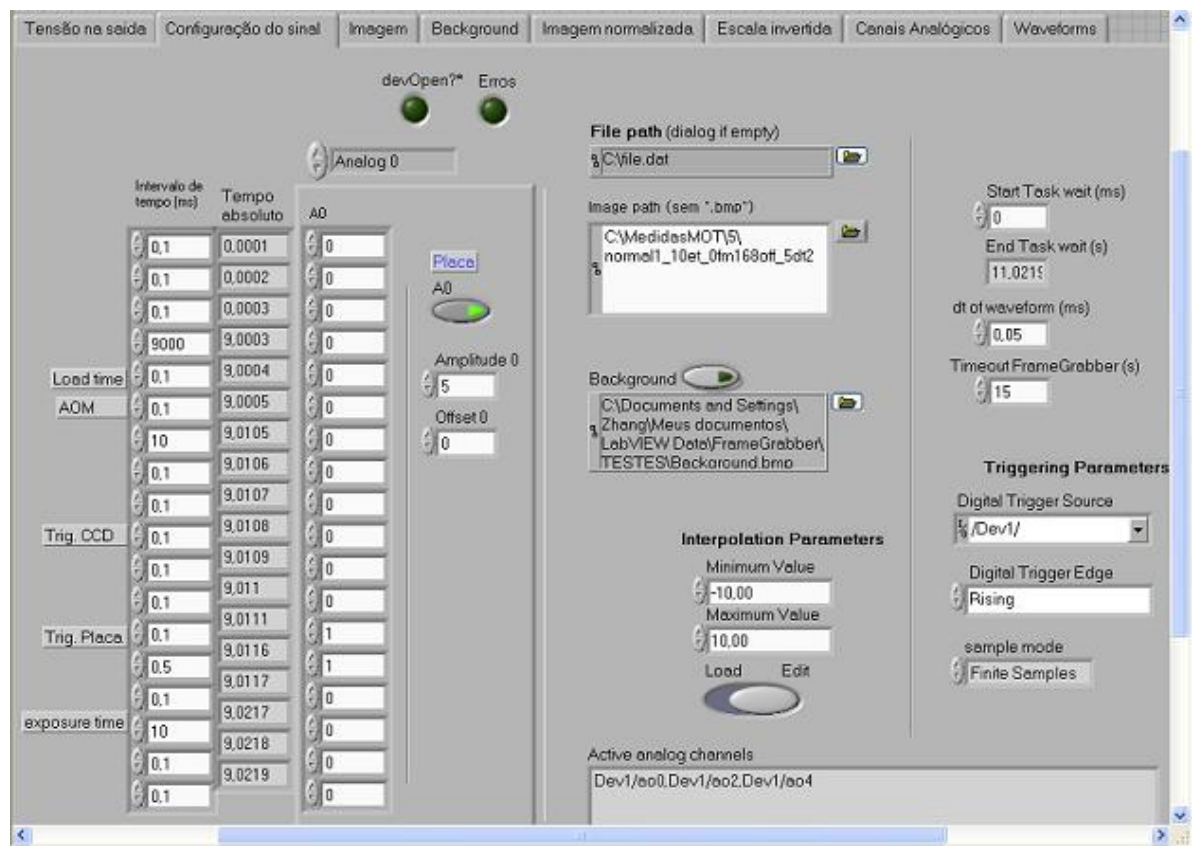

Figura 3.24: Painel de controle do programa de aquisição de imagens.

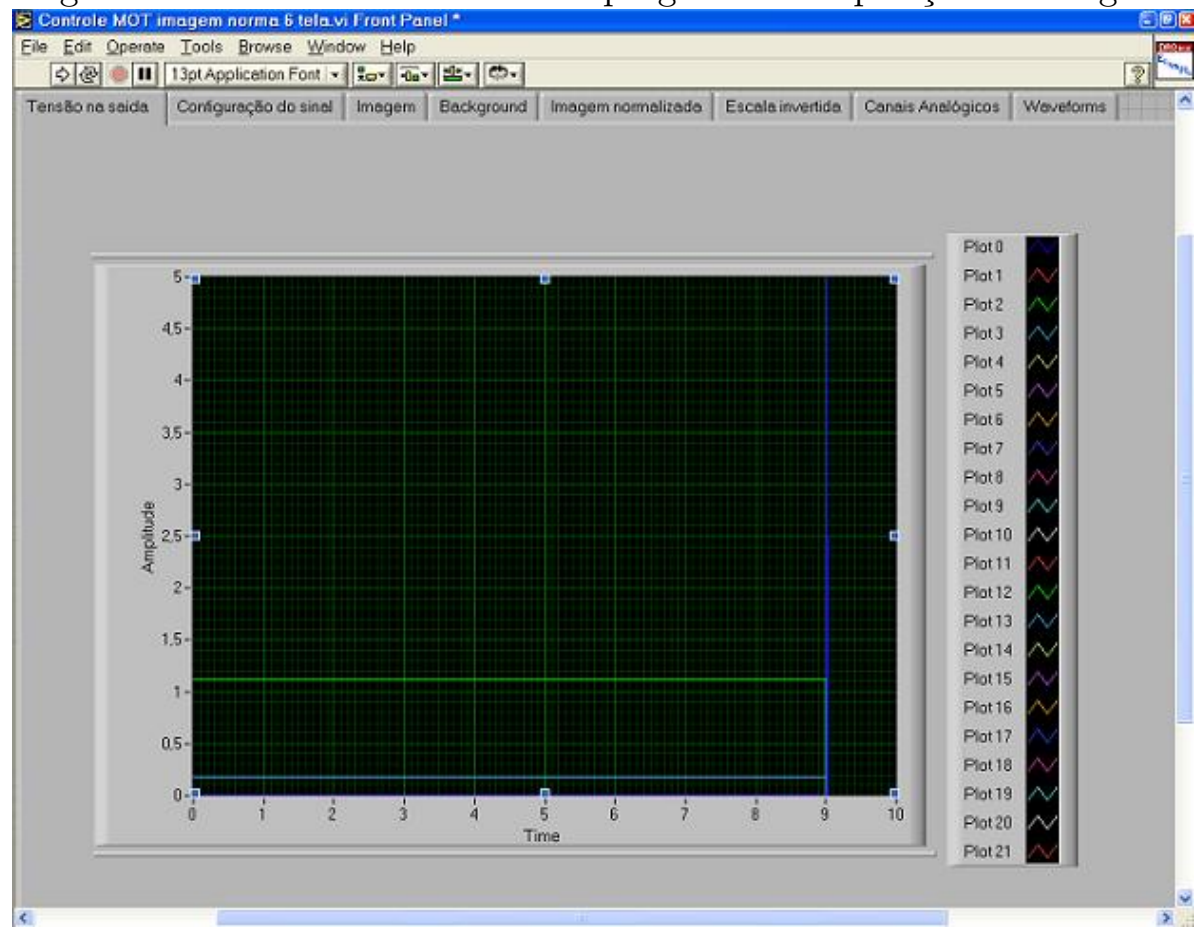

Figura 3.25: Painel que mostra os sinais eletrônicos geradas pelo programa de aquisição. 


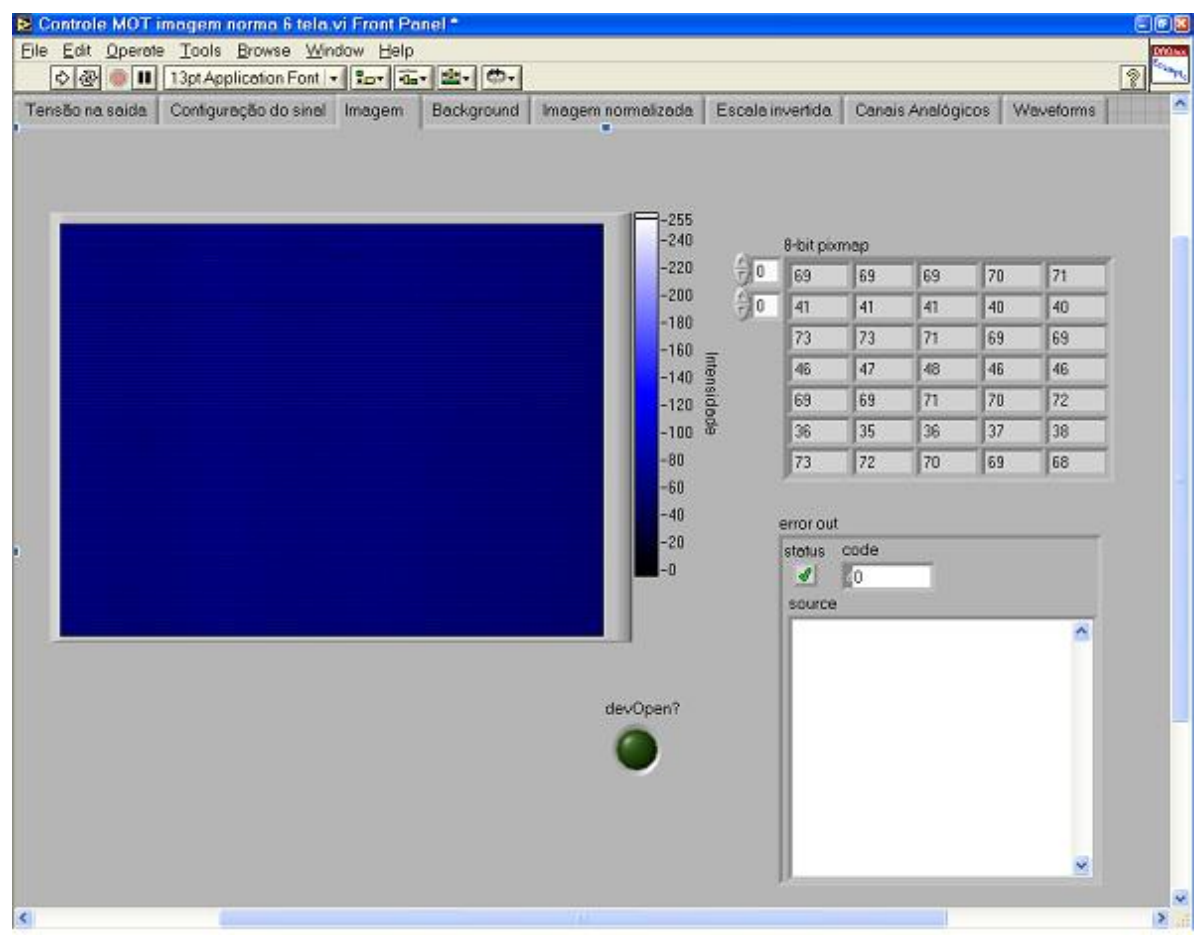

Figura 3.26: Tela que exibe a imagem capturada.

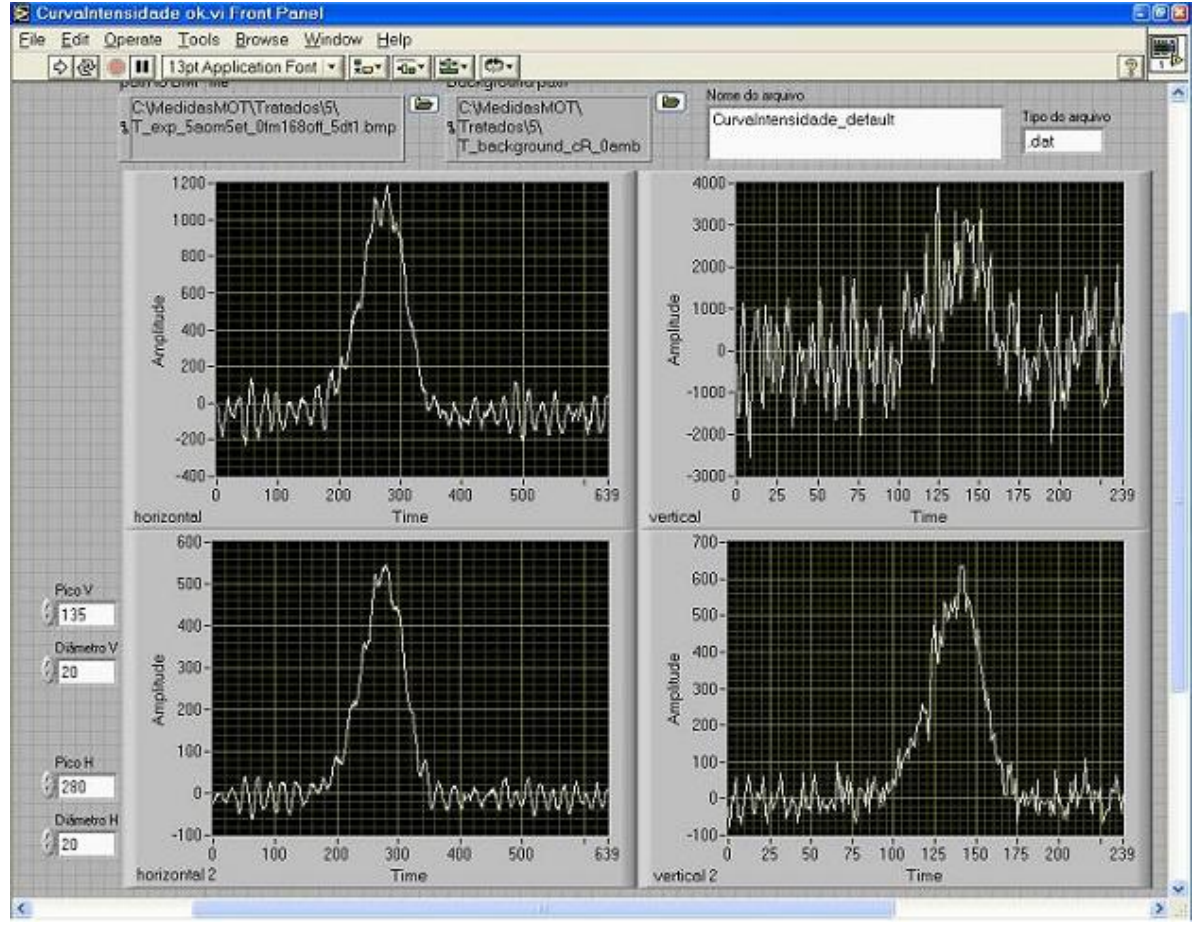

Figura 3.27: Tela do programa de análise de imagens. 
para saber o tamanho da nuvem. As figuras $3.24,3.25,3.26$ e 3.27 mostram algumas imagens do software e o gráfico 3.28 é um exemplo do ajuste do tamanha da nuvem.

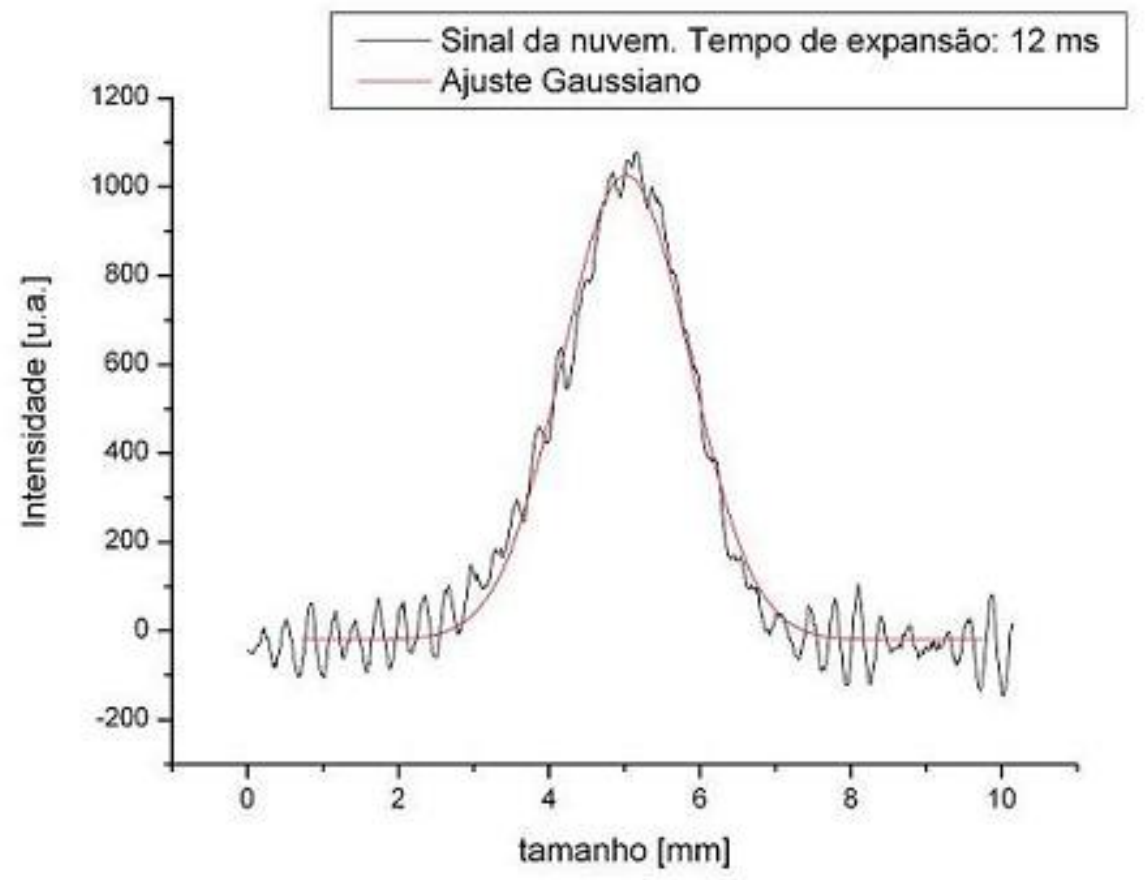

Figura 3.28: Perfil de intensidade da nuvem e o ajuste gaussiano. Neste exemplo, a largura na meia altura é igual a $1,7 \mathrm{~mm}$.

Temos agora as ferramentas necessárias para o controle e a geração reprodutível de nuvens de átomos frios. Outros controles devem ser adicionados com o tempo, como o chaveamento do campo magnético. Este campo deve ser desligado para que a nuvem de átomos sofra uma expansão realmente livre, porém em uma primeira aproximação, para a demonstração do sistema de controle, vamos realizar a medida da quantidade de átomos, do tamanho e da velocidade quadrática média dos átomos aprisionados, como veremos nó próximo capítulo. 


\section{Capítulo 4}

\section{Resultados}

Neste capítulo apresentaremos os resultados obtidos durante o projeto. Caracterizamos vários parâmetros da nuvem de átomos frios. A nuvem possui diâmetro médio de aproximadamente 1,5 mm e é possível visualizá-la a olho nu na ausência da luz ambiente.

\subsection{Número de átomos}

Calculamos o número de átomos na nuvem usando a intensidade da fluorescência emitida. O mais importante nesta medida é separar o efeito da luz de fundo, comparando as intensidades medidas com e sem a nuvem. Desligamos o campo magnético para obter a segunda situação, pois assim minimizamos as alterações da fluorescência de fundo. Utilizamos um detector amplificado PDA50 da Thorlabs. Este detector possui um ajuste de ganho de sinal que possibilita medição de foto-corrente fraca, fixamos o ganho no máximo. Para aumentar ainda mais a intensidade do sinal, focalizamos a imagem da fluorescência da nuvem sobre o detector através de uma lente plano-convexa com raio de $1,5 \mathrm{~cm}$ e distância focal de $10 \mathrm{~cm}$. A lente é posicionada a $30 \mathrm{~cm}$ da 


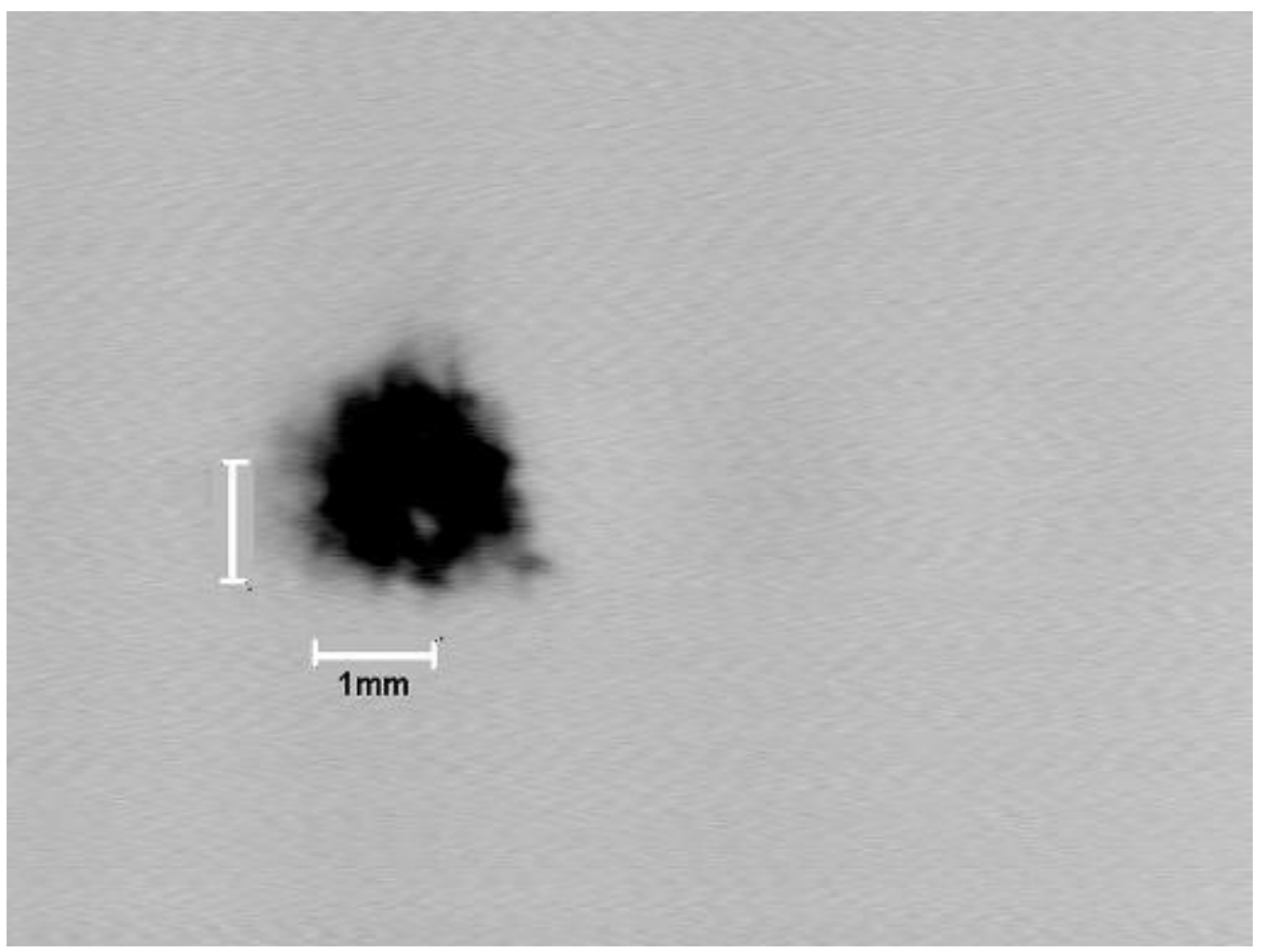

Figura 4.1: Foto da nuvem de átomos de ${ }^{85} R b$ aprisionados. A cor foi invertida para melhor visualização. 
nuvem.

Calibramos para o detector a relação entre a voltagem de saída (proporcional à sua fotocorrente) versus a potência da radiação. Usamos um medidor de potência do Newport, modelo 1815-C, e o feixe do laser Vortex da New Focus operando no modo de potência constante. Sabendo o ângulo sólido do feixe, verificamos que a potência total irradiada pela nuvem é $97,6 \mu \mathrm{W}$.

A energia de cada fóton é obtida pela fórmula $E=h c / \lambda$, onde $h$ é o constante de Planck, $c$ é a velocidade da luz e $\lambda$ é o comprimento de onda que para o nossa caso é 780,24 nm. Dividindo a potência total pela energia do fóton conseguimos saber o número de fótons espalhados pela nuvem por segundo, depois dividindo este número pela taxa de espalhamento de fótons do átomo sabemos o número de átomos aprisionados na nuvem.

A taxa de espalhamento total de fótons por átomo $R$ é dada pela equação (2.32), usando esta fórmula calculamos que $R$ é igual a $3,5 \cdot 10^{6}$ fótons/(s·átomo) com os seguintes dados: a soma de intensidades dos seis feixes de aprisionamento $I$ é igual a $60 \mathrm{~mW} / \mathrm{cm}^{2}$; a intensidade de saturação $I_{s}$ é $1,64 \mathrm{~mW} / \mathrm{cm}^{2}$ para ${ }^{85} R b$ [27]; a largura natural da linha de transição $\Gamma$ é igual a $6 \mathrm{MHz}$, e a dessintonia do feixe $\delta$ é de $15 \mathrm{MHz}$.

Calculamos que a quantidade de átomos na nuvem é da ordem de $1,1 \cdot 10^{8}$. Este valor é semelhante ao encontrado em [55]. Para comparação, na primeira armadilha magneto-ótica realizada em célula de vapor (com átomos de Césio) o número de átomos aprisionados foi 1, 8·10 $[20]$. 


\subsection{Tempo de carga}

$\mathrm{O}$ crescimento do número de átomos aprisionados $\mathrm{N}(\mathrm{t})[53,55]$ é descrito pela equação:

$$
N(t)=N_{0}(1-\exp (-t / \tau))
$$

O tempo característico de carregamento da nuvem $\tau$ é o tempo que a nuvem leva para atingir o nível estacionário $N_{0}$. Esse parâmetro também representa o tempo médio que o átomo permanece dentro da nuvem antes de ser expelido por uma colisão. Na pressão em que trabalhamos ( $1 \cdot 10^{-8}$ mbar $)$, o tipo de colisão predominante é com os átomos de fundo, que têm energias cinéticas muito maiores que os átomos aprisionados. Como o número de átomos aprisionados é diretamente proporcional à fluorescência emitida pela nuvem, para saber a evolução do carregamento da nuvem medimos o crescimento da fluorescência.

Inicialmente com as bobinas desligadas, não há campo magnético na armadilha. Ligamos as bobinas subitamente, permitindo a formação da nuvem de átomos frios e registramos o aumento da fluorescência com o mesmo detector PDA50 e com o mesmo arranjo ótico. Ajustamos a curva medida e estimamos que o tempo característico de carregamento da nuvem $\tau$ é $1,3 \mathrm{~s}$ (vide o gráfico 4.2).

\subsection{Temperatura da nuvem}

A temperatura da nuvem é proporcional à velocidade média quadrática dos átomos. Medimos a expansão da nuvem fria para calcular esta velocidade. A figura 4.3 a seguir mostra as imagens da nuvem registradas em diferentes intervalos de expansão livre. A partir desses dados podemos extrair a velocidade média e calcular a temperatura dos átomos. 


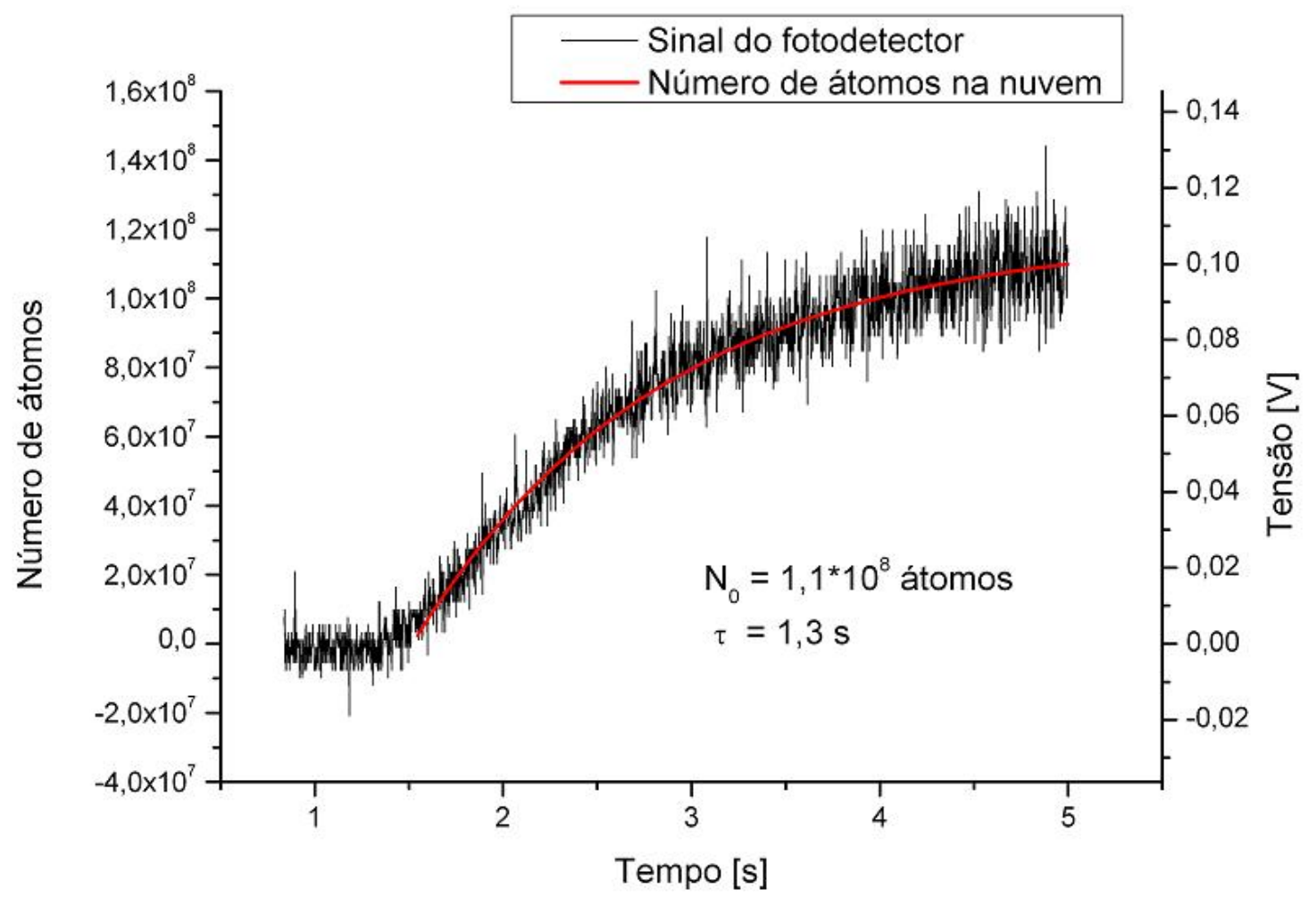

Figura 4.2: Tempo de carga da nuvem é aproximadamente 1,3 s. 


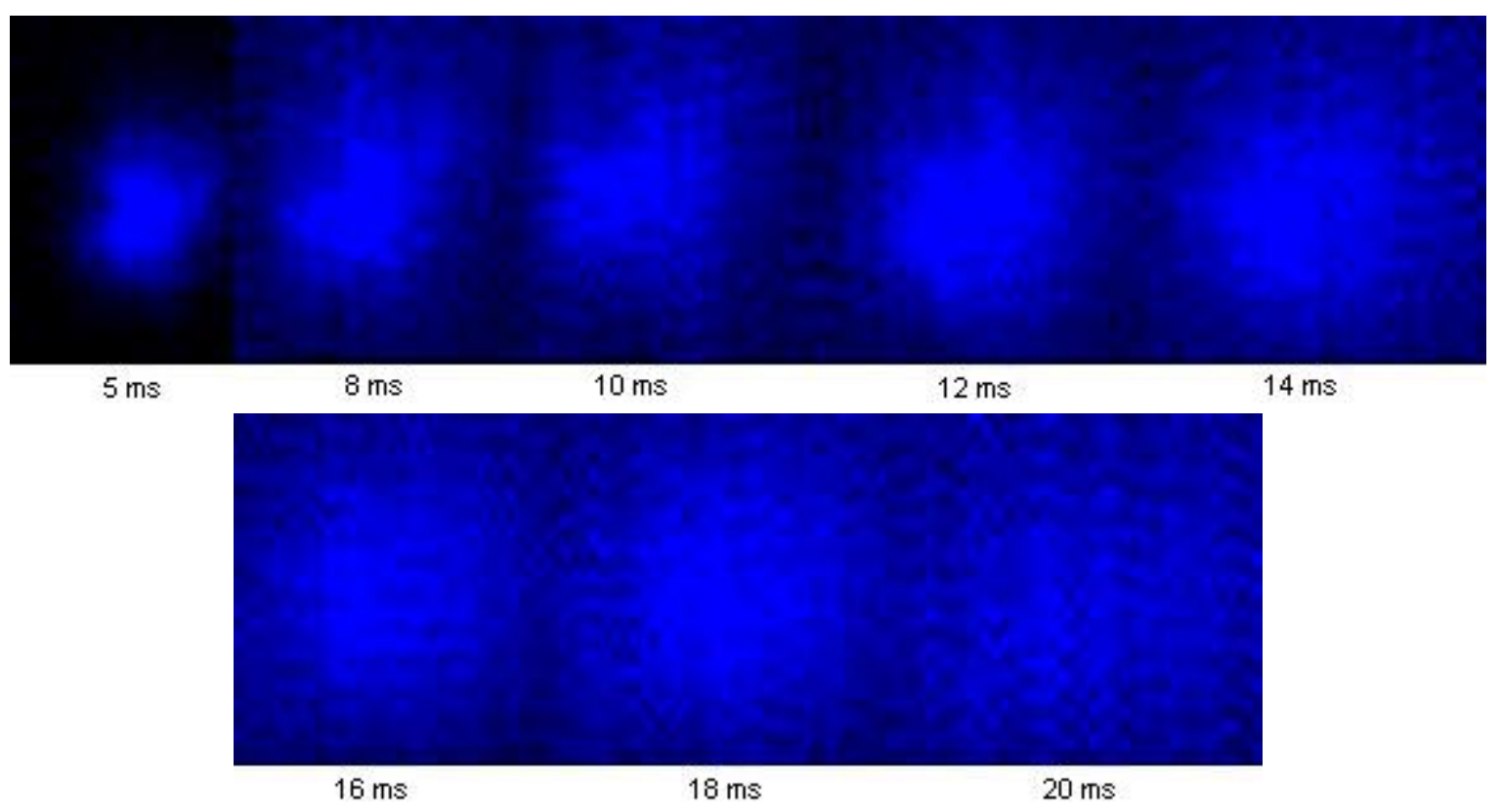

Figura 4.3: Fotos da expansão livre da nuvem.

Utilizando o programa de análise em LabVIEW criado por nós, tiramos os perfis de intensidade da nuvem. Ajustamos os dados com curvas gaussianas e construímos o gráfico da expansão da nuvem com tempo (figura 4.4). A velocidade média estimada é $9,7 \mathrm{~cm} / \mathrm{s}$ e a temperatura é aproximadamente $96 \mu \mathrm{K}$ (O limite Doppler do ${ }^{85} \mathrm{Rb}$ é $140 \mu \mathrm{K}$ [16]). Na literatura, a temperatura da nuvem é normalmente encontrada entre 50 a $70 \mu \mathrm{K}$ [56], indicando que a nossa armadilha ainda pode ser otimizada.

Com estes resultados, mostramos que o sistema desenvolvido permite o controle da armadilha magneto-ótica, atuando de forma reprodutível sobre o vapor atômico, realizando o aprisionamento, resfriamento e imagem da nuvem atômica. Estas condições são fundamentais para conseguirmos realizar as próximas etapas de espectroscopia de átomos frios e manipulação de estados vibracionais em redes óticas unidimensionais. 


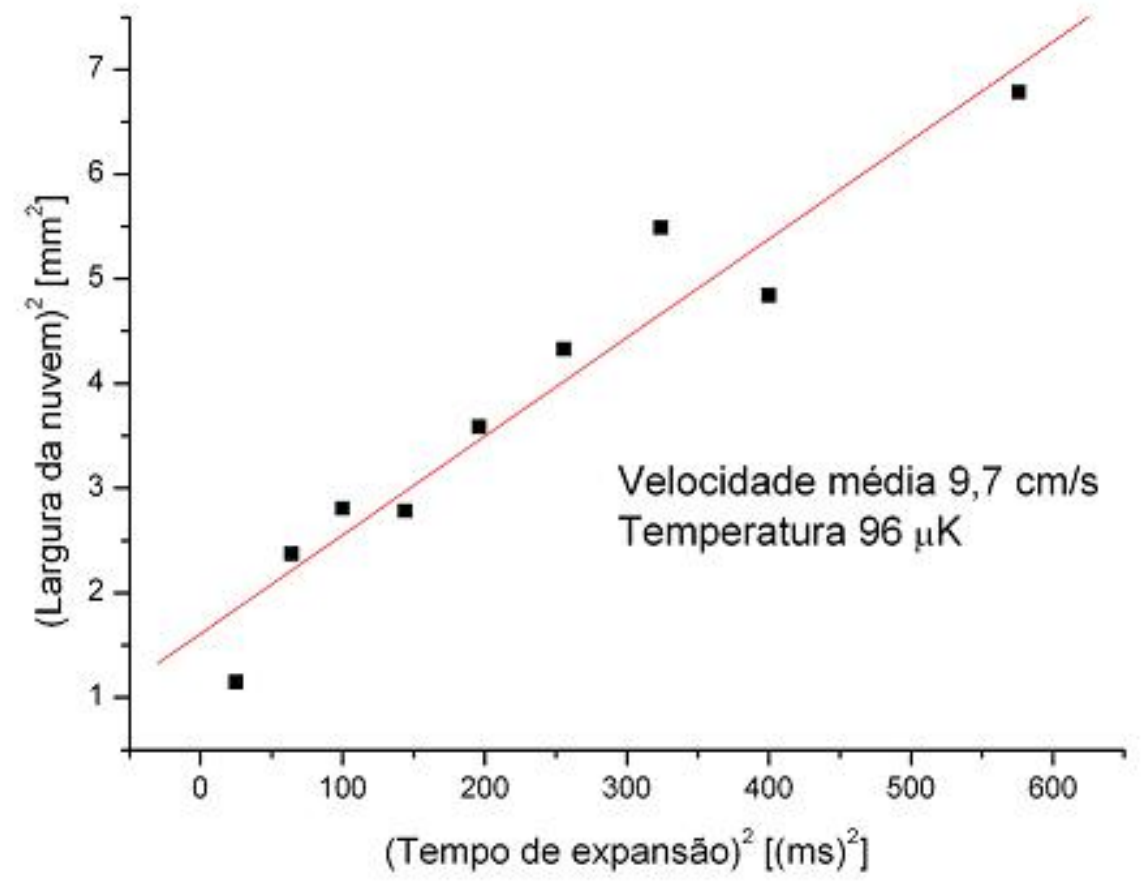

Figura 4.4: Gráfico mostrando a expansão livre quadrática da nuvem. 


\subsection{Rede ótica}

Uma dos principais funções da armadilha magneto-ótica é servir como base para experiências de rede ótica (optical lattice) [31]. Uma rede ótica é um potencial periódico estacionário formado pela interferência de feixes laser contra-propagantes com polarizações lineares e perpendicular. O potencial em uma dimensão (1D) possui formato sinusoidal. A armadilha fornece átomos frios ${ }^{1}$, que possuem velocidade média muito baixa, para serem capturados pela rede ótica.

Quando os átomos estão sob a influência de campo elétrico propagante, a interação com os fótons causa mudança de suas energias através do efeito Stark AC ou Light Shift. Este deslocamento de energia produz uma força de dipolo dependente da dessintonia que confina o átomo na rede.

O uso de rede com campo longe de ressonância atômica pode capturar um átomo se a velocidade dele for baixa o suficiente. Esta velocidade limite depende da freqüência e polarização dos feixes e do amplitude do potencial, e normalmente corresponde, no máximo, à temperaturas da ordem de $\mathrm{mK}$.

A região de captura (poço de potencial) é pequena, da dimensão do comprimento de onda. O aprisionamento pode ser feito na região de máxima intensidade, no caso de dessintonia para vermelho; ou de mínima intensidade, no caso de dessintonia para azul. No primeiro caso, o espalhamento de fótons é máximo na região de captura, tornando o aprisionamento menos eficiente devido à perda de átomos por aquecimento com o espalhamento de luz, o que pode ser minimizado com o aumento da dessintonia. Os parâmetros do laser podem ser variados para modificar a amplitude dos poços de potencial sem afetar os vetores da rede.

\footnotetext{
${ }^{1}$ Neste caso, uma nuvem térmica. Os átomos não estão condensados!
} 
Rede ótica unidimensional foi demonstrada pela primeira vez em 1987 com um feixe atômico atravessando uma onda estacionaria intensa [57]. As redes óticas bidimensionais ou tridimensionais são estruturas semelhantes às redes cristalinas. Estudos em redes óticas permitem a aplicação da física do estado sólido, antes estudada apenas em cristais [58, 59]. Outros efeitos, como oscilação de Bloch, apenas puderam ser observados nesses sistemas [60], pois as redes óticas são essencialmente livres de defeitos, diferentemente dos cristais. Precisamos apenas filtrar espacialmente o feixe laser para garantir uma frente de onda limpa e um único modo transverso.

\subsubsection{Montagem planejada}

Os feixes da rede são gerados por um MOPA (Master Oscillator Power Amplifier). O nosso MOPA é construído a partir da modificação de um laser de diodo série 8630 da empresa $S D L$ (hoje $J D S U$ ) e sintonizado usando um laser mestre [37]. O MOPA fornece um feixe com potência de até $500 \mathrm{~mW}$ e a mesma freqüência do laser mestre. Serão utilizados uma série de AOMs integrados com computador para controlar precisamente a freqüência e amplitude dos feixes.

A detecção dos átomos será feita de várias formas. Com uma câmera CCD poderemos obter a imagem de fluorescência das nuvens atômicas que caem da região aprisionada. Podemos medir diretamente os feixes da rede, sabendo as flutuações de intensidade podemos obter a força exercida pela rede nos átomos. A sondagem da população será feita através de dois feixes, bombeio e prova, posicionados logo abaixo da rede. A fluorescência será captada por um fotodetector de avalanche (figura 4.5). 


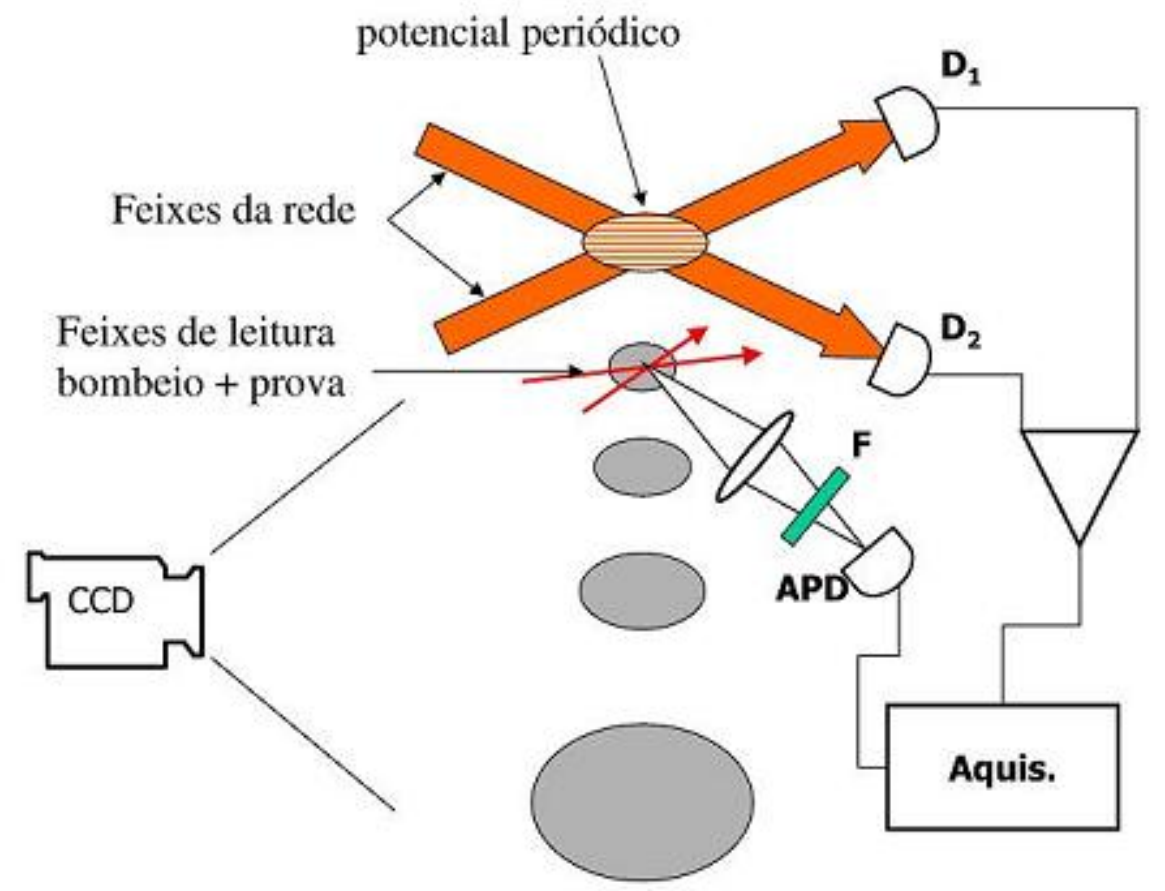

Figura 4.5: Sistema de detecção proposta para a rede ótica. 


\section{Capítulo 5}

\section{Conclusões e Perspectivas}

Neste trabalho fizemos uma revisão histórica do desenvolvimento da área de resfriamento e aprisionamento de átomos com laser e analisamos teoricamente o funcionamento de armadilha magneto-ótica. Foi derivada a força da pressão de radiação e foram descritos os principais mecanismos envolvidos na manipulação de átomos com a luz.

Construímos uma armadilha magneto-ótica para átomo de rubídio e todo o sistema necessário para o controle e caracterização do arranjo. Exceto as bombas de vácuo, todo o sistema foi montado deste o início, incluindo os lasers, a câmara de vácuo e os equipamentos de controles eletrônicos. Foram dedicados bastantes esforços para garantir o controle preciso da frequência e dessintonia dos feixes laser. Trabalhamos muito com o planejamento dos esquemas óticos, com os AOM's, a espectroscopia saturada e o travamento de frequência dos feixes.

Conseguimos resfriar e confinar uma quantidade significativa de átomos frios, o que demonstra que a armadilha é funcional. Medimos as principais características da armadilha e os valores são compatíveis com os encontrados na literatura. 
Não conseguimos montar a rede ótica no nosso trabalho, este projeto está sendo seguido por um estudante de doutorado do nosso grupo. Pretendemos incluir a montagem no arranjo da MOT e utilizar a amostra de átomos frios para carregar a rede ótica. O projeto inicial será baseado no trabalho [56].

Também há uma outra linha de pesquisa com EIT (Transparência Eletromagneticamente Induzida). Já foi feita no nosso grupo pesquisa de EIT em célula de vapor de rubídio na temperatura ambiente [47]. Há plano para realizar as medidas na MOT pois a nuvem fria diminuirá em muito a influência de processos dissipativos e melhorará as medidas. 


\section{Apêndice A}

\section{Especificações do laser de diodo}

A seguir estão incluídas as especificações do diodo e do tubo de colimação utilizados nos nossos lasers de aprisionamento e de rebombeio. O modelo do diodo é Sanyo DL7140-201S e do tubo de colimação é Thorlabs LT230P-B. Os dados são fornecidos pelos fabricantes. 


\section{INFRARED LASER DIODE DL-7140-201S}

\section{Features}

- Wavelength : $785 \mathrm{~nm}$ (Typ.)

- Low threshold current : Ith = $30 \mathrm{~mA}$ (Typ.)

- High operating temperature : $60^{\circ} \mathrm{C}$ at $70 \mathrm{~mW}(\mathrm{CW})$

\section{Applications}

Optical disc system (CD-R)

Absolute Maximum Ratings

$\left(\mathrm{Tc}=25^{\circ} \mathrm{C}\right)$

\begin{tabular}{|c|c|c|c|c|}
\hline \multicolumn{2}{|c|}{ Parameter } & Symbol & Ratings & Unit \\
\hline \multirow{2}{*}{ Light Output } & $\mathrm{CW}$ & $\mathrm{Po}(\mathrm{CW})$ & 80 & \multirow{2}{*}{$\mathrm{mW}$} \\
\cline { 2 - 4 } & Pulse $^{1)}$ & $\mathrm{Po}(\mathrm{pulse})$ & 85 & \\
\hline \multirow{2}{*}{$\begin{array}{l}\text { Reverse } \\
\text { Voltage }\end{array}$} & Laser & \multirow{2}{*}{ VR } & 2 & \multirow{2}{*}{$\mathrm{V}$} \\
\cline { 2 - 4 } & $\mathrm{PD}$ & & 30 & \\
\hline \multicolumn{2}{|l|}{ Operating Temperature } & $\mathrm{Topr}$ & -10 to +60 & ${ }^{\circ} \mathrm{C}$ \\
\hline \multicolumn{2}{|l|}{ Storage Temperature } & $\mathrm{Tstg}$ & -40 to +85 & ${ }^{\circ} \mathrm{C}$ \\
\hline
\end{tabular}

1) Pulse Width $\leq 1.0 \mu \mathrm{s}$, Duty $50 \%$

Electrical and Optical Characteristics

\begin{tabular}{|c|c|c|c|c|c|c|c|}
\hline & & & & \multicolumn{2}{|c|}{$\left(\mathrm{Tc}=25^{\circ} \mathrm{C}\right)$} \\
\hline \multicolumn{2}{|c|}{ Parameter } & Symbol & Condition & Min. & Typ. & Max. & Unit \\
\hline \multicolumn{2}{|c|}{ Threshold Current } & Ith & $\mathrm{CW}$ & - & 30 & 50 & $\mathrm{~mA}$ \\
\hline \multicolumn{2}{|c|}{ Operating Current } & lop & $\mathrm{Po}=70 \mathrm{~mW}$ & - & 100 & 140 & $\mathrm{~mA}$ \\
\hline \multicolumn{2}{|c|}{ Operating Voltage } & Vop & $\mathrm{Po}=70 \mathrm{~mW}$ & - & 2.0 & 2.8 & V \\
\hline \multicolumn{2}{|c|}{ Lasing Wavelength } & Lp & $\mathrm{Po}=70 \mathrm{~mW}$ & 775 & 785 & 800 & $\mathrm{~nm}$ \\
\hline \multirow{2}{*}{$\begin{array}{l}\text { Beam 2) } \\
\text { Divergence }\end{array}$} & Perpendicular & Qv & $\mathrm{Po}=70 \mathrm{~mW}$ & 15 & 17 & 20 & $\circ$ \\
\hline & Parallel & Qh & $\mathrm{Po}=70 \mathrm{~mW}$ & 6 & 8 & 10 & $\circ$ \\
\hline \multirow{2}{*}{$\begin{array}{l}\text { Off Axis } \\
\text { Angle }\end{array}$} & Perpendicular & $\mathrm{dQv}$ & - & - & - & \pm 3 & $\stackrel{\circ}{\circ}$ \\
\hline & Parallel & dQh & - & - & - & \pm 2 & $\circ$ \\
\hline \multicolumn{2}{|c|}{ Differential Efficiency } & $\mathrm{dPo} / \mathrm{dlop}$ & - & 0.6 & 1.0 & 1.4 & $\mathrm{~mW} / \mathrm{mA}$ \\
\hline \multicolumn{2}{|c|}{ Monitoring Output Current } & Im & $\mathrm{Po}=70 \mathrm{~mW}$ & 0.10 & 0.25 & 0.6 & $\mathrm{~mA}$ \\
\hline \multicolumn{2}{|c|}{ Astigmatism } & As & $\mathrm{Po}=70 \mathrm{~mW}$ & - & - & 10 & $\mu \mathrm{m}$ \\
\hline
\end{tabular}

2) Full angle at half maximum

Note: The above product specification are subject to change without notice

Tottori SANYO Electric Co., Ltd. Electroniic Device Business Headquarters

LED Division

5-318, Tachikawa, Tottori 680-8634 Japan TEL : +81-857-21-2137 FAX : +81-857-21-2161

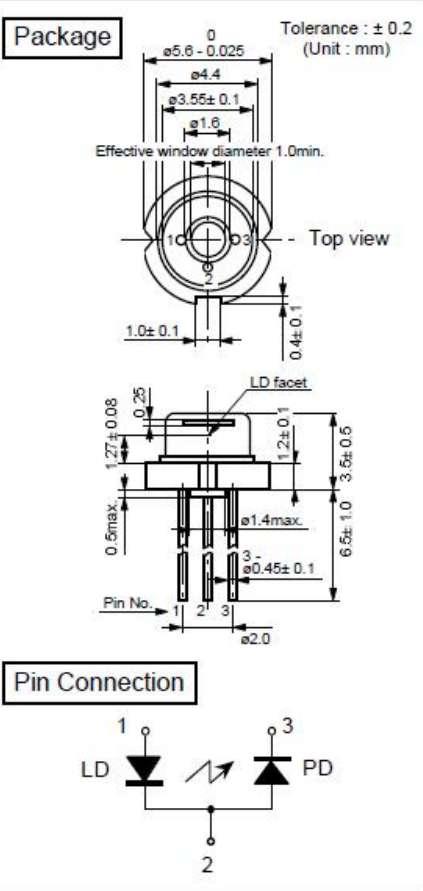

$\left.\mathrm{TC}=25^{\circ} \mathrm{C}\right)$ 


\section{Characteristics}

Output power vs. Forward current

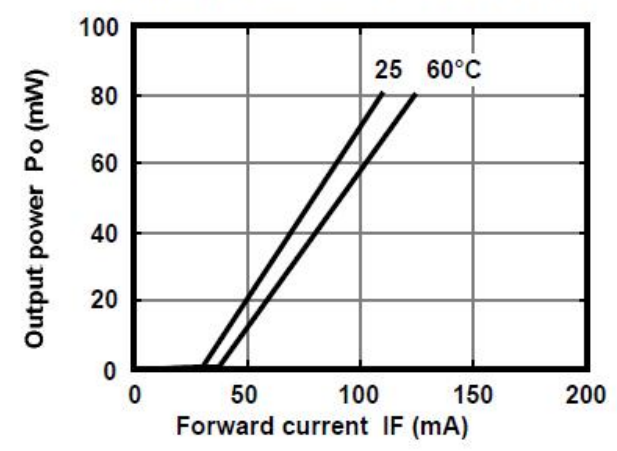

Monitor current vs. Output power

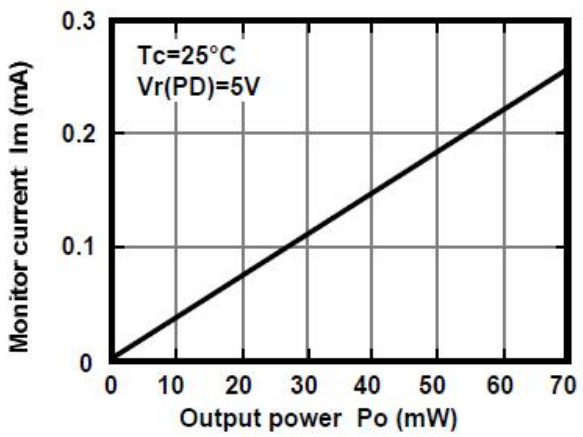

Lasing wavelength vs. Temperature

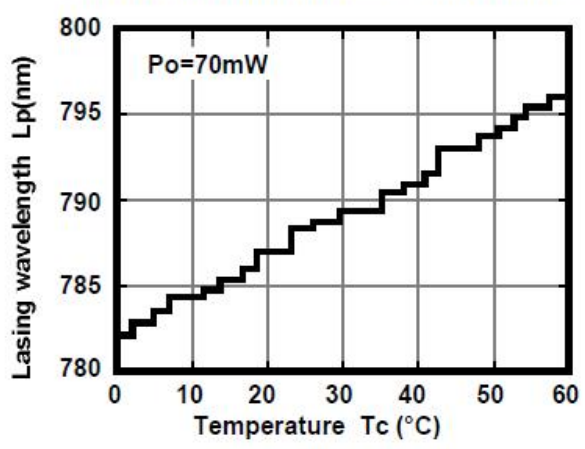

Threshold current vs. Temperature

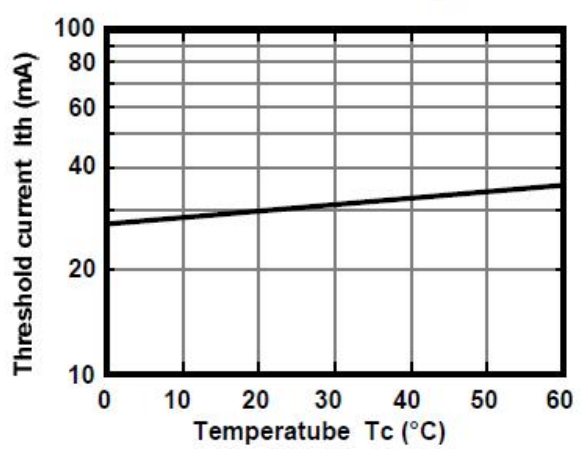

Beam divergence

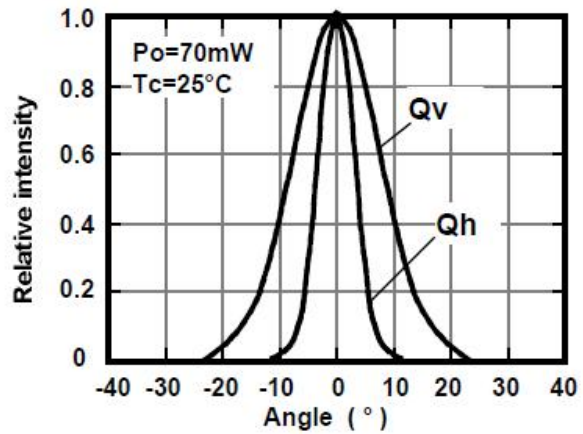

Output power vs. Lasing wavelength

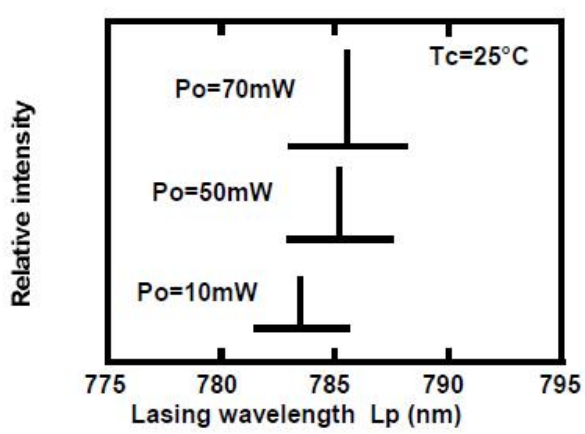

This is typical data and it may not represent all products 


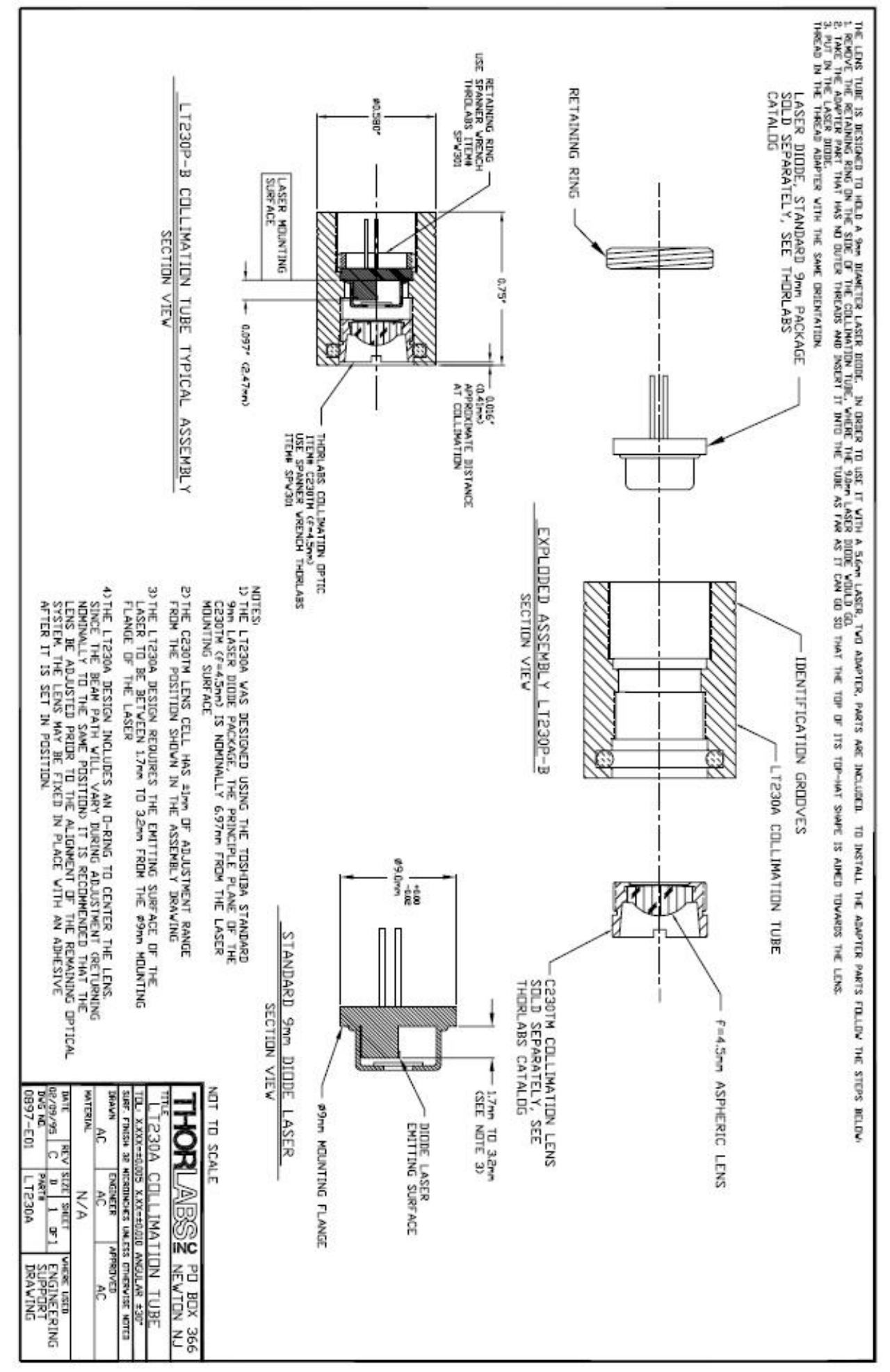




\section{Apêndice B}

\section{Laser com cavidade externa}

Os lasers livres têm potência de saída alta, mas normalmente a largura de linha não é estreita o suficiente para distinguir níveis hiperfinos. Podemos controlar a freqüência dos lasers livres usando um laser mestre com cavidade externa, que tem a largura de linha fina mas com pouca potência. O projeto do laser com cavidade externa é baseado no artigo do K. B. MacAdam, et $a l$ [54]. A cavidade externa do laser mestre é formada pela adição de uma rede de difração, com isto a oscilação dos feixes ocorre entre a rede e a face posterior do diodo. Uma pequena parte do feixe de saída é refletida de volta pela rede de difração o que reforça o mesmo modo de oscilação dentro do diodo, reduzindo a largura de banda do feixe de saída e deixando a freqüência bem definido. No entanto, muita potência de saída é perdida devida à filtragem da rede de difração.

No laser mestre foi utilizado uma peça chamada flexure mount (MFM-050) da empresa Newport. Esta peça é feita de aço, muito resistente e flexível. Ela serve como a conexão entre a rede de difração e o braço que é fixado na base do laser (ver o desenho B.1). As ligações do flexure mount são formados por tiras de aço fina, deixando a peça bem flexível. Com isto 


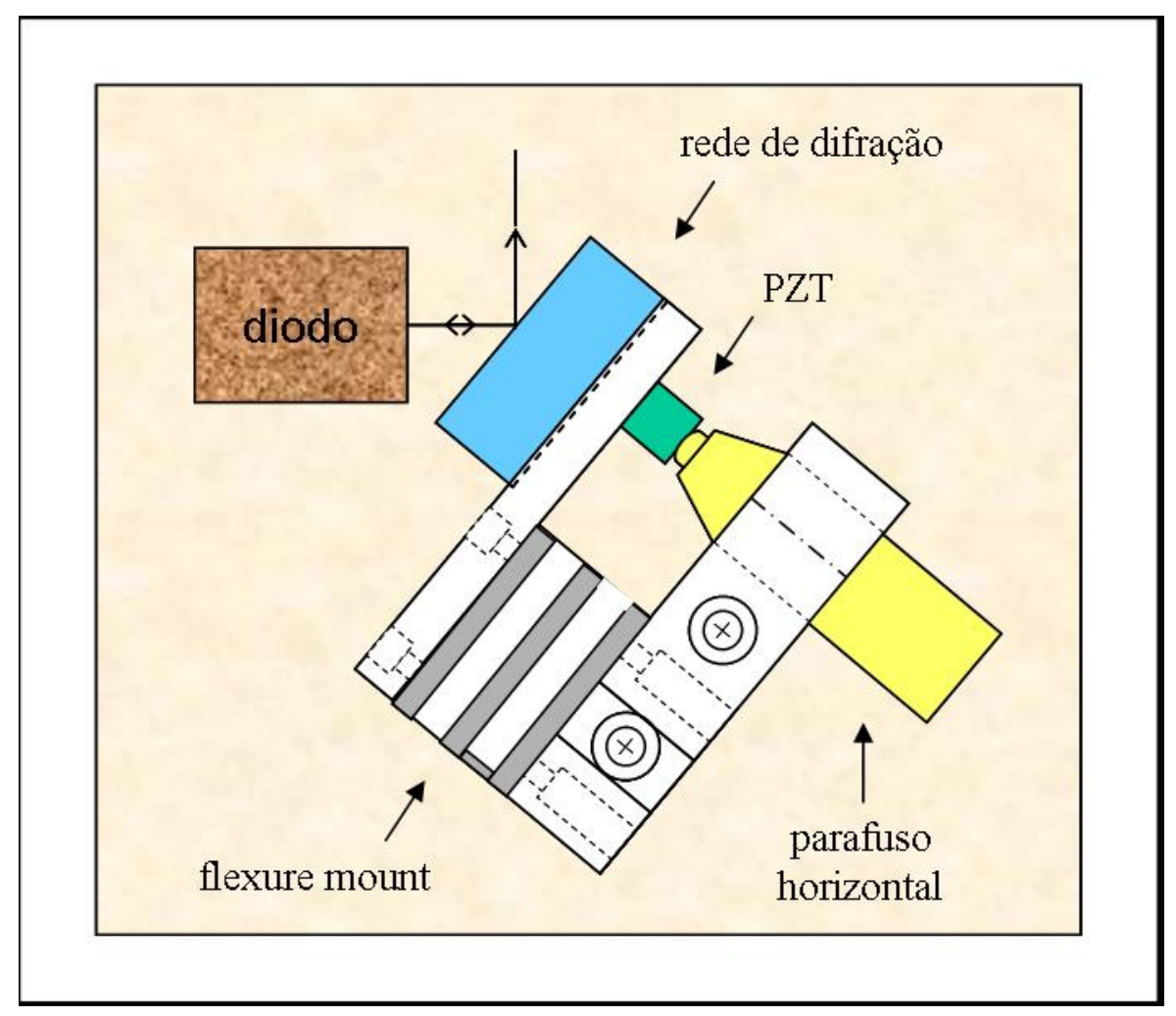

Figura B.1: Laser com cavidade externa (vista superior).

a posição da rede de difração é controlada precisamente, sendo que um parafuso micrométrico controla a inclinação horizontal e um parafuso no próprio flexure mount regula a inclinação vertical. Um cristal piezoelétrico (PZT) é colocado para poder varrer micrométricamente o ângulo horizontal entre a rede de difração e o feixe do diodo. Esta varredura ajuda a sintonizar a freqüência do laser.

O desenho esquemático dos suportes de laser com cavidade externa são mostrados na figura B.2. 


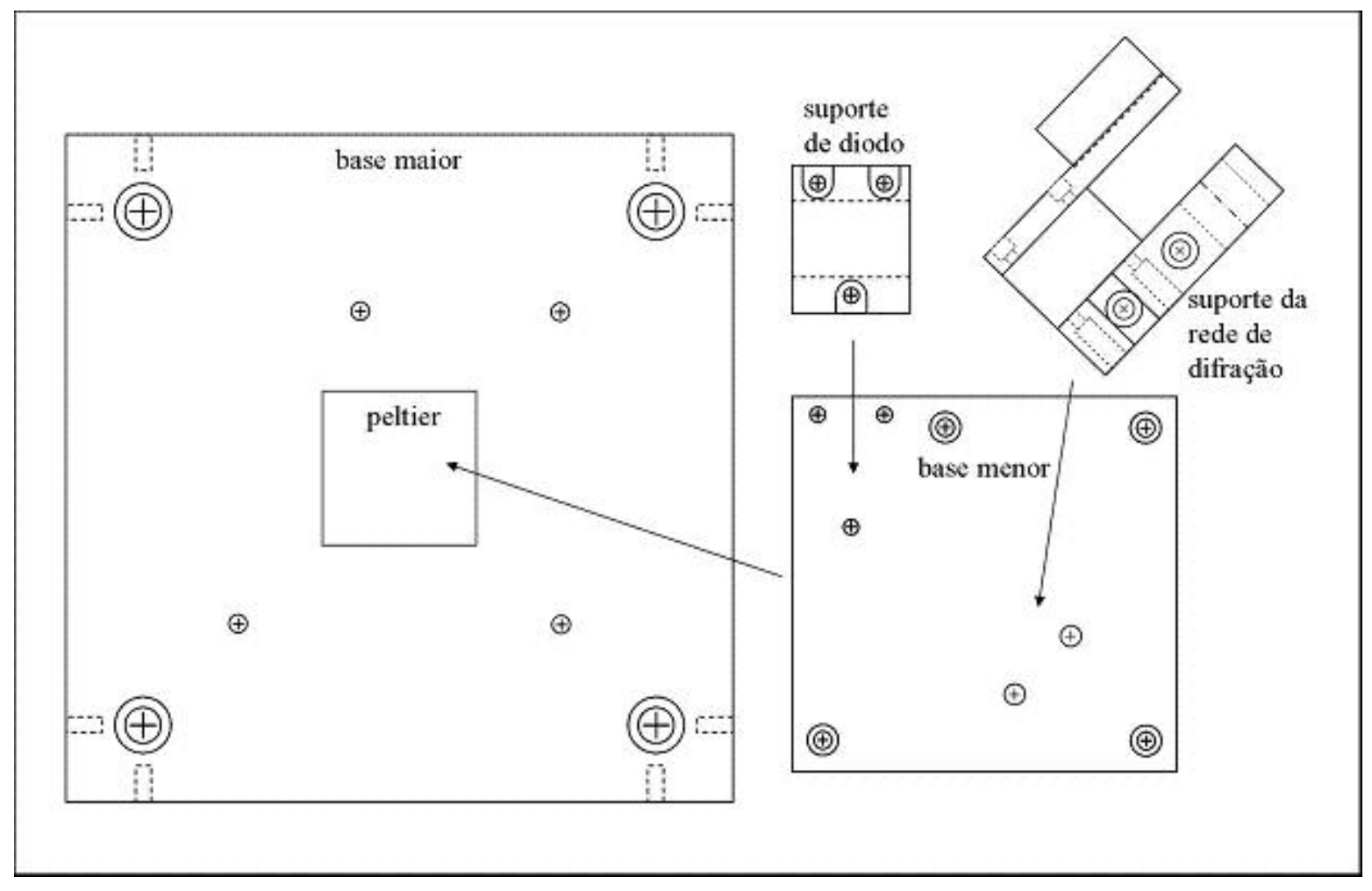

Figura B.2: Desenho dos suportes do laser com cavidade externa. O suporte de diodo é de cobre, os outros são de alumínio. Os círculos com um cruz no meio simbolizam as posições dos parafusos. O diâmetro do parafuso é proporcional ao tamanho do círculo. 


\section{Referências Bibliográficas}

[1] A. Einstein, "Zum quantum theorie der strahlung", Phys. Z. 18, 121 (1917).

Versão traduzida em Português: "Sobre a teoria quântica da radiação", Rev. Bras. Ens. Fís. 27, 93 (2005).

[2] P. Lebedev, Ann. Phys. 6, 433 (1901).

[3] E. F. Nichols, e G. F. Hull, Phys. Rev. 17, 26 (1903).

[4] R. Frisch, Z. Phys. 86, 42 (1933).

[5] T. Hansh e A. Shawlow, "Cooling of gases by laser radiation", Opt. Commun. 13, 68 (1975).

[6] D. Wineland e H. Dehmelt, "Proposed $10^{14} \delta \nu / \nu$ laser fluorescence spectroscopy on $\mathrm{Tl}^{+}$ mono-ion oscillator", Bull. Am. Phys. Soc. 20, 637 (1975).

[7] D. Wineland, R. Drullinger e F. Walls, "Radiation-pressure cooling of bound resonant absorbers", Phys. Rev. Lett. 40, 1639 (1978).

[8] W. Phillips e H. Metcalf, "Laser deceleration of an atom beam", Phys. Rev. Lett. 48, 596 (1982). 
[9] S. Chu, L. Hollberg, J. Bjorkholm, A. Cable e A. Ashkin, "Three-Dimensional Viscous Confinement and Cooling of Atoms by Resonance Radiation Pressure", Phys. Rev. Lett. 55, $48(1985)$.

[10] E. Raab, M. Prentiss, A. Cable, S. Chu e D. Pritchard, "Trapping of neutral sodium atoms with radiation pressure", Phys. Rev. Lett. 59, 2631 (1987).

[11] Y. Castin, H. Wallis e J. Dalibard, "Limit of Doppler cooling", J. Opt. Soc. Am. B 6, 2046 (1989).

[12] P. Lett, R. Watts, C. Westbrook, W. Phillips, P. Gould e H. Metcalf, "Observation of atoms laser cooled below the Doppler limit", Phys. Rev. Lett. 61, 169 (1988).

[13] J. Dalibard e C. Cohen-Tannoudji, "Laser cooling below the Doppler limit by polarization gradients: simple theoretical models", J. Opt. Soc. Am. B 6, 2023 (1989).

[14] W. Phillips, P. Gould e P. Lett, "Cooling, stopping, and trapping atoms", Science 239 877 (1988).

[15] S. Chu, "Laser manipulation of atoms and particles", Science 253, 861 (1991).

[16] C. Adams e E. Riis, "Laser cooling and trapping of neutral atoms", Prog. Quant. Electr. 21, 1 (1997).

[17] S. Chu, "The manipulation of neutral particles", Rev. of Mod. Phys. 70, 685 (1998).

[18] C. Cohen-Tannoudji, "Manipulating atoms with photons", Rev. of Mod. Phys. 70, 707 (1998). 
[19] W. Phillips, "Laser cooling and trapping of neutral atoms", Rev. of Mod. Phys. 70, 721 (1998).

[20] C. Monroe, W. Swann, H. Robinson e C. Wieman, "Very cold trapped atoms in a vapor cell", Phys. Rev. Lett. 65, 1571 (1990).

[21] M. Anderson, J. Ensher, M. Matthew, C. Wieman e E. Cornell, "Observation of BoseEinstein Condensation in a dilute atomic vapor", Science 269, 198 (1995).

[22] K. Davis, M. Mewes, M. Andrews, N. van Druten, D. Durfee, D. Kurn e W. Ketterle, "Bose-Einstein Condensation in a gas of sodium atoms", Phys. Rev. Lett. 75, 3969 (1995).

[23] S. Chu, "Cold atoms and quantum control", Nature 416, 206 (2002).

[24] A. Leanhardt, T. Pasquini, M. Saba, A. Schirotzek, Y. Shin, D. Kielpinski, D. E. Pritchard e W. Ketterle, "Cooling Bose-Einstein Condensate below 450 picoKelvin", Science 301, $1513(2003)$.

[25] L. Allen e J. Eberly, Optical Resonance and two-level atoms, Dover Pub. (1975).

[26] C. Cohen-Tannoudji, J. Dupont-Roc e G. Grynberg, Atom-Photon interactions, WileyInterscience (1998).

[27] H. Metcalf e P. van der Straten, Laser cooling and trapping, Springer-Verlag, New York (1999).

[28] C. Cohen-Tannoudji, B. Diu e F. Laloë, Quantum Mechanics-Vol.I, Wiley-Interscience (1977) 
[29] M. Scully e M. Zubairy, Quantum Optics, Cambridge Univ. Press (1997).

[30] J. Miller, R. Cline e D. Heinzen, "Far-off-resonance optical trapping of atoms", Phys. Rev. A 47, R4567 (1993).

[31] P. Jessen e I. Deutsch, "Optical Lattices", Adv. Atom. Mol. Opt. Phys. 37, 95 (1996).

[32] W. D. Phillips, "Laser cooling and trapping of neutral atoms", Proceedings of the International School of Physics "Enrico Fermi" Course CXVIII, 289 (1992).

[33] P. Lett, W. Phillips, S. Rolston, C. Tanner, R. Watts e C. Westbrook, "Optical molasses", J. Opt. Soc. Am. B 62084 (1989).

[34] W. Demtröder, Laser Spectroscopy, Springer.

[35] S. Salinas, Introdução à física estatística, EDUSP (1999).

[36] A. Ashkin e J. Gordon, "Stability of radiation-pressure particle traps: an optical Earnshaw theorem", Opt. Lett. 8, 511 (1983).

[37] F. Campolim, dissertação de mestrado "Resfriamento e aprisionamento magneto-ótico de átomos de rubídio", Universidade de São Paulo (2001).

[38] J. Reitz, F. Milford e R. Christy, Foundations of electromagnetic theory, Addison-Wesley Pub. Co. (1993).

[39] A. Migdall, J. Prodan, W. Phillips, T. Bergeman e H. Metcalf, "First Observation of Magnetically Trapped Neutral Atoms", Phys. Rev. Lett. 54, 2596 (1985). 
[40] T. Bergeman, G. Erez e H. Metcalf, "Magnetostatic trapping fields for neutral atoms", Phys. Rev. A 35, 1535 (1987).

[41] P. Ungar, D. Weiss, E. Riis e S. Chu, "Optical molasses and multilevel atoms: theory", J. Opt. Soc. Am. B 6, 2058 (1989).

[42] C. Cohen-Tannoudji, "Atomic motion in laser light", Fundamental systems in quantum optics : UJFG, NATO ASI, Les Houches, session LIII, Course 1 (1990).

[43] C. Cohen-Tannoudji e W. Phillips, "New mechanisms for laser cooling", Phys. Today 33 (1990).

[44] Manual de instruções da Varian "572 Ionization Gauge Tube" (2002).

[45] C. Garrido Alzar, tese de doutorado "Estudo de propriedades quânticas dos feixes sonda e de bombeio na transparência induzida por laser", Universidade de São Paulo (2002).

[46] L. Cruz, tese de doutorado "Flutuações de campos eletromagnéticos interagindo com meios atômicos coerentemente preparados", Universidade de São Paulo (2005).

[47] F. Barbosa, dissertação de mestrado "Flutuações do campo eletromagnético no regime de Transparência Eletromagneticamente Induzida", Universidade de São Paulo (2009).

[48] Manual de instruções da Varian "Varian Mechanical Vacuum pumps SD 40" (1992).

[49] Manual de instruções da Varian "Turbo-V 70 pumps" (1997).

[50] Manual de instruções da Varian "VacIon Plus 25" (1995).

[51] http://www.efeitopeltier.com.br/. 
[52] http://www.mspc.eng.br/eletrn/peltier_110.shtml.

[53] A. Yariv, Quantum Electronics, John Wiley and Sons (1989).

[54] K. B. MacAdam, A. Steinbach e C. Wieman, "A narrow-band tunable diode laser system with grating feedback, and a saturated absorption spectrometer for $\mathrm{Cs}$ and $\mathrm{Rb}$ ", Am. J. Phys. 60, 1098 (1992).

[55] C. Wieman, G. Flowers, S. Gilbert, "Inexpensive laser cooling and trapping experiment for undergraduate laboratories", Am. J. Phys. 63, 317 (1995).

[56] S. Myrskog, tese de doutorado "Motional state manipulation of ultra-cold atoms", universidade de Toronto (2003).

[57] C. Salomon, J Dalibard, A. Aspect, H. Metcalf e C. Cohen-Tannoudji, "Channeling atoms in a laser standing wave", Phys. Rev. Lett. 59, 1659 (1987).

[58] K. Petsas, A. Coates e G. Grynberg, "Crystallography of optical lattices", Phys. Rev. A 50, 5173 (1994).

[59] I. Bloch, "Ultracold quantum gases in optical lattices", Nature 1, 23 (2005).

[60] M. Raizen, C. Salomon, Q. Niu, "New light on quantum transport", Phys. Today 50, 30 (1997). 